\title{
III. Konfliktpunkt Entnazifizierung
}

\section{Entnazifizierungspolitik und -praxis der Militärregierung}

Innerhalb der Geschichte der Entnazifizierung sind zwei Phasen zu unterscheiden: 1. die Entnazifizierungspolitik der amerikanischen Militärregierung ohne oder mit nur geringer deutscher Mitwirkung, die bis März 1946 andauerte, 2. die Entnazifizierung in deutscher Zuständigkeit, aber unter amerikanischer Kontrolle nach der Verabschiedung des ,,Gesetzes zur Befreiung von Nationalsozialismus und Militarismus“, kurz Befreiungsgesetz (BefrG), die im wesentlichen Ende 1948 abgeschlossen war.

Die ursprünglichen Planungen des State Department hatten die Entnazifizierung als politische Personalsäuberung konzipiert und als Zielgruppe NS-Funktionäre und politische Beamte im Bereich des öffentlichen Dienstes, der staatlichen und kommunalen Selbstverwaltung definiert. Mit einem breiten Raster, das nach damaligen Schätzungen auf etwa zwei der angenommenen fünf Millionen NSDAP-Mitglieder zutraf, hoffte man, denjenigen Personenkreis festlegen zu können, der im öffentlichen Dienst keine Anstellung behalten oder erwerben sollte ${ }^{1}$. War der Personenkreis auf Expertenebene bereits relativ weit gefaßt worden, so erfolgte mit dem Vordringen Morgenthaus in der amerikanischen Administration eine dramatische Verschärfung der Entlassungsrichtlinien. Zwar konnte sich das Kriegs- und das Finanzministerium in der Endfassung der JCS 1067 vom 26. April 1945 nicht vollständig durchsetzen ${ }^{2}$, doch kam auch nicht mehr der entscheidende Gesichtspunkt des State Department, daß die Entnazifizierung primär die Etablierung demokratischer Eliten abschirmen solle, zum Tragen.Im besetzten Deutschland war jedoch das Programm einer weitgefaßten Personalsäuberung selbst im Spektrum der deutschen Opposition gegen das NS-Regime nicht konsensfähig ${ }^{3}$.

Die amerikanische Entnazifizierungspraxis während der ersten Besatzungswochen ist bisher nicht gründlich untersucht worden. Sowohl Lutz Niethammer wie Hans Woller in seiner Regionalstudie über Ansbach und Fürth gelangen jedoch zu dem Urteil, daß von einer größeren Entlassungswelle nicht die Rede sein könne, da sich die örtlichen Militärkommandanten zuerst auf die Aufrechterhaltung von Ordnung und Sicherheit sowie auf die Wiederingangsetzung der wichtigsten Versorgungseinrichtungen konzentrierten. Allem Anschein nach beschränkte sich bis zur festen Etablierung der Militärregierung die Entnazifizierung im wesentlichen auf die Entlassung von Behördenleitern, Landräten und Bürgermeistern, kurz auf die Verwaltungsspitzen ${ }^{4}$. Die örtlichen Militärkommandanten gingen dabei mehr oder weniger nach freiem Ermessen vor und entschieden zumeist nach dem Gesichtspunkt technischer oder bürokratischer Kompetenz, wobei Fehl-

1 Zur Planungsphase vgl. Niethammer, Entnazifizierung, S. 32-68.

2 Endfassung der JCS 1067: ,, Alle Mitglieder der Nazipartei, die nicht nur nominell in der Partei tätig waren, alle, die den Nazismus oder Militarismus aktiv unterstützt haben, und alle anderen Personen, die den alliierten Zielen feindlich gegenüberstehen, sollen entfernt und ausgeschlossen werden aus öffentlichen Ämtern und aus wichtigen Stellungen in halböffentlichen und privaten Unternehmungen." Zit. nach Ruhl, Neubeginn, S. 60.

${ }^{3}$ Vgl. Niethammer, Entnazifizierung, S. 68-117.

4 Vgl. Niethammer, Entnazifizierung, S.138ff.; Woller, Gesellschaft, S. $74 \mathrm{ff}$. 
entscheidungen und ein mehrfacher Personalwechsel innerhalb der Verwaltungsspitzen zu den unvermeidbaren Anlaufschwierigkeiten der Besatzungsherrschaft gehörten. Ab Ende Juni setzte dann mit einem scharfen Zugriff die erste große Entlassungswelle ein. Nach groben Schätzungen der Militärregierung waren in der gesamten US-Zone bis Anfang August rund 80000 Personen im Zuge des ,, automatischen Arrests" verhaftet und weitere 70000 als NS-Aktivisten entlassen worden ${ }^{5}$.

Grundlegend für die Entnazifizierung wurde die USFET-Direktive vom 7. Juli 1945. Sie bestimmte die Uberprüfung aller Inhaber von relativ präzise definierten Schlüsselpositionen anhand des großen ,Fragebogens“, dessen 131 Einzelfragen einen detaillierten Einblick in den Lebenslauf und die politische Vergangenheit erlaubten ${ }^{6}$. Ergaben sich Anhaltspunkte, daß die betreffende Person mehr als ein nur nomineller Nazi gewesen war, so bestimmte die Direktive die Entlassung, und zwar ohne Rücksicht auf personellen Ersatz und ohne Berücksichtigung etwaiger Rechtsansprüche wie Kündigungsfrist, Ablösungs- oder Ruhegehalt. Die Auswertung der Fragebogen oblag der Special Branch $(\mathrm{SpBr}$ ), die als Unterabteilung der Public Safety Division (PS) für die einheitliche Umsetzung der Entnazifizierungsrichtlinien verantwortlich war. Zur Auswertung der eingehenden Fragebogen standen Special Branch fünf Einstufungsgruppen zur Verfügung: I. „Mandatory removal“": Der Betroffene ist zu entlassen bzw. nicht einzustellen, sein Vermögen zu blockieren, seine Bezüge zu stoppen.

II. ,,Discretionary, adverse recommendation“: Entlassung empfohlen, Entscheidung bleibt jedoch der zuständigen Fachabteilung überlassen.

III. „Discretionary, no adverse recommendation“: wie Gruppe II, Special Branch spricht aber keine förmliche Empfehlung aus.

IV. ,No objection“ bzw, ,,no evidence“: keine Einwendung gegen Weiterbeschäftigung bzw. Anstellung.

V. ,,Retention recommended“ 'bzw. ,, evidence of Anti-Nazi activity“: Weiterbeschäftigung bzw. Anstellung wird wegen vorliegender Beweise für antinationalsozialistische Betätigung empfohlen.

Die Gruppe der Entlassungspflichtigen war mit über 125 Einzelmerkmalen umfassend definiert. $\mathrm{Zu}$ ihr gehörten unter anderem alle Mitglieder der NSDAP vor dem 1. Mai 1937, dem Inkrafttreten des Reichsbeamtengesetzes, alle Amtsträger der NSDAP sowie aller angeschlossener Organisationen, alle Offiziere und Unteroffiziere der Waffen-SS, der SA, des NS-Kraftfahrkorps und des NS-Fliegerkorps, alle Mitglieder der SS, der Gestapo und alle vor dem 1. April 1933 eingetretenen Mitglieder der SA. In die Kategorie „mandatory removal“" fiel auch die führende Schicht des Verwaltungsapparates, unabhängig von einer etwaigen Mitgliedschaft in NS-Organisationen: alle Spitzenbeamte bis herab zur Referentenebene in den Reichsministerien, Ministerialdirektoren, Regierungspräsidenten und Landräte in den Landesverwaltungen, Bürgermeister in den Kommunen, bis zum Polizeileutnant, Oberstaatsanwalt und Landgerichtspräsidenten. Weitere Entlassungskriterien betrafen alle Generalstabs- und NS-Führungsoffiziere, die leitenden Personen der Militär- und Rüstungsverwaltungen in den besetzten Gebieten, Wehr-

${ }^{5}$ IfZ, MA 560, OMGUS, Monthly Report of the Military Governor for July 1945.

${ }^{6}$ Zur Entstehungsgeschichte vgl. Niethammer, Entnazifizierung, S. 147 ff. IfZ, MA 1479/14, USFET-Direktive vom 7.7.1945; deutsche Ubersetzung: BayHStA, MSo 90. 
wirtschaftsführer, hohe und mittlere Amtsträger im Reichsnährstand und Wirtschaftsverbänden. Hinzu kamen schließlich mutmaßliche Kriegsverbrecher, Denunzianten und Mittäter an Verbrechen gegen rassisch, politisch oder religiös Verfolgte.

In der zweiten und dritten Kategorie, deren Unterscheidung im Ermessen der Special Branch lag, war vor allem die weit definierte militärische und wirtschaftliche Elite des Dritten Reiches erfaßt. Zu ihnen zählten die Berufsoffiziere der Reichswehr und Wehrmacht, Junker sowie die wirtschaftliche Oberschicht. Weitere Verdachtsgründe richteten sich gegen alle Mitglieder der NSDAP und der SA, alle Freiwilligen der Waffen-SS und Anwärter der Allgemeinen SS, die Unterführer der HJ und des BDM; auch die Mitgliedschaft im Stahlhelm, im Kyffhäuserbund oder bei den Deutschen Christen und der Deutschen Glaubensbewegung war als mögliche Belastung in den schematischen Kriterien erfaßt.

Stand die Entlassung von Deutschen Christen und Mitgliedern der Deutschen Glaubensbewegung aus dem öffentlichen Dienst im Ermessen der örtlichen Special Branch, so legte die Direktive für die Kirchen, die als Körperschaft des öffentlichen Rechts ebenfalls unter die Entnazifizierungsbestimmungen fielen, einen Sonderstatus fest: ,,You will remove from ecclesiastical office (normally through the established ecclesiastical authorities) all churchmen who are proved by investigation to have been active Nazis. New officials will not be appointed by you, ecclesiastical authorities will fill their own vacancies. You will, however, ensure that such appointees have not been active Nazis. Ecclesiastical institutions must not be permitted to propagate Nazi ideology in any form." 7

Diese Bestimmung, die bis zur Verabschiedung des Befreiungsgesetzes im März 1946 in Kraft blieb, setzte dem Entnazifizierungseifer von Special Branch enge Grenzen. Ihr lag die Annahme zugrunde, daß die Kirchenleitungen alle beanstandeten Pfarrer im Zuge der Selbstreinigung von sich aus entfernen würden. Wie trügerisch die Hoffnung auf die Kooperationsbereitschaft der Kirchenführer war, sollte die Militärregierung bald am Beispiel der bayerischen und der württembergischen Landeskirche erfahren.

Als verhängnisvoll erwies sich weniger der Schematismus der Direktive, der auf deutscher Seite bei allen politischen Gruppierungen Widerspruch hervorrief, der aber andererseits für eine rasche politische Säuberung durch die Besatzungsmacht unumgänglich war, als vielmehr die Eskalation der Entlassungskategorien. Die drastische Verschärfung der Bestimmungen erfolgte nicht aufgrund ,,inhaltlicher Neubesinnung oder Einsicht in praktische Mängel der Säuberungsrichtlinien, sondern sie diente in erster Linie der Besänftigung der öffentlichen Meinung in den USA“8. Die Direktive stellte nicht zuletzt eine Konzession an Morgenthau und andere Vertreter des ,,Vansittarismus“ dar, die den Nationalsozialismus als Ausdruck einer nationalen Kollektivpathologie interpretierten, jedoch mit ihren deutschlandpolitischen Vorstellungen im März 1945 bei Präsident Roosevelt gescheitert waren ${ }^{9}$.

Den nächsten Schritt zur Aufhebung der politischen Säuberungskonzeption unternahm das Militärgesetz Nr. 8 vom 26. September 1945, das die Entnazifizierung auf alle

\footnotetext{
7 Section VII, Part 2, Par. 4. Zu den Deutschen Christen und der von Wilhelm Hauer geführten Deutschen Glaubensbewegung vgl. Meier, Deutschen Christen.

${ }^{8}$ Henke, Säuberung, S. $16 \mathrm{f}$.

${ }^{9}$ Vgl. Graml, Teilung Deutschlands, S. $55 \mathrm{ff}$.
} 
Bereiche der Wirtschaft ausdehnte ${ }^{10}$. Grundlegend neu war dabei, daß es sich formell um ein deutsches Gesetz handelte, das die Militärregierung als Inhaber der obersten Gewalt erließ, während die bisherigen Entnazifizierungsrichtlinien als reine Verwaltungsmaßnahmen des Siegers erlassen worden waren und die Entlassungskategorien nicht mit der Frage der individuellen oder kollektiven Schuld verknüpft hatten. Kernsatz des Gesetzes war die Bestimmung: , Die Beschäftigung eines Mitgliedes der NSDAP oder einer der ihr angeschlossenen Organisationen in geschäftlichen Unternehmungen aller Art in einer beaufsichtigenden oder leitenden Stellung oder in irgendeiner anderen Stellung als der eines gewöhnlichen Arbeiters ist gesetzwidrig. "11

Diese nunmehr völlig undifferenzierte Entlassungsbestimmung mußte die politische Säuberung innerlich vollends aushöhlen und zur Personalkatastrophe führen. Der Konflikt zwischen den Mindestanforderungen einer arbeitsfähigen Verwaltung und den weitgefaßten Entlassungskategorien, der den öffentlichen Dienst bereits weitgehend lahmlegte, drohte nun auch den gesamten Bereich der Wirtschaft zu erfassen. Dennoch beurteilte der württembergische Ministerpräsident Reinhold Maier, ein entschiedener Kritiker der amerikanischen Entnazifizierungspolitik, das Gesetz als ,,einen bedeutsamen Fortschritt" ${ }^{12}$, da es erstmals jedem Betroffenen ein Widerspruchsrecht einräumte. Voraussetzung war der Nachweis, daß man der NSDAP oder einer anderen NS-Organisation nur als nominelles Mitglied angehört hatte. Aus diesem Einspruchsrecht entwickeiten sich die deutschen Vorprüfungsausschüsse, die nach einer an der Strafprozeßordnung orientierten Beweisaufnahme den Einspruch begutachteten. Die letztendliche Entscheidung blieb allerdings der örtlichen Militärregierung überlassen ${ }^{13}$.

Zielten die Entnazifizierungsdirektiven, zumindest tendenziell, auf die generelle Entfernung aller NSDAP-Mitglieder in allen Bereichen ab, so konzentrierte sich in der Praxis die Säuberungsenergie auf den öffentlichen Dienst. Bis Ende November 1945 hatte Special Branch 783045 Fragebogen ausgewertet und dabei 163887 Entlassungen angeordnet und weitere 59699 empfohlen. An der Spitze lag Bayern mit 100865 angeordneten Entlassungen, was einem Anteil von 23 Prozent an allen ausgewerteten bayerischen Fragebogen entsprach, gefolgt von Hessen, unter Einschluß der US-Enklave Bremen, mit 32849 (19 Prozent) und Württemberg-Baden mit 30173 (18 Prozent) ${ }^{14}$. Die Entlassungsverfügungen durch Special Branch geben allerdings nicht die Anzahl der tatsächlich Entlassenen an, wenngleich die erteilten Ausnahmen zur Weiterbeschäftigung belasteter Personen von 21 Prozent Mitte September nach der Patton-Affäre auf fünf Prozent abfielen ${ }^{15}$.

Bis Ende März 1946 waren 1,26 von 1,39 Millionen Fragebogen ausgewertet: 50 Prozent stammten von Beschäftigten oder Bewerbern aus dem öffentlichen Dienst, 29 Prozent kamen aus Handel, Handwerk und Industrie, 21 Prozent aus anderen Bereichen. 24 Prozent aller Beschäftigten des öffentlichen Dienstes galten als entlassungspflichtig; ih-

${ }^{10}$ Das MG-Gesetz Nr. 8 war im Laufe eines Vormittags entworfen und ohne Konsultierung der Special Branch und des State Department sofort in Kraft gesetzt worden. Vgl. Niethammer, Entnazifizierung, S.240ff.

${ }^{11}$ In: Kropat, Hessen, S. 237.

12 Rundfunkansprache Maiers vom 7.11.1945. Zit. nach Sauer, Neubeginn, S. 138.

13 Vgl. Niethammer, Entnazifizierung, S. $244 \mathrm{ff}$.

${ }^{14} \mathrm{SpBr}$-Statistik zum 1.12.1945, in: IfZ, MA 560, OMGUS, Monthly Report of the Military Governor for November 1945.

$15 \mathrm{Vgl}$. Niethammer, Entnazifizierung, S.250f. 
nen standen 43 Prozent gegenüber, bei denen sich keine Anzeichen für NS-Aktivität gefunden hatten. Hinzu kamen 8 Prozent Entlassungsempfehlungen, so daß nahezu ein Drittel aller Beschäftigten des öffentlichen Dienstes entlassen werden sollte. Gegen weitere 25 Prozent bestanden Bedenken, ohne daß jedoch Special Branch die Entlassung empfohlen hatte ${ }^{16}$. Der hohe Anteil völlig unbelasteter Personen ist ein eindeutiges Indiz für die Resistenz weiter Bevölkerungsteile und zeigt, daß viele Angehörige des öffentlichen Dienstes es nicht für nötig gehalten hatten, zur Existenzsicherung der NSDAP beizutreten oder kleine Posten in anderen NS-Organisationen zu übernehmen. Im einzelnen zeigt die Statistik mit dem 31. März 1946 als Stichtag folgendes Bild:

Auswertung der Fragebogen durch Special Branch bis zum 31. März $1946^{17}$

\begin{tabular}{lrrrrrr}
\hline $\begin{array}{l}\text { SpBr- } \\
\text { Einstufung }\end{array}$ & $\begin{array}{c}\text { Offentlicher Dienst } \\
\text { Beschäftigte/Bewerber }\end{array}$ & \multicolumn{2}{c}{$\begin{array}{c}\text { Gewerbe und Industrie } \\
\text { Beschäftigte/Bewerber }\end{array}$} & Ubrige & Insgesamt \\
\hline I & 101727 & 25684 & 47795 & 12927 & 29654 & 217787 \\
& $(24 \%)$ & $(12 \%)$ & $(17 \%)$ & $(14 \%)$ & $(11 \%)$ & $(17 \%)$ \\
II & 32627 & 15061 & 19197 & 6240 & 13670 & 86795 \\
& $(8 \%)$ & $(7 \%)$ & $(7 \%)$ & $(7 \%)$ & $(5 \%)$ & $(7 \%)$ \\
III & 102543 & 55756 & 61586 & 22258 & 73901 & 316035 \\
& $(25 \%)$ & $(26 \%)$ & $(22 \%)$ & $(24 \%)$ & $(28 \%)$ & $(25 \%)$ \\
IV & 181743 & 117009 & 148868 & 49537 & 146075 & 643232 \\
& $(43 \%)$ & $(54 \%)$ & $(54 \%)$ & $(54 \%)$ & $(55 \%)$ & $(51 \%)$ \\
V & 5729 & 1333 & 624 & 488 & 1726 & 5729 \\
& $(<0,5 \%)$ & $(1 \%)$ & $(<0,5 \%)$ & $(1 \%)$ & $(1 \%)$ & $(<0,5 \%)$ \\
\hline Summe & 420189 & 214843 & 278070 & 91450 & 265.026 & 1269578 \\
& $(100 \%)$ & $(100 \%)$ & $(100 \%)$ & $(100 \%)$ & $(100 \%)$ & $(100 \%)$ \\
\hline
\end{tabular}

Eine Ưbersicht über die bis Ende März 1946 im öffentlichen Dienst tatsächlich erfolgten Entlassungen, die von den Einstufungen durch Special Branch zu unterscheiden sind, gibt der folgende Auszug aus einer Gesamtstatistik, die ebenfalls entlassene Beschäftigte und abgelehnte Bewerber trennt:

Entlassungen im öffentlichen Dienst bis zum 31. März $1946^{18}$

\begin{tabular}{|c|c|c|c|c|}
\hline \multirow{2}{*}{$\begin{array}{l}\mathrm{SpBr}_{\mathrm{p}} \text { - } \\
\text { Einstufung } \\
\mathrm{I}\end{array}$} & \multicolumn{2}{|c|}{$\begin{array}{c}\text { Beschäftigte } \\
\text { Beibehalten/Entlassen }\end{array}$} & \multicolumn{2}{|c|}{$\begin{array}{c}\text { Bewerber } \\
\text { Angestellt/Abgewiesen }\end{array}$} \\
\hline & 468 & 101259 & 19 & 25665 \\
\hline II & 2901 & 29726 & 520 & 14541 \\
\hline III & 95785 & 6749 & 50076 & 5680 \\
\hline IV & 179541 & 2202 & 112490 & 4519 \\
\hline V & 1528 & 30 & 1274 & 59 \\
\hline Summe & 280223 & 139966 & 164379 & 50464 \\
\hline
\end{tabular}

\footnotetext{
16 SpBr-Statistik zum 31.3.1946, in: IfZ, MA 560, OMGUS, Monthly Report of the Military Governor for March 1946.

${ }^{17}$ Ebenda. Die Tabelle enthält geringfügige Rundungsfehler.

${ }^{18}$ Ebenda.
} 
Dieser Statistik zufolge, die die genauesten verfügbaren Daten enthält, waren in der US-Zone 139996 Beschäftigte des öffentlichen Dienstes sowie 68568 Beschäftigte aus Handel, Gewerbe und Industrie entlassen worden; gleichzeitig verwehrte die Militärregierung 50464 Bewerbern für den öffentlichen Dienst und 22888 Bewerbern in der Wirtschaft aus politischen Gründen die Anstellung bzw. die Wiederanstellung nach der Rückkehr aus Kriegsdienst und Gefangenschaft. Rechnet man die Anzahl der Entlassenen oder Zurückgewiesenen aus anderen Bereichen hinzu, so waren 336892 Personen unmittelbar von der Entnazifizierung betroffen. Offen bleibt dabei allerdings die Dunkelziffer der mit oder ohne Wissen der jeweils zuständigen Fachabteilungen umgangenen Entlassungsverfügungen, worauf Special Branch nachdrücklich hinwies. Im März 1946 standen in Bayern die Vollzugsmeldungen für 23 Prozent der Beschäftigungsverbote seit langem aus, in Hessen betrug der Anteil 14 Prozent und Württemberg-Baden 11 Prozent $^{19}$. Hinzu kommt eine schwer abschätzbare Dunkelziffer von Fällen, in denen das Beschäftigungsverbot durch bewußte Falschmeldung oder nur nominelle Umsetzungen auf niedrigere Positionen unterlaufen wurde.

Am stärksten betroffen war die Beamten- und Lehrerschaft, die bereits 1933/34 zu 20 bzw. 30 Prozent in der NSDAP organisiert war ${ }^{20}$. Die Entnazifizierung führte 1945/46 $\mathrm{zu}$ einer tiefgreifenden Umstrukturierung des öffentlichen Dienstes, wie das Beispiel Hessen zeigt: Hier wurden bis zum 1. Mai 1946 von 34060 Beamten nicht weniger als 57 Prozent entlassen, von 29003 Angestellten und 16747 Arbeiter im öffentlichen Dienst 34 bzw. 15 Prozent. Zum gleichen Stichtag betrug der Gesamtpersonalstand $86288 \mathrm{Be}-$ dienstete, von den 55,4 Prozent aus der Zeit vor 1945 übernommen, 42,7 Prozent neu eingestellt und 1,9 Prozent wiedereingestellt worden waren; zur letzten Gruppe zählten frühere Angehörige des öffentlichen Dienstes, die von den Nationalsozialisten entlassen worden waren. Vergleichsweise glimpflich kam dagegen die wirtschaftliche Führungsschicht davon. In Hessen verloren gerade 26,4 Prozent aller leitenden Angestellten aus der privaten Wirtschaft ihren Posten ${ }^{21}$. Die gesellschaftspolitischen Auswirkungen des personellen Strukturwandels kamen jedoch infolge der Expansion des öffentlichen Dienstes und der zügigen Wiedereinstellung der 1945/46 Entlassenen nur begrenzt zum Tragen.

Von den Entlassungen unter dem Diktat der Militärregierung war - entgegen der landläufigen Meinung und entgegen dem Anschein der rigiden Direktiven - letztlich nur eine Minderheit der NSDAP-Mitglieder betroffen. Immerhin waren 2,45 Millionen Deutsche der NSDAP vor dem Aufnahmestopp am 1. Mai 1933 beigetreten, deren Gesamtmitgliedschaft sich bis Kriegsende auf rund 6 Millionen erhöht hatte ${ }^{22}$. Wenn dennoch die Entnazifizierung, wie kaum eine andere Maßnahme der Militärregierung, die deutsche Offentlichkeit in einer Zeit erregte, als Millionen ausgebombt, auf der Flucht oder in Kriegsgefangenschaft und weitere Millionen als Kriegsopfer zu betrauern waren, so ist die Ursache weniger in der Zahl der tatsächlich Entlassenen oder zurückgewiesenen Bewerbern zu sehen als in gravierenden politischen und psychologischen Fehlern der amerikanischen Entnazifizierungspolitik. Obschon schematische Auswertungskriterien für

\footnotetext{
19 Niethammer, Entnazifizierung, S. 255.

20 Parteistatistik der NSDAP vom 1.1.1935. Zit. nach Broszat, Staat Hitlers, S. 254.

${ }^{21}$ Kropat, Hessen, S. 243 f.

22 Vgl. Broszat, Staat Hitlers, S. $252 \mathrm{ff}$.
} 
die Militärregierung unerläßlich waren, mußte sich die Uberdehnung der Bestimmungen und die unterschiedslose Überprüfung aller irgendwie Belasteter schlecht auf die Kooperationsbereitschaft konservativer wie linker NS-Gegner auswirken. Nach einer Aufstellung von 1947 machte die Zahl der ihres Amtes enthobenen politischen Beamten in der US-Zone gerade ein Siebtel aller seit 1945 aus dem öffentlichen Dienst Entlassenen aus. 1946 befanden sich unter ihnen allein 23643 Mitarbeiter der Reichsbahn und 20075 Beschäftigte der Reichspost ${ }^{23}$. Damit aber war das Konzept der politischen Säuberung von durchaus weit zu definierenden Schlüsselpositionen endgültig verlassen. Noch stärker als die Entnazifizierungspraxis, deren tatsächlicher Umfang noch tragbar - wenn auch nicht politisch vernünftig - war, stellten die Direktiven eine Bedrohung für alle Mitglieder der NSDAP und der ihr angeschlossenen Organisationen dar und mußten deshalb zwangsläufig zu der politisch fatalen Solidarisierung der Mitläufer mit wirklichen NS-Aktivisten führen. Aus verständlichen Gründen bestimmte nicht die Tatsache, daß die Entlassungen weit unter den normativen Entlassungskriterien lagen, die öffentliche Diskussion und Meinung, sondern die Befürchtung, die bisherigen Entlassungen seien nur der Anfang. Tatsächlich fielen im März 1946620617 von 1,26 Millionen überprüfter Personen in eine der drei Kategorien, die prinzipiell eine Entlassung erlaubten; ein Ende der ständigen Ausweitung des zu überprüfenden Personenkreises war zu diesem Zeitpunkt nicht abzusehen.

All diese Faktoren mußten zu einer grundlegenden Revision der amerikanischen Politik führen, die im März 1946 mit der Ưbertragung der Entnazifizierung auf deutsche Stellen auch stattfand. Die bisherigen Grundfehler wurden jedoch nicht nur beibehalten, sondern vielmehr verstärkt: Jetzt erfaßte und überprüfte man die gesamte erwachsene Bevölkerung und verknüpfte die politische Säuberung mit der Straf- oder Sühnekonzeption, die nunmehr zur offiziellen Begründung avancierte. Wie hätte aber eine vernünftige Alternative aussehen können?

Ein denkbares Modell hätte in der Auflistung der politischen, gesellschaftlichen und wirtschaftlichen Schlüsselstellungen liegen können, deren Besetzung an die Erfüllung bestimmter und entsprechend der jeweiligen Bedeutung abgestufter politischer Qualifikationsmerkmale gebunden gewesen wäre. In einem solchen Modell hätten die detaillierten Auswertungskriterien für den Fragebogen als Negativauswahl für einen fest umrissenen Kreis von Schlüsselpositionen ihre Berechtigung gehabt und durch den Nachweis von ",positive political, liberal and moral qualities", wie ihn eine wenig bekannte OMGUSDirektive vom September 1946 forderte ${ }^{24}$, ergänzt werden können. Die Begrenzung auf Schlüsselstellungen hätte bereits Ende 1945 den gleichen Effekt erzielt wie die Massenentnazifizierung durch die deutschen Spruchkammern, die notwendigerweise zu ,,Mitläuferfabriken“" verkommen mußten, mit der großzügigen Rehabilitierung von entlassenen Parteimitgliedern aber auch zahlreiche Ungerechtigkeiten der amerikanischen Entlassungspraxis wiedergutmachten.

"Jeder Entnazifizierungsplan mußte sich", wie der bekannte amerikanische Theologe Reinhold Niebuhr 1949 bemerkte, ,, bei einer so tief korrumpierten Nation wie der deutschen als ungenügend erweisen. Irgendeinen Plan brauchte man schließlich, um die

${ }^{23}$ Niethammer, Entnazifizierung, S. 254; IfZ, MA 560, OMGUS, Monthly Report of the Military Governor for March 1946.

${ }^{24}$ NA, RG 260, 5/341-1/6-10, Removal of Important German Officials vom 21.9.1946. 
Schafe von den Böcken zu scheiden. Aber kein denkbarer Plan kann alle Schattierungen der Teilhabe an der Schuld gerecht behandeln, in die die Einzelnen angesichts des kollektiven Bösen verstrickt waren. " 25 Die Erwartung einer effizienten und dennoch dem Einzelfall gerecht werdenden Säuberung überschritt bei weitem die Möglich- und Fähigkeiten einer Militärregierung, deren Mitarbeiter 1945/46 kaum intime Kenntnisse der lokalen Situation besitzen konnten. Die entscheidende Frage, wer Mitläufer, trotz Mitgliedschaft und kleiner Ämter, und wer NS-Aktivist, auch ohne Parteibuch, gewesen war, konnte nur von den Deutschen selbst beurteilt werden. Die Übertragung der Verantwortung auf deutsche Stellen war aber 1945, angesichts des außerordentlichen Stellenwertes der Entnazifizierung für die amerikanische Offentlichkeit, nicht denkbar. Für den Aufbau eines rein deutschen Säuberungsverfahrens auf dem Verwaltungswege, wie es die deutsche Auftragsverwaltung Württemberg-Hohenzollerns unter der Führung Carlo Schmids in der französischen Besatzungszone erfolgreich praktizierte, bestand deshalb in der amerikanischen Zone keine Verwirklichungsmöglichkeit; hatte dieses Modell doch die säuberungspolitische Passivität der französischen Militärregierung zur Voraussetzung ${ }^{26}$. Dennoch hätte, wie Niebuhr fortfuhr, , ,ein größeres Maß an Bescheidenheit" die amerikanische Militärregierung "vor manchen Fehlern bewahren können“.

\section{Die Kritik der Kirchen 1945/46}

In dem politischen Vakuum der ersten Nachkriegswochen, als die Bildung von Parteien und Gewerkschaften noch strikt untersagt war, besaßen allein die Kirchen die Möglichkeit, politische Positionen zu beziehen. Die süddeutschen Kirchenführer traten gegenüber der Besatzungsmacht sehr selbstbewußt auf. Sie konnten dies um so leichter tun, da die bayerische und die württembergische Landeskirche die Auseinandersetzung mit den Deutschen Christen während des Kirchenkampfes wie auch den Zusammenbruch der NS-Diktatur nahezu unbeschädigt überstanden hatten, während sich die Landeskirchen in Hessen und Bremen erst mühsam reorganisieren mußten. Auf katholischer Seite führte Kardinal Faulhaber, der bereits am 2. Mai in einem Rundschreiben an den Klerus die NS-Verbrechen in den Konzentrationslagern gegen die Bombardierung deutscher Städte aufgerechnet hatte ${ }^{27}$, den Widerstand gegen die in ersten Zügen sichtbar werdende Säuberungspolitik der Militärregierung an. Die Kritik richtete sich dabei weniger gegen die Entlassung von hohen NS-Funktionären als gegen den befürchteten Verlust konservativer Machtbastionen im öffentlichen Dienst.

In einem Schreiben an Pius XII. vom 21. Juni brachte der Mainzer Bischof Stohr dies deutlich zum Ausdruck: Die ,,radikale Beseitigung aller Nazis“ sei eine ,,Sinnlosigkeit, an der die ganze Verwaltung zusammenbrechen müsse und nur der Kommunismus Freude haben könne. [...] Man fängt an zu denken: die Russen können auch nicht schlimmer sein - und beginnt auch den Bolschewismus erträglich zu finden." Stohr em-

${ }^{25}$ Germany. Vengeance or justice, in: The Nation, Nr. 4 vom 23.7.1949. Vg1. auch Henke, Grenzen.

${ }^{26} \mathrm{Vgl}$. Henke, Säuberung, S. $20 \mathrm{ff}$.

27 Vgl. Faulhaber an Diözesanklerus vom 2.5.1946, in: Akten Kardinal Michael von Faulhabers 1917-1945, Bd.2: 1935-1945. Bearbeitet von Ludwig Volk, Mainz 1978, S. $1047 \mathrm{ff}$. 
pörte vor allem, daß die Militärregierung vielfach auf SPD- und Gewerkschaftsfunktionäre zurückgriff: „Fast der einzige Befähigungsnachweis zur Besetzung eines Amtes scheint der Aufenthalt eines Kandidaten in Dachau oder sonstwo im Gefängnis zu sein. Man hat sich angewöhnt, nur den ,Antifaschisten' als berechtigt anzusehen. Und als solcher gilt ungefähr nur der Bierbankpolitiker, der sich gegen die Nazis geäußert hat und nicht jene aufrechten Christen, die ihrem Gewissen gemäß durch ihre Haltung all die Jahre hindurch einen grundsätzlichen Widerstand gegen das Naziregime gelebt haben, ohne den die Handvoll ,Antifaschisten` zur Lächerlichkeit verurteilt wären. Und diese aufrechten Christen sehen sich jetzt ausgeschaltet von Amt und Einfluß gegenüber unfähigen Emporkömmlingen sozialistischer Vergangenheit." 28

Eine scharfe Entnazifizierung mußte mit der Entlassung kirchentreuer Parteimitglieder und ihrer Ersetzung aus Kreisen der Arbeiterbewegung und des liberalen Bürgertums den politischen Einfluß der Kirchen schmälern und die Durchsetzung kirchlicher Konzeptionen, etwa des konfessionellen Volksschulwesens, beeinträchtigen. Als der württembergische Militärgouverneur Dawson Mitte Juli Wurm eröffnete, daß die amerikanische Regierung für die Ubergangszeit lieber ein ,,gewisses Chaos" in Kauf nehme, als auf die politische Säuberung zu verzichten, entgegnete Wurm, die ,,Verfolgung Unschuldiger" und die „Heranziehung ungeeigneter, ja amoralistischer und krimineller Elemente zur Ubernahme größerer oder kleiner Verantwortung “ riefe im deutschen Volk ,,Verstimmung, Depression und Verärgerung " hervor ${ }^{29}$. Die Äußerungen Stohrs und Wurms sind charakteristisch für die Stimmung weiter konservativ-kirchlicher Kreise, die sich mit dem Nationalsozialismus arrangiert hatten und nun mit einem gewissen Entsetzen erlebten, daß ihre alten weltanschaulichen Gegner von der Entnazifizierung profitierten.

Beide Punkte sprach der katholische Bischof von Regensburg, Michael Buchberger, am 18. Juli 1945 in einem Schreiben an die örtliche Militärregierung an, das die erste offizielle Eingabe eines Kirchenführers aus der US-Zone darstellt: Viele der entlassenen Beamten und Lehrer seien nur infolge schweren Drucks der NSDAP beigetreten und hätten "wegen ihrer ,schwarzen' Einstellung viel Quälerei und Zurücksetzungen erdulden" müssen. Sie hätten die Befreiung aus ,,dieser unwürdigen und drückenden Sklaverei“ herbeigesehnt und müßten nun die ,furchtbare Tragik“" erleben, in noch tieferes Elend gestoßen zu werden. ,,Das ist für sie um so härter und bitterer als andere, die von den Nazis nie etwas zu erdulden hatten, weil sie nicht ,schwarz' waren, in ihrer Stellung bleiben dürfen oder gar in hervorragende Stellung eingesetzt werden." Die Militärregierung dürfe nur diejenigen entlassen, , die persönliche Schuld auf sich geladen oder durch ihre positive Arbeit im Dienste des Nationalsozialismus mit schuld sind an dem großen Unglück, das über Deutschland und einen großen Teil der Welt gekommen ist" ${ }^{\text {“30. }}$

Die Fürsprache der Kirchenführer ist vor dem Hintergrund der Entnazifizierungsdirektive vom 7. Juli $1945 \mathrm{zu}$ sehen. Sie richtete sich insbesondere gegen alle Amtsträger der NSDAP und ihrer Gliederungen, die Mitglieder der SS sowie gegen den Personenkreis, der vor dem 1. Mai 1937 der NSDAP bzw. vor dem 1. April 1933 der SA beigetreten war.

\footnotetext{
28 Stohr an Pius XII vom 21.6.1945, in: Akten deutscher Bischöfe, Bd. 6, S. $532 \mathrm{ff}$.

${ }^{29}$ LKAS, NL Hartenstein 52/3, Bericht Pressels über Empfang Wurms durch den Militärgouverneur am 19.7.1945.

${ }^{30}$ Buchberger an Militärregierung Regensburg vom 18.7. 1945, in: Akten deutscher Bischöfe, Bd. 6, S. $579 f$.
} 
Da die NSDAP am 1. Mai 1933 eine allgemeine Aufnahmesperre verhängt hatte, die im Prinzip bis zum 1. Mai 1939 bestand, allerdings für ehemalige Mitglieder des Stahlhelms Ende 1935 und für in anderen NS-Organisationen bewährte Parteianwärter im Frühjahr 1937 aufgelockert worden war, galt die kirchliche Fürsprache hauptsächlich den vor dem 1. Mai 1933 eingetretenen Parteimitgliedern. Indirekt kam dies auch in der Eingabe Buchbergers zum Ausdruck: ,,In der ersten Zeit der nationalsozialistischen Herrschaft, in welcher Hitler auch ein Konkordat mit dem $\mathrm{Hl}$. Stuhl abgeschlossen hat, schien es, als ob die Regierung nichts anderes wollte als einen friedlichen Wiederaufbau Deutschlands. Zu dieser Zeit sind viele der Partei beigetretenen im guten Glauben, daß die Nazi ihre Regierung auf den Boden des Christentums stellen werden, so wie es Hitler in seinem Programm und seinen Reden feierlich versprochen hatte. Als sie dann merkten, daß sie betrogen wurden und daß gegen das Christentum ein Vernichtungskampf geführt wurde, war es nicht mehr möglich, aus der Partei auszutreten, denn die brutale Gewaltherrschaft verhinderte jeden freien Willensentschluß.“31

Diese Argumentation sollten die Militärregierung und die Spruchkammern in den nächsten Jahren noch häufig zu hören bekommen. Sie bildete die klassische Verteidigung all derjenigen - unter ihnen zahlreiche evangelische Pfarrer -, die Christentum und NS-Ideologie für vereinbar gehalten und sich von der Machtergreifung Hitlers die Überwindung der weltanschaulichen Neutralität des Weimarer Staates zugunsten eines stärkeren kirchlichen Einflusses erhofft hatten. Die Militärregierung war jedoch unter der Zielvorgabe der Demokratisierung auf die Ausscheidung der Nationalsozialisten aus dem öffentlichen Dienst festgelegt und unterschied deshalb nicht zwischen kirchentreuen, kirchenfernen und kirchenfeindlichen NSDAP-Mitgliedern. Da die erste Entlassungswelle vor allem NS-Funktionäre traf sowie Parteimitglieder, die vor der Aufnahmesperre der NSDAP beigetreten waren, war die Behauptung, die meisten der Entlassenen seien der NSDAP nur gezwungenermaßen beigetreten, zudem wenig überzeugend.

Die systematische Ủberprüfung des öffentlichen Dienstes, die in Bayern ab Juli einsetzte, sowie die wiedererwachte Furcht vor der politischen Linken führte zur partiellen Uberwindung des konfessionellen Mißtrauens. Befriedigt hielt Meiser am 4. Juli in einem Aktenvermerk nach einer Unterredung mit dem Jesuitenpater Max Pribilla fest: Auch die katholische Kirche sehe ,,im Bolschewismus die uns gemeinsam drohende Gefahr, die uns das Trennende zurückstellen und ohne gegenseitiges Mißtrauen zusammenstehen heiß $\mathrm{t}^{\text {“32 }}$. Auf dieser Grundlage basierte sowohl die interkonfessionelle Zusammenarbeit in den Gründungszirkeln der CDU/CSU wie auch zwischen den Kirchenspitzen, die sich in einem denkwürdigen Ereignis ökumenischer Zusammenarbeit konkretisierte.

Am 20. Juli wandten sich Meiser und Faulhaber in einer gemeinsamen Eingabe direkt an OMGUS und forderten die Militärregierung auf, nach den Grundsätzen der Gerechtigkeit und Menschlichkeit vorzugehen und ,,die Schuld der einzelnen durch persönliche Uberprüfung, also nicht pauschal, zu bemessen“. Die Abkehr vom Nationalsozialismus und der Wiederaufbau ,im Geiste des Christentums“ dürfe nicht durch vermeidbare Härten in der Rechtspflege gestört werden. Im einzelnen führten sie gegen die schematischen Entlassungskategorien ins Feld: ,,Es bleibt doch für den Strafrichter ein gewaltiger Unterschied, ob der Beitritt zur Partei freiwillig erfolgte oder unter Drohungen laut oder

31 Ebenda.

32 LKAN, NL Meiser 212, Aktennotiz Meisers vom 4.7.1945. Vgl. Kap. IV/2. 
leise erzwungen wurde. Ein gewaltiger Unterschied, ob die Beteiligung an der Partei in der bloßen Beitragsleistung bestand oder in fanatischer Mitarbeit und Propaganda der nationalsozialistischen Weltanschauung, etwa der Rassenlehre, der Losung, Judentum und später auch Christentum auszurotten, durch Euthanasie ein Volk rassisch zu heben, auch in ganz aussichtsloser Lage bis zum letzten Mann zu kämpfen. “ Desweiteren plädierten Meiser und Faulhaber für die Unterscheidung, ob der Parteibeitritt ,,in dem guten, wenn auch naiven Glauben an die Versprechungen des Parteiprogramms" erfolgt sei oder, ,aus niedrigen Beweggründen der Rachsucht oder Selbstsucht". Im zweiten Punkt der Eingabe wandten sie sich gegen die ,,pauschale Verurteilung aller SS-Männer" und verwiesen darauf, daß gegen Kriegsende ganze Wehrmachtseinheiten der Waffen-SS unterstellt worden seien. Auch seien viele Fachleute zum Eintritt in die allgemeine SS gezwungen worden. Ein dritter Punkt betraf die Fürsprache für 102 verhaftete Bankiers und Industrielle. Sie seien wohl NSDAP-Mitglieder gewesen, hätten aber weder an den Kriegsvorbereitungen noch gar an den NS-Verbrechen persönlichen Anteil gehabt. Abschließend betonten Meiser und Faulhaber: , Wir wollen dem Richter nicht in die Arme fallen, der die Verantwortlichen zur Rechenschaft zieht. Wir konnten aber nicht schweigen, wo Amt und Gewissen und die Liebe zu unserem Volk zu reden geboten. Auch die Gerichte der Nachkriegszeit werden vor dem Richterstuhl der Geschichte und letzten Endes vor dem Richterstuhl des Allmächtigen nachgeprüft werden. "33

Wenige Tage später, am 25. Juli, meldete sich auch Wurm mit einer Eingabe an die württembergische Militärregierung zu Wort: Die Entlassung zahlreicher Beamter gefährde die geordnete Fortführung der Verwaltung und beschwöre die Gefahr herauf, „,daß fachlich unfähige und charakterlich ungeeignete Elemente in die Beamtungen einziehen". Viele NSDAP-Mitglieder hätten einen ,, offenen oder heimlichen Kampf" gegen das NS-Regime geführt, seien ihrer Kirche treu geblieben und hätten , unsagbar“ unter den kirchenfeindlichen Bestrebungen gelitten. Der Fürsprache für kirchlich gesinnte Parteimitglieder folgte der Satz: ,,Viele Nicht-Parteigenossen, die sich heute breit machen, waren einst ohne Halt und Charakter und stellten auch als Beamte, die aus irgendeinem Motiv nicht Parteigenossen werden konnten, keineswegs immer eine Elite dar. "Zugleich warnte Wurm davor, daß die Verzweiflung der entlassenen Nationalsozialisten für ,, heraufkommende kommunistische Bewegungen, die wir mit großer Sorge feststellen “, den geeigneten Nährboden abgebe. In Hinblick auf seine späteren Stellungnahmen verdient die scheinbare Selbstverständlichkeit festgehalten zu werden, mit der Wurm den Nationalsozialismus als den ,,Alpdruck eines alles Recht und alle Menschlichkeit brutal zerstörenden Regimes" charakterisierte. Wie die bayerische Eingabe, verlangte Wurm die Begrenzung der Entlassungsaktion auf besonders aktive Nationalsozialisten und schlug der Militärregierung hinsichtlich der Mitläufer vor: ,,Fordern Sie von Männern, für die auch die Kirche eintreten kann, eine klare öffentliche Stellungnahme gegen ihre Vergangenheit, aber dann lassen Sie den Geist der Versöhnung walten, geben Sie ihnen eine Bewährungsfrist und damit eine neue Chance, um gerade als Beamte zu zeigen, was sie unter einem gerechten und menschlichen Regime zu leisten vermögen. “ 34

Am selben Tag wurde auch der Bischof von Rottenburg bei der Militärregierung vorstellig. Sproll, einer der schärfsten NS-Gegner im katholischen Episkopat, wandte sich

${ }^{33}$ Meiser und Faulhaber an OMGUS vom 20.7.1945, in: Akten deutscher Bischöfe, Bd. 6, S. 585 f.

34 LKAS, NL Hartenstein 52/3, Wurm an OMGWB vom 25.7.1945. 
ebenfalls gegen die schematische Entlassungspraxis, da sie den tatsächlichen Verhältnissen nicht gerecht werde, unterließ jedoch jegliche Diffamierung des neueingestellten Verwaltungspersonals und plädierte für die ,Beiziehung vertrauenswürdiger und berufener deutscher Instanzen". Eine solche Instanz stelle der Stuttgarter Oberbürgermeister Arnulf Klett dar, dessen Vorschläge zur Entnazifizierung Sproll nachdrücklich unterstützte $^{35}$. Klett hatte sich im Juni für eine individuelle Fallprüfung eingesetzt, dabei aber einen Säuberungswillen an den Tag gelegt, der in einigen Punkten über den damaligen amerikanischen Forderungskatalog hinausging. Er forderte die ,,unbarmherzige Ausmerzung“ aller Zuträger des SD, der Denunzianten und all derjenigen, die ,, sich an Brutalitäten gegenüber Andersrassigen, insbesondere bei den sogen. Judenaktionen, beteiligt

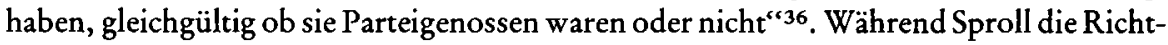
linien des Stuttgarter Oberbürgermeisters, die dem evangelischen Oberkirchenrat ebenfalls bekannt waren, befürwortete, verblieb die Kritik Wurms ausschließlich negativ. Hier lag der fundamentale Unterschied zwischen den beiden Eingaben, obwohl sie in der Sache mit ähnlicher Argumentation für Milde gegenüber den ,, nur nominellen Parteigenossen" eintraten. Da Wurm die Unterstützung der deutschen Säuberungsbemühungen durch den katholischen Bischof jedoch nicht teilte, konnte es in Württemberg nur zu einem zeitlich koordinierten Vorgehen der Kirchen, nicht aber zu einer gemeinsamen Eingabe kommen.

Anfang August teilte Colonel Jackson, der Stuttgarter Stadtkommandant, Oberkirchenrat Hartenstein mit, die Militärregierung sei fest entschlossen, die Entnazifizierung ,,rücksichtslos durchzuführen in dem vollen Wissen, daß sie zu einer tiefen Krisis im Volksleben und in der Verwaltung führen werde. [.. . ] Sie seien überzeugt, daß sich neue, fähige und wagemutige Männer genug finden, um die neuen, großen Aufgaben mit frischen Ideen und klaren Leitgedanken (visions) durchzuführen. " Es könne deshalb nicht die Aufgabe der Kirche sein, für Leute einzutreten, die in der Vergangenheit nicht die nötige Charakterstärke gezeigt hätten; vielmehr sei es ihre Aufgabe, ,,in ernster Besprechung und gründlicher Uberlegung neue Namen zu nennen für alle Stellen, die durch Pg frei würden“. Hartenstein war von diesen Ausführungen ,,tief betroffen“ und erwiderte: „,Der Ruf der Partei 1933 habe sich ausgesprochen an den Idealismus der besten Männer gewandt und die Ausdrücke, Neues Deutschland, Christliches Deutschland' usw. seien in den ersten Monaten von 1933 von größter Wirkung auf alle Kreise gewesen. Viele unserer besten Leute seien damals dem Ruf Hitlers gefolgt. “ Die Erwiderung zeigt anschaulich das Dilemma der evangelischen Kirche, die 1933 die Machtergreifung Hitlers begeistert begrüßt hatte und deshalb 1945 nur über ein geringes Reservoir unbelasteter und fachlich qualifizierter Laien verfügte. Hartenstein beschwor die Kirchenleitung, ,sich klar zu machen, daß wir vor einer absolut entschlossenen, fast leidenschaftlichen Idee des Aufbaus eines neuen Deutschlands mit völlig neuen Kräften stehen". Deshalb sei ein „,sehr grundsätzliches Wort" des Landesbischofs unumgänglich, um ,dem Leitbild der Amerikaner ein ebenso deutliches Leitbild unserer Auffassung entgegenzusetzen. [...] Wir müssen nun auch auf breiter Basis mit durchschlagenden Gründen und auf lange

${ }^{35}$ Sproll an OMGWB vom 25.7.1945, in: Akten deutscher Bischöfe, Bd. 6, S.607f.; LKAS, NL Hartenstein 52/3. Zur Haltung Sprolls während des Dritten Reiches vgl. P. Kopf/M. Miller, Die Vertreibung von Bischof Johannes Baptista Sproll von Rottenburg 1938-1945, Mainz 1971.

${ }^{36}$ LKAS, NL Hartenstein 52/3, Richtlinien für die Prüfungsarbeit vom 12.6.1945. 
Sicht arbeiten, sonst verbrauchen wir den Kredit und das große Vertrauen der Kirche in Deutschland." 37

Am 3. Oktober, wenige Tage nach der Verkündigung des Militärgesetzes Nr.8, wandte sich Wurm mit einer Denkschrift direkt an OMGUS. Sie skizzierte die Grundlagen des deutschen Berufsbeamtentums, insbesondere das Recht auf lebenslängliche Anstellung im Staatsdienst. Die Massenentlassungen von Parteimitgliedern verstoße in flagranter Weise gegen das Beamtenrecht, das selbst vom NS-Regime respektiert worden sei, und führe zu einer unerträglichen Rechtsunsicherheit. Die meisten NSDAP-Mitglieder seien nur nominelle Parteigenossen gewesen, die das NS-Regime innerlich entschieden abgelehnt hätten: ,That must be said particulary of those who have resisted the strong pressure to break away from the church. "Die Kirchentreue galt Wurm als das oberste Kriterium; deshalb zählte er auch alle vor dem 1. Mai 1937 eingetretenen Beamten zu den im Grunde untadeligen Mitläufern. 1933 seien viele Beamte Opfer einer geschickten Propaganda geworden und hätten an die christlichen Zielsetzungen des Nationalsozialismus geglaubt. Hatte nicht der Papst, fragte Wurm, 1933 mit dem nationalsozialistischen Deutschland das Reichskonkordat abgeschlossen? War nicht das Regime vom Ausland diplomatisch anerkannt? ,,For all these reasons many of our best within and without the civil service then followed Hitler's call. [...] We therefore do not think it is justifiable to measure the degree of political offence by the date of entrance into the party. " 38

Im Entwurf der Denkschrift wurden noch weitere Entlastungsgründe geltend gemacht: Der Nationalsozialismus und die Zustimmung zum Ermächtigungsgesetz sei ,, die elementare Reaktion des deutschen Volkes auf das furchtbare Versailler Diktat" gewesen. Der Endredaktion fiel auch ein Passus zum Opfer, der ungewollt auf die politische Mitverantwortung der Kirche hinwies: ,In welcher Beleuchtung mußte die NS-Bewegung auch den christlichen Kreisen des Volkes erscheinen, wenn Pastor Martin Niemöller von ihr in seinem vielgelesenen Buch ,Vom U-Boot zur Kanzel' als von einem gewaltigen Werk der völkischen Einigung und Erhebung redet und diesem Werk wünscht, daß es auf der Grundlage der Gottesgabe der Bibel einen unerschütterlichen Grund und dauernden Bestand gewinne?'r39 Die Kirche könne sich, so fuhr Wurm fort, nicht für die Entnazifizierung einsetzen, da sie Ausdruck eines Rache- und Vergeltungsdenkens sei, sondern habe im Gegenteil die Pflicht - ,, in accordance with the command of our Lord" - vor ihrer Durchführung zu warnen. Auch die evangelische Kirche leistete ihren Beitrag zum Wiederaufbau: , It cannot, however, be the task of the church to assist the Military Government in the replacement of party members within the civil service by suggesting names of substitutes. By doing so we should certainly transgress our task and load a responsibility upon us which we simply cannot shoulder. The evil consequences of such a cooperation would surely affect the Church in the one way or other."40

Zweifellos war die amerikanische Entlassungspraxis von ,,zahlreichen Ungerechtigkeiten überschattet “41, doch schoß die Kritik weit darüber hinaus. Daß Wurm ausdrücklich auch die bereits 1933 oder davor eingetretenen Beamten gegenüber der Militärregie-

37 LKAS, NL Hartenstein 52/2, Hartenstein an Oberkirchenrat vom 10.8.1945.

${ }^{38} \mathrm{NA}, \mathrm{RG} 84,737 / 3$, Wurm an OMGUS vom 3.10.1946.

${ }^{39}$ LKAS, NL Hartenstein 50/1, Entwurf, o. D.

40 NA, RG 84, 737/3, Wurm an OMGUS vom 3.10.1945.

41 Woller, Gesellschaft, S. 102. 
rung verteidigte und eine konstruktive Mitarbeit beim Neuaufbau eines demokratisch orientierten Verwaltungsapparats explizit ablehnte, verweist auf die politische Zielsetzung: Die zumeist konservative, vielfach kirchentreue Beamtenschaft, die einst den Deutschnationalen nahegestanden und sich dann mit dem Nationalsozialismus arrangiert hatte, sollte vor der politischen Säuberung gerettet werden. Ganz in diesem Sinne definierte denn auch die Denkschrift den Kreis der zu entlassenden Nationalsozialisten als ,,the small group of those who won and kept their office as ,old fighters', activists or terrorists, those superficial opportunists without professional training and lacking in charakter with them National-Socialism tended more and more to fill the preferred superior offices". Der taktische Charakter der formaljuristischen Argumentation mit dem Beamtenrecht zeigte sich nicht zuletzt auch darin, daß Wurm sich nicht für die Wiedereinstellung der vom NS-Regime entlassenen sozialdemokratischen oder jüdischen Beamten einsetzte.

Im letzten Abschnitt der Denkschrift legte Wurm erstmals eigene Vorschläge zur Entnazifizierung vor: 1. Die angestrebte Entlassung aller NSDAP-Mitglieder müsse unverzüglich aufgegeben werden, da sie eine ungerechte Maßnahme darstelle und es höchst fragwürdig sei, ob genügend qualifiziertes Ersatzpersonal gefunden werden könne, ,, who really have the call for leadership“. 2 . Alle bereits entlassenen Beamten sollten, sofern sie sich nicht aktiv für die NSDAP betätigt hätten, auf Probe wiedereingestellt werden. 3. Alle Beamten, die der NSDAP bis zuletzt angehörten, sollten in einem gesetzlich festgelegten Verfahren individuell überprüft werden. Dazu seien für jeden Berufsstand Prüfungsausschüsse einzurichten, denen mindestens zwei unbelastete Angehörige aus dem Berufstand des zu Uberprüfenden angehören müßten. Entsprechend dem Grad der jeweiligen Belastung könne der Ausschuß eine der folgenden Maßnahmen aussprechen: Wiedereinsetzung in das frühere Amt, neue Untersuchung nach sechsmonatiger Probezeit, Versetzung in ein anderes Amt gleichen Ranges, Versetzung in ein Amt von geringerer Bedeutung, Pensionierung mit vollem Ruhegehalt, Pensionierung mit gekürzter Pension, vorläufige Pensionierung, Entlassung mit einem Úbergangsgehalt von drei Monaten, Entlassung ohne Übergangsgehalt ${ }^{\mathbf{4 2}}$. Der Maßnahmenkatalog konnte freilich nicht darüber hinwegtäuschen, daß sich die Denkschrift über die zentrale Frage, welche Tatbestandsmerkmale den aktiven, zu entlassenden Nationalsozialisten auszeichneten, ausschwieg. Die Denkschrift Wurms blieb auch weit hinter anderen Säuberungsmodellen aus konservativen Kreisen zurück ${ }^{43}$ und war, da sie keine Bereitschaft zur konstruktiven Mitarbeit erkennen ließ, nicht geeignet, die evangelische Kirche als ernsthaften Diskussionspartner für die amerikanische Militärregierung ins Spiel zu bringen. Jacob Beam aus dem politischen Beraterstab Clays empfahl denn auch, lediglich den Empfang zu bestätigen und eine Kopie der Denkschrift an das State Department zu senden ${ }^{44}$.

Anfang Dezember 1945 wandten sich Meiser und Faulhaber nochmals in einer gemeinsamen Petition an die Militärregierung und baten um die Freilassung der aufgrund des ,automatischen Arrests“ internierten Personen, die sich überwiegend aus unteren und mittleren Funktionsträgern der NSDAP und Mitarbeitern der SS, des SD und der Ge-

42 NA, RG 84, 737/3, Wurm an OMGUS vom 3.10.1945.

${ }^{43} \mathrm{Vgl}$. Denkschrift des bayerischen Ministerpräsidenten Schäffer vom 1.8.1945. Dazu Niethammer, Entnazifizierung, S. $174 \mathrm{ff}$.

44 NA, RG 84, 731/3, Beam an Mann vom 14.10.1945. 
stapo zusammensetzten: Alle Verhafteten, denen kein ,,ernstliches Verbrechen “ nachgewiesen werden könne und die ,schlimmstenfalls als bloße Mitläufer" zu bezeichnen seien, sollten umgehend aus den Internierungslagern entlassen werden. Der Kirche liege es fern, wirklich Schuldige der Bestrafung zu entziehen, doch gehöre es zu ihren Pflichten, auch für Verbrecher an die Barmherzigkeit des Richters zu appellieren. ,Wieviel mehr müssen wir es als unser Recht und unsere Pflicht ansehen, da fürbittend unsere Stimme zu erheben, wo nicht kriminelle Tatbestände vorliegen, sondern nur Unbedachtheit, menschliche Schwäche, vielleicht auch mangelnder Mannesmut, viele zu einem Schritt getrieben haben, den nachträglich niemand mehr bereut, als die nun so hart zur Rechenschaft Gezogenen selbst." 45

Die massive Kritik an der Entnazifizierungspolitik mußte in der Militärregierung unvermeidlich den Eindruck verstärken, daß die Kirchen nur bedingt als Bündnispartner für die Demokratisierung Deutschlands angesehen werden konnten. Auf der Stabskonferenz Clays am 6. Oktober 1945 formulierte General Conrad, der Direktor der Intelligence Division, unwidersprochen die Einschätzung: ,Considerable portion of the clergy that now exists is extremely reactionary and strong nationalist, although not necessarily Nazi. "46 Differenzierter analysierte eine im Januar 1946 fertiggestellte Studie des Office of Research and Intelligence die politische Rolle der deutschen Kirchen vor dem Hintergrund ihrer traditionellen Fixierung auf die Mittelschichten: Nirgends werde der Bruch zwischen der politischen und sozialen Orientierung der Arbeiterschaft und den konservativen Mittelschichten deutlicher als in der Frage der Entnazifizierung. Während die deutsche Linke die politische Säuberung als unerläßliche Voraussetzung für die Etablierung der Demokratie unterstütze, befürchte die Rechte zusammen mit Vertretern der politischen Mitte, die Entnazifizierung werde zur Schwächung der Mittelschichten und damit zur politischen Herrschaft der Linken führen. Die große Mehrheit der katholischen und protestantischen Pfarrerschaft versuche deshalb mit allen Mitteln, die Entnazifizierung zu entschärfen und zu bremsen. Die schärfsten Wortführer seien hierbei Kardinal Faulhaber und Bischof Wurm. Die entschiedene Ablehnung einer umfassenden politischen Säuberung beruhe maßgeblich auf dem Interesse der Kirchen an der Erhaltung des konservativen Beamtenapparates. Er habe während des Dritten Reiches vielfach antikirchliche Verordnungen abgeschwächt; deshalb erwarte man eine ähnliche Verhaltensweise auch unter einem linken Regime ${ }^{47}$.

Die namentlich nicht bekannten Verfasser der Studie waren sich bewußt, daß die ablehnende Haltung der Kirchenführer weniger aus der früheren Sympathie für den Nationalsozialismus resultierte als vielmehr aus ihrer konservativen Grundorientierung und ihrem Interesse an der Durchsetzung kirchlich-christlicher Normen in Staat und Gesellschaft. In dieser Perspektive lag die eigentliche Gefahr nicht in der Beibehaltung ehemaliger Parteigänger des Nationalsozialismus, sondern im Vordringen links orientierter Kräfte, die die Trennung von Staat und Kirche verfochten. Diese primär politische Moti-

45 Eingabe Meisers und Faulhabers an OMGUS vom 7.12.1945, in: Akten deutscher Bischöfe, Bd. 6, S. $861 \mathrm{ff}$. Zur Internierungspolitik vgl. Niethammer, Entnazifizierung, S. $255 \mathrm{ff}$.

${ }^{46}$ IfZ, Fg 12/2, Minutes of Staff Meeting vom 6.10.1945.

${ }^{47}$ NA, RG 84, 757/22, Office of Research and Intelligence, The Churches and Political Life in Post-War-Germany, o. D. (Januar 1946). Vgl. NA, RG 84, 757/23, Murphy an Secretary of State vom 3.5.1946. 
vation läßt sich in allen Eingaben, wenn auch in unterschiedlicher Stärke, nachweisen. Ende September 1945 erklärte der Mainzer Bischof Stohr den Amerikanern nochmals in aller Deutlichkeit, ihre Entnazifizierungspolitik sei nicht nur von zahlreichen Fehlgriffen und ungerechtfertigten Härten begleitet, sondern rufe auch ,,a new German sickness“ hervor: , The German people will be pushed from a Radical Right to an Extreme Left and subject to new frightful terror." 48

Zweifellos hatten die Kirchenführer der Militärregierung die politische Einsicht voraus, daß viele NSDAP-Mitglieder keine überzeugten Nationalsozialisten mehr waren und im Interesse des sozialen Friedens, früher oder später, wieder integriert werden mußten. Dieses Anliegen vermochten die Kirchen jedoch, wenn sie - wie alle politischen Gruppierungen in Deutschland - eine differenziertere Beurteilung forderten, nur unzureichend zu vermitteln. Der frontale Angriff auf die Entnazifizierung und die oft recht apologetischen Rechtfertigungsversuche mußten die Glaubwürdigkeit des kirchlichen Engagements erschüttern, zumal die Kritik bereits im Mai 1945 mit den ersten, noch sehr begrenzten Säuberungsmaßnahmen der Militärregierung eingesetzt hatte und so gut wie gar keine Erwägungen zu dem Problemkreis von Schuld und Sühne enthielt. Die Frage, ob der Verlauf der Entnazifizierung eine andere Wendung genommen hätte, wenn die Kirchen sachgemäßer und differenzierter argumentiert hätten, läßt sich dennoch nur verneinen. Die Militärregierung handelte unter dem Diktat politischer Vorgaben und unter dem starken Druck der öffentlichen Meinung in den Vereinigten Staaten, so daß die deutschen Kirchen keine realen Einflußchancen besaßen. Diese Situation änderte sich grundlegend im Sommer 1946, als mit der Verabschiedung des Befreiungsgesetzes die Durchführung der politischen Säuberung in deutsche Hände überging.

\section{Entstehung und Durchführung des Befreiungsgesetzes}

Parallel zur deutschen Kritik an der amerikanischen Entlassungspraxis gewannen seit Spätsommer 1945 auch in der Militärregierung diejenigen Kritiker an Einfluß, die aus dem selbstgeschaffenen Dilemma der weitgehenden Paralysierung des Verwaltungsapparates die Folgerung zogen, die politische Säuberung den Deutschen selbst zu übertragen.

Anfang Januar 1946 einigten sich die Ministerpräsidenten der Länder auf einen Gesetzesentwurf, einen Kompromiß zwischen dem bayerischen Rehabilitierungskonzept und dem hessischen Entwurf einer genuin politischen Säuberung ${ }^{49}$. Er sah die Bildung von „Spruchkammern" vor, die entsprechend der ,,individuellen Verantwortlichkeit" und der ,,tatsächlichen Gesamthaltung“ des Betroffenen abgestufte Disziplinarmaßnahmen verhängen konnten. Für NS-Aktivisten war zusätzlich eine Reihe von Sühnemaßnahmen -Entzug des Wahlrechts, Beschränkungen in der Berufsausübung, teilweiser Einzug des

48 NA, RG 84, 737/3, Stohr an Crum, ERA-Branch, vom 29.9.1945.

$49 \mathrm{Vgl}$. Niethammer, Entnazifizierung, S. $260 \mathrm{ff}$. In der bayerischen Staatsregierung unter Wilhelm Hoegner (SPD) lag das Sonderministerium in Händen von Heinrich Schmitt (KPD); in der großhessischen Landesregierung unter Karl Geiler (parteilos) wurde das Befreiungsministerium von Gottlob Binder (SPD) verwaltet. Federführend in der württembergischen Landesregierung unter Reinhold Maier (DVP) war Justizminister Josef Beyerle (CDU), erst in der Schlußphase wurde der spätere Befreiungsminister Gottlob Kamm (SPD) beteiligt. 
Vermögens - zwingend vorgeschrieben. Fallen gelassen waren die im hessischen Entwurf verankerte gesetzliche Schuldvermutung und die darauf basierenden einstweiligen Disqualifizierungen. Ebenso fehlte die Registrierung aller Belasteten und die Schaffung einer politischen Anklagebehörde. Der Entwurf stieß auf heftigen Widerspruch der Special Branch, die bereits einen Vorentwurf als den ,Sieg jener Entnazifizierungskräfte unter den verantwortlichen Deutschen" bezeichnet hatte, , die ein kunstvolles und sorgfältig ausgearbeitetes Programm vorbereitet haben, nicht um die Entnazifizierung zu vollenden, sondern um sie zu vernichten"so.

Special Branch vertrat die Auffassung, daß die Militärregierung die Entnazifizierung als politisch begründete Maßnahme qua Siegerautorität durchführen und jede Vermischung mit strafrechtlichen Gesichtspunkten vermeiden müsse. Völlig konträr zu diesem Konzept lag das im Dezember 1945 verabschiedete Kontrollrats-Gesetz Nr. 10, das die Konzeption der Legal Division von OMGUS widerspiegelte. Es schuf die Rechtsgrundlage für die umstrittenen Kriegsverbrecherprozesse und bildete mit der Konstruktion der sogenannten Organisationsverbrechen, die der deutschen Rechtstradition fremd war, die Arbeitsgrundlage für den Nürnberger Gerichtshof. Entsprechend der Anklage verurteilte der Gerichtshof im September 1946 das Korps der politischen Leiter der NSDAP, die Gestapo, den SD und die SS als verbrecherische Organisationen. Freigesprochen von diesem Vorwurf wurden die Reichsregierung, der Generalstab und das Oberkommando der Wehrmacht sowie die SA ${ }^{51}$.

Mit dem Kontrollrats-Gesetz Nr. 10 fand auch die Forderung der Legal Division, die Mitgliedschaft in anderen NS-Organisationen strafrechtlich zu verfolgen, Eingang in die Diskussion über die zukünftige Entnazifizierungspolitik und löste die politisch orientierte Entlassungskonzeption von Special Branch ab. Nach monatelangen Beratungen erließ der Kontrollrat am 12. Januar 1946 die Entnazifizierungs-Direktive Nr. 2452, die an den Formalbelastungskategorien der amerikanischen Richtlinien festhielt und zu einer einheitlichen Handhabung der politischen Säuberung in allen vier Besatzungszonen führen sollte, wozu es jedoch nie kam.

Gegenüber der Verhandlungsdelegation des Länderrats bestand Clay im Februar 1946 auf der UUbernahme des Belastungskatalogs der Kontrollratsdirektive. Als ausschlaggebend für die letztendliche Zustimmung auf deutscher Seite erwies sich, daß die Vertreter der Militärregierung deutlich durchblicken ließen, es gehe vor allem um einen Gesetzestext, der sich, wie der bayerische Sonderminister Pfeiffer festhielt, in Amerika ,,optisch gut präsentieren müsse“"53. Die Juristen beider Delegationen waren sich darin einig, daß nicht die Formalbelastungskategorien das Wesentliche darstellten, sondern ihre juristisch festgeschriebene Widerlegbarkeit; damit war die Rehabilitierung für bereits Entlassene gegeben. Das freie richterliche Ermessen, das den Deutschen ausdrücklich konzediert wurde, machte das Ultimatum annehmbar. Nach außen aber erweckte die Diktion des Gesetzes den Eindruck unnachsichtiger Härte, womit das Ansehen der Militärregierung gegenüber der amerikanischen Offentlichkeit gewahrt war.

50 Zit. nach Niethammer, Entnazifizierung, S. 300 .

${ }^{51}$ Vgl. Werner Maser, Nürnberg. Tribunal der Sieger, Düsseldorf 1977; Bradley F. Smith, Der Jahrhundert-Prozeß. Die Motive der Richter von Nürnberg. Anatomie einer Urteilsfindung, Frankfurt a. Main 1977.

52 In: Sammlung.

${ }^{53}$ Bericht Pfeiffers vom 20.2.1946. Zit. nach Niethammer, Entnazifizierung, S.316. 
Das ,,Gesetz Nr. 104 zur Befreiung von Nationalsozialismus und Militarismus“, so der offizielle Titel, wurde am 5. März 1946 verkündet und galt für die Länder Bayern, Großhessen und Württemberg-Baden. In der Enklave Bremen trat es erst am 9. Mai 1947 nach der Konstituierung des Landes Bremen in Kraft. Als Zielsetzung proklamierte es den Ausschluß all derjenigen aus dem gesellschaftlichen Leben, ,, die die nationalsozialistische Gewaltherrschaft aktiv unterstützt oder sich durch Verstöße gegen die Grundsätze der Gerechtigkeit und der Menschlichkeit oder durch eigensüchtige Ausnutzung der dadurch geschaffenen Zustände verantwortlich gemacht haben"54. Der grundlegende Unterschied zu den bisherigen Entnazifizierungsbestimmungen der Militärregierung war in Artikel 2 formuliert:

„Die Beurteilung des Einzelnen erfolgt in gerechter Abwägung der individuellen Verantwortlichkeit und der tatsächlichen Gesamthaltung [...]. Außere Merkmale wie die Zugehörigkeit zur NSDAP, einer ihrer Gliederungen oder einer sonstigen NS-Organisation sind nach diesem Gesetz für sich allein nicht entscheidend für den Grad der Verantwortlichkeit. Sie können zwar wichtige Beweise für die Gesamthaltung sein, können aber durch Gegenbeweise ganz oder teilweise entkräftet werden."

Grundlage des neuen Verfahrens bildete die Registrierung der gesamten Bevölkerung über 18 Jahre, die einen 14 Fragegruppen umfassenden ,,Meldebogen“ auszufüllen hatte. Die Grobsortierung der Meldebogen erfolgte durch die öffentlichen Kläger der Spruchkammern. Sie schieden den vom Gesetz nicht betroffenen Personenkreis aus und nahmen entsprechend der Formalbelastung eine vorläufige Einstufung der Betroffenen in fünf Gruppen vor:

I: Hauptschuldige

II: Belastete: Aktivisten, Militaristen, Nutznießer

III: Minderbelastete

IV: Mitläufer

V: Entlastete

Als Hauptschuldige galten unter anderem alle leitenden Mitarbeiter des Reichssicherheitshauptamtes, der Grenz-, Ordnungs- und Kriminalpolizei, die Offiziere der SS sowie alle Angehörigen der Gestapo. Hinzu kamen alle Amtsträger der NSDAP, einschließlich der Amtsleiter auf Kreisebene, und die höheren und mittleren Amtsträger der zahlreichen NS-Organisationen, aber auch Generalstabsoffiziere und Führungskräfte der Militärund Zivilverwaltungen in den besetzten Gebieten. Zu den NS-Aktivisten zählten generell die unteren Chargen der NS-Organisationen, alle NSDAP-Mitglieder vor dem 1. Mai 1937, alle Mitglieder der Waffen-SS und der SS sowie Berufsoffiziere der Wehrmacht nach 1936 bis herab zum Generalmajor.

Die Spruchkammern, die aus einem Vorsitzenden, mindestens zwei Beisitzern und dem öffentlichen Kläger bestanden, führten das Verfahren nach freiem Ermessen durch. Festgelegte Verfahrensregeln waren die Erforschung der Wahrheit von Amts wegen, die Vernehmung von Zeugen, auch unter Eid, der Anspruch des, „Betroffenen“ (Angeklagten) auf rechtliches Gehör und Rechtsbeistand. Die Widerlegung der Schuldvermutung oblag dem Betroffenen und stellte den Kernpunkt der Verteidigung dar. Die Umkehrung der Beweislast widersprach dem traditionellen Strafrecht und löste in der deutschen Of-

54 Art. 1 BefrG. Das BefrG wird nach dem Regierungsblatt der Regierung Württemberg-Baden, Nr. 8 vom 1.4. 1946 zitiert. 
fentlichkeit heftige Kritik aus. Allerdings stellte dies die einzig praktikable Lösung dar; andernfalls hätte eine riesige Anklagebehörde aufgebaut werden müssen, die ihrerseits nicht minder heftigen Widerspruch hervorgerufen hätte. In der praktischen Durchführung zeigte sich überdies sehr bald, daß die Umkehrung der Beweislast kaum zum Nachteil der Betroffenen ausfiel, da die Spruchkammern fast jeden zum Mitläufer erklärten.

Bis zum 30. September 1946 hatten die Kammern insgesamt 9628 Urteile gefällt und dabei 20 Betroffene in Gruppe I, 215 in Gruppe II und 686 in Gruppe III eingestuft. 90,4 Prozent galten als Mitläufer bzw. Entlastete, während die öffentlichen Kläger 46 Personen in Gruppe I, 1198 in Gruppe II und 636 in Gruppe III eingereiht hatten und nur 80,5 Prozent der Angeklagten als Mitläufer oder Entlastete gelten lassen wollten ${ }^{55}$. Bereits in dieser ersten Bilanz kündigte sich die Entwicklung des Spruchkammerwesens zur ,,Mitläuferfabrik" an.

Die Spruchkammern entschieden über die Einstufung der Betroffenen und setzten in ihrem ,Spruch“ (Urteil) die ,,Sühnemaßnahmen“(Strafen) fest. Gegen die Entscheidung konnte Berufung an der Berufungskammer eingelegt werden, der ein zum Richteramt befähigter Jurist vorsitzen mußte. Als Sühnemaßnahmen konnten für Hauptschuldige bis zu zehn Jahre Arbeitslager und vollständiger Vermögenseinzug, für NS-Aktivisten bis zu fünf Jahre Arbeitslager und teilweiser Vermögenseinzug angeordnet werden. Hinzu kamen in beiden Gruppen der Verlust der Pensions- oder Rentenansprüche aus öffentlichen Mitteln, die Aberkennung der bürgerlichen Ehrenrechte und ein auf mindestens zehn bzw. fünf Jahre festgesetztes Verbot, in anderer als ,,gewöhnlicher Arbeit" tätig zu sein. Für Minderbelastete galt eine „Bewährungsfrist“" von höchstens drei Jahren, innerhalb derer sie keine leitende Tätigkeit ausüben durften; davon ausgenommen war die Führung von Kleinbetrieben mit weniger als zehn Arbeitnehmern. Weitere Sühnemaßnahmen für Minderbelastete bestanden in der Kürzung des Gehalts bzw. des Ruhestandsgehalts und in einer einmaligen oder laufenden Geldzahlung an den Wiedergutmachungsfonds. Für Mitläufer galten nur die beiden zuletzt genannten Maßnahmen. Entlastet war, wer nur formell NS-Organisationen angehört hatte und zugleich nachweisen konnte, daß er „,nach Maß seiner Kräfte aktiven Widerstand gegen die NS-Gewaltherrschaft geleistet und dadurch Nachteile erlitten hat" ${ }^{\text {"56. }}$

Das Befreiungsgesetz stellte unverkennbar einen Formelkompromiß zwischen zwei unterschiedlichen Konzeptionen dar: Obwohl es Elemente der rein politisch motivierten Entlassungskonzeption von Special Branch enthielt, die insbesondere in den Belastungskategorien und im Beschäftigungsverbot nach Art. 58 BefrG kulminierten, überwog doch die Transformation einer politischen Grundsatzentscheidung auf die juristische Ebene, in deren Mittelpunkt die Beurteilung der individuellen Verantwortung und Schuld nach strafrechtlichen Maßstäben stand. Damit war die an sich notwendige politische Entscheidung über Art und Umfang der Personalsäuberung, über die sowohl unter den deutschen Parteien wie auch in der Militärregierung kein einheitlicher Konsens bestand, umgangen und auf die dehnbare Interpretation und Anwendung des Gesetzes verschoben worden.

Die Frage, ob das Befreiungsgesetz ein Strafgesetz und ob es als rückwirkendes Gesetz rechtswidrig sei, beherrschte von nun an die öffentliche Diskussion und verstellte den

55 Niethammer, Entnazifizierung, S. 406.

56 Art. 13 BefrG. 
Blick auf die genuin politische Dimension der Entnazifizierung. Unter den deutschen Juristen rechtfertigte eine kleine sozialdemokratische Minderheit, angeführt von Adolf Arndt aus dem hessischen Justizministerium, das Gesetz als Strafmaßnahme durch Mittäterschafts- und Teilnahmekonstruktionen aus dem deutschen Strafrecht. Die meisten Juristen hoben jedoch den strafrechtlichen Charakter bei gleichzeitiger Verletzung strafrechtlicher Grundprinzipien hervor, um das Befreiungsgesetz als rechtswidrig zu klassifizieren. Aus diesem Dilemma entstand die von einer Minderheit konservativer und liberaler Juristen durchgesetzte Meinung, das Befreiungsgesetz sei ein Recht sui generis ${ }^{57}$. Dem entsprach auch die Ersetzung traditioneller strafrechtlicher Begriffe durch eine neue Terminologie (Spruchkammer, Belastung, Betroffener, Sühne etc.). Maßgeblich für die Unterstützung von konservativer Seite waren in erster Linie staatspolitische Erwägungen, da die Militärregierung keinen Zweifel daran ließ, daß sie die Durchführung des Befreiungsgesetzes als Testfall für die Ubertragung weiterer Zuständigkeiten auf deutsche Stellen begriff.

Die juristische Debatte verstellt jedoch leicht den Blick auf das Wesentliche: Gerade der Strafcharakter des Gesetzes eröffnete den von der Militärregierung qua Besatzungsrecht bereits Entlassenen die Rehabilitierung, da nunmehr von deutscher Seite alle Fälle neu aufgerollt wurden. Bestimmte diese Absicht bereits die Ausarbeitung des Gesetzes, so sprengte die Durchführungspraxis die ursprünglich ins Auge gefaßten Dimensionen, was zu heftigen Konflikten mit der Militärregierung führen mußte. Der Schwachpunkt der konservativen Kritik war die Außerachtlassung der Entstehungsgeschichte des Befreiungsgesetzes und der konkreten historischen Situation. Denn gegenüber der bisherigen Entlassungspraxis der Militärregierung stellte das Gesetz mit der Verankerung rechtsstaatlicher Grundsätze - rechtliches Gehör, Unabhängigkeit der Richter, freie Beweiswürdigung - einen sichtbaren Fortschritt dar. Der heftig erhobene Vorwurf des unzulässigen rückwirkenden Strafcharakters implizierte zugleich, was die Kritiker kaum bedachten, daß die Entlassung von ehemaligen NSDAP-Mitgliedern juristisch gedeckt sei, solange sie nicht strafrechtlich begründet, sondern von den Siegermächten, gestützt auf die bedingungslose Kapitulation des Deutschen Reiches, im Zuge der Verwaltungsanordnung erfolgte. Hier bewegte sich die konservative Kritik in Widersprüchen, die Ausdruck der prinzipiellen Ablehnung einer durchgreifenden politischen Säuberung in weiten bürgerlichen Kreisen waren.

Bis Ende März 1947 waren den Spruchkammern in Bayern 6,2 Millionen Meldebogen zur Bearbeitung zugegangen, in Württemberg-Baden 2,7 und in Hessen waren es Ende September 19473 Millionen. Vom Gesetz betroffen waren, nach Angaben von Ende 1949, in Bayern 1,9 Millionen Einwohner, in Württemberg-Baden 0,7 und in Hessen $0,9^{58}$. Rund 3,5 Millionen Einwohner der US-Zone hatten demnach irgendeiner Gliederung der NSDAP oder einer sonstigen NS-Organisation angehört. Vom Befreiungsgesetz war unmittelbar ein Drittel der gesamten Bevölkerung über 18 Jahre betroffen; rechnet man die indirekt betroffenen Familienmitglieder hinzu, so waren es über zwei Drittel. Diese globalen Zahlen sagen allerdings nichts über die Zusammensetzung der Formalbe-

${ }^{57}$ Vgl. den offiziösen Kommentar von Erich Schullze (Hrsg.), Gesetz zur Befreiung von Nationalsozialismus und Militarismus, München 1946 (mehrere Auflagen). Weitere Literatur: Niethammer, Entnazifizierung, S. $327 \mathrm{ff}$.

58 Niethammer, Entnazifizierung, S.451, 540; Sauer, Neubeginn, S.153, 164; Kropat, Hessen, S. 243 . 
lastung aus. Die Entnazifizierungsstatistik Württembergs erfaßte im September 1947 630000 Betroffene, von denen 223940 nach der Formalbelastung in Gruppe I und II fielen; während die restlichen zwei Drittel nach der Schuldvermutung den Gruppen III und IV angehörten ${ }^{59}$.

Die Auswertung der Meldebogen blockierte monatelang den Spruchkammerapparat, der zwar mit der Unterrichtung der Nicht-Betroffenen auf Hochtouren lief, hinsichtlich der Bewältigung der Entnazifizierung aber nur bürokratischen Leerlauf produzierte. Die Ende September 1946 erlassene Jugendamnestie und die Mitte 1947 in Kraft tretende Weihnachtsamnestie, die bis 1949 zur Einstellung von 2,8 Millionen Verfahren führten, erfolgten zu spät, um den politischen Säuberungsgehalt des Befreiungsgesetzes noch retten zu können. Von der Weihnachtsamnestie profitierte die Masse der kleinen Mitläufer, soweit ihr Jahreseinkommen vor 1945 unter 4500 RM gelegen oder sie stark erwerbsbehindert waren, von der Jugendamnestie alle nach 1919 Geborenen. Der Umfang der Amnestien übertraf die Zahl der tatsächlich durchgeführten Spruchkammerverfahren bei weitem; auf ein Spruchkammerurteil kamen drei Amnestiebescheide ${ }^{60}$. Die Masse der vom Befreiungsgesetz Betroffenen kam mit der Spruchkammer also überhaupt nicht in Berührung.

Zu den Eigentümlichkeiten der deutschen Entnazifizierung gehörte es, daß spürbare Nachteile durch die Spruchkammerentscheidung meist nicht verhängt, sondern vielmehr aufgehoben wurden. Nach Art. 58 BefrG durfte niemand, der nach der Formalbelastung als Hauptschuldiger oder NS-Aktivist anzuklagen war, bis zum Abschluß des Spruchkammerverfahrens in anderer als ,,gewöhnlicher Arbeit“ beschäftigt werden. Die vorläufige Entlassung aus Stellungen mit aufsichtsführenden, organisatorischen oder personalpolitischen Kompetenzen traf naturgemäß in besonders hohem Maß den oberen Mittelstand und die obere, zum Teil auch untere Dienstklasse der öffentlichen Verwaltung, während das Beschäftigungsverbot für belastete Arbeiter und kleine Angestellte kaum Auswirkungen hatte. Nach einer Schätzung Niethammers waren allein in Bayern rund 160000 Personen vom vorläufigen Beschäftigungsverbot betroffen; allerdings ist die Zahl der tatsächlich Entlassenen aufgrund zahlreicher Ausnahmegenehmigungen wesentlich geringer anzusetzen. Nach der Einschränkung des Art. 58 BefrG durch das 1. Anderungsgesetz Ende 1947 waren noch rund 120000 Personen betroffen. Das vorläufige Beschäftigungsverbot erfaßte im wesentlichen denselben Personenkreis, der bereits vor Inkrafttreten des Befreiungsgesetzes von der Militärregierung entlassen worden war und führte somit kaum zu neuen Entlassungen. Rechnet man die Anzahl jener Internierten und Entlassenen hinzu, die unter die Amnestien fielen oder deren Fälle vom öffentlichen Kläger niedergeschlagen wurden, so betrug in Bayern, dem bevölkerungsreichsten Land der US-Zone, die Gesamtzahl derjenigen, die schon vor der Spruchkammerentscheidung gravierende Nachteile hatten, ,,mindestens 180000, höchstens 210000"61. Für diese Personengruppe bedeutete das Befreiungsgesetz, so paradox es klingen mag, einen großen Fortschritt, da die Spruchkammern in 90 Prozent der Fälle die auf Maßnahmen der Militärregierung zurückgehenden Diskriminierungen aufhoben.

Zu den eigentümlichen Wirkungen der Entnazifizierungspraxis gehörte weiterhin, daß

\footnotetext{
${ }^{59}$ BayHStA, MSo 93, Ubersicht über erledigte Fälle in Württemberg-Baden vom 3.9.1947.

${ }^{60} \mathrm{Vgl}$. Niethammer, Entnazifizierung, S. $436 \mathrm{ff}$.

61 Ebenda, S. $575 \mathrm{f}$.
} 
die Konzentration der Spruchkammern auf die Rehabilitierung der Mitläufer zur Verschiebung der schweren Fälle führte, die beim überstürzten Abbruch der Entnazifizierung 1948 allzu oft mit geringen Strafen davonkamen. So wurde, um nur ein Beispiel herauszugreifen, Alfred Hugenberg, der mehr zur Zerstörung der Weimarer Demokratie beigetragen hatte als mancher SA-Führer, 1949 als harmloser Mitläufer eingestuft ${ }^{62}$. Die Klage, die kleinen Nazis gehängt, die großen aber laufen gelassen zu haben, erwies sich nur zu oft als berechtigt. Hätten sich die Spruchkammern jedoch sofort auf die schweren Fälle konzentriert, worauf die Militärregierung drängte, so hätten die bereits Entlassenen noch länger auf ihre Rehabilitierung warten müssen.

Das Sozialprofil der rund 950000 Spruchkammerbetroffenen beschreibt Niethammer folgendermaßen: ,Etwa die Hälfte [...] entstammte der breiten Einkommensgruppe ( 2500 bis $5000 \mathrm{RM} / \mathrm{Jahr}$ ) der qualifizierten Facharbeiter, mittleren Büroangestellten, der mittleren und gehobenen Beamtenlaufbahn, des kleinen Einzelhandels und Gewerbes. [...] Die untere Mittelschicht stellt den Normalfall der Kammertätigkeit dar: überwiegend kleine Amtsträger der NSDAP und ihrer Gliederungen, deren Formalbelastung die Rechtsvermutung ,Aktivismus' begründete, weshalb die Anklagebehörden nicht selbst die Amnestie erlassen durften. [...] Während die Gesamtzahl der Spruchkammerbetroffenen in Bayern etwa 1/10 der Erwerbspersonen von 1939 entspricht, machen die entnazifizierten Arbeiter nur rund $3 \%$ der Arbeiterschaft von 1939 aus. Dagegen wurde etwa 1/6 der Selbständigen, 1/3 der Angestellten und jedenfalls mehr als die Hälfte der Beamten einem Spruchkammerverfahren unterworfen. "63 Das Spruchkammerverfahren traf damit genau jene sozialen Schichten, aus denen sich die evangelische Pfarrerschaft rekrutierte - ein Faktum, das in seinen Auswirkungen auf die Haltung der Kirche kaum überschätzt werden kann. Im Mittelpunkt der Entlassungsmaßnahmen der Militärregierung stand die bürokratische Dienstklasse, vor allem die Angestellten und Beamten des öffentlichen Dienstes, der auch die Väter von einem Drittel der evangelischen Pfarrer angehörten. Einem Arbeiter- oder unselbständigen Handwerkerhaushalt entstammten hingegen nur 3,4 Prozent der Pfarrerschaft ${ }^{64}$.

Die statistische Bilanz der deutschen Entnazifizierung ist die Bilanz einer großzügigen Rehabilitierung ehemaliger Parteimitglieder, die in vielen Fällen ungerechtfertigte Entlassungen seitens der Militärregierung zurücknahm, noch häufiger aber Gnade vor Recht gehen ließ ${ }^{65}$. In Bayern waren nach der Klageerhebung, die weitgehend der Formalbelastung folgte, 39,5 Prozent aller verhandelten Spruchkammerfälle, d.h. nach Abzug von rund 1,5 Millionen Verfahren, die aufgrund der Amnestien ohne Verhandlung eingestellt worden waren, als schwere Fälle klassifiziert. Dagegen hielten die Spruchkammern in erster Instanz die Einstufung in Gruppe I und II in 2,56 Prozent der Fälle für angemessen. Dieser an sich bereits sehr niedrige Prozentsatz reduzierte sich im Laufe der Berufungsverhandlungen auf 0,83 Prozent aller rechtskräftigen Sprüche. Ähnliche Zahlen liegen für Hessen vor ${ }^{66}$.

${ }^{62}$ Henke, Entnazifizierung, S. 22. Vgl. die von Niethammer, Entnazifizierung, S. 581 f., zitierten haarsträubenden Fehlurteile.

${ }^{63}$ Niethammer, Entnazifizierung, S. 551, 553.

${ }^{64}$ Pfarrerstatistik nach Berufen der Väter von 1950, in: KJ 1955, S. $400 \mathrm{f}$.

${ }^{65}$ Zur Durchführung vor Ort vgl. Woller, Gesellschaft, S. 119-165; Ettle, Entnazifizierung in Eichstätt.

${ }^{66}$ Vgl. Niethammer, Entnazifizierung, S. 543; Kropat, Hessen, S. 243 f. 
Im August 1949, nach dem überstürzten Abbruch der Entnazifizierung im Vorfeld der Gründung der Bundesrepublik, verzeichnete die Gesamtstatistik der tatsächlich durchgeführten Spruchkammerverfahren für die US-Zone folgende Angaben:

Statistik der durchgefübrten Spruchkammerverfabren in der US-Zone bis zum August 194967

\begin{tabular}{lrrrr}
\hline Gruppe & Bayern & Württemberg-Baden & Hessen & Bremen \\
\hline I & 743 & 461 & 416 & 34 \\
II & 11040 & 5372 & 5350 & 360 \\
III & 52940 & 24459 & 28208 & 815 \\
IV & 215585 & 121110 & 133722 & 14640 \\
V & 8828 & 3388 & 5279 & 959 \\
Jugend-A. & 33544 & 35599 & 20471 & 158 \\
Weihnachts-A. & 116165 & 42389 & 34963 & 1221 \\
andere Gründe & 15122 & 9885 & 6565 & 345 \\
\hline Summe & 453957 & 242663 & 234974 & 18532 \\
\hline
\end{tabular}

Mit wahrhaft gigantischem Verwaltungsaufwand machten die Spruchkammern bis Ende 1949 in 950126 Verfahren 1586 Hauptschuldige und 22122 NS-Aktivisten, Militaristen oder Nutznießer des NS-Regime namentlich ausfindig; hinzu kamen $106422 \mathrm{Min}$ derbelastete, die bereits einer Bewährungsgruppe mit einer Höchstfrist von drei Jahren angehörten. In dem langwierigen Entnazifizierungsprozeß löste sich das Personal der NS-Diktatur mehr oder weniger in nichts auf. Die Frage nach der politischen Verantwortung der alten Herrschaftseliten für den Aufstieg und die Etablierung des Nationalsozialismus war vom Befreiungsgesetz, das die individuelle organisatorische Teilnahme in den Mittelpunkt rückte, erst gar nicht gestellt worden.

Noch vor der Verabschiedung des Ausführungsgesetzes zum Artikel 131 des Grundgesetzes im Jahre 1951, der den aus politischen Gründen entlassenen Angehörigen des öffentlichen Dienstes ein sehr weitgehendes Recht auf Wiedereinstellung gewährte ${ }^{68}$, hatte die Rückflut entlassener Parteimitglieder alle Dämme gebrochen. In Hessen waren 1945 im Zuge der amerikanischen Entlassungspraxis 34 Prozent der Mitarbeiter des öffentlichen Dienstes entlassen worden; bis Mitte 1949 befanden sie sich alle-bis auf 2 Prozent wieder im Dienst ${ }^{69}$. Ähnliche Zahlen liegen für Württemberg-Baden und Bayern vor. Nach Statistiken der Militärregierung besaßen Ende 1948 41,5 Prozent der Beamten der

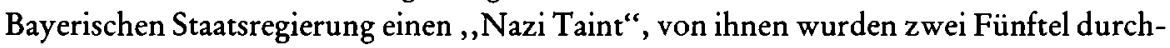
gehend im Dienst beibehalten und drei Fünftel nach Abschluß ihres Spruchkammerverfahrens wieder übernommen. Einen ,Anti-Nazi Background“" besaßen dagegen nur 0,7 Prozent der Beamten. Den geringsten Anteil belasteter Beamter wies das Innenministerium mit 28,6 Prozent auf, im Justizministerium waren es beachtliche 57,6, den Höchst-

${ }^{67}$ Statistik vom 31.8.1949, in: Fürstenau, Entnazifizierung, S.228. Vgl. Gesamtstatistik vom 30.9.1950, in: FitzGibbon, Denazification, S. 134.

68 Vgl. Fürstenau, Entnazifizierung, S. 148 ff.; Steinbach, NS-Gewaltverbrechen, S. 38 ff.

${ }^{69}$ Niethammer, Entnazifizierung, S. 531. 
stand hielt das Landwirtschaftsministerium mit 76,5 Prozent. Von den Beamten des Regierungsbezirks Oberbayern stellten ehemalige NSDAP-Mitglieder in den Stadtverwaltungen 42 Prozent, in den Gemeindeverwaltungen 45, in den Landkreisverwaltungen 67 und in den Bezirksverwaltungen gar 81 Prozent. Von den entlassenen Lehrern wurden 86 Prozent wieder eingestellt. Den entsprechenden Anteil in Industrie, Gewerbe und freien Berufen sowie auf dem kulturellen Sektor schätzte die Militärregierung Ende 1948 auf 90 Prozent $^{70}$.

Die Reintegration ehemaliger Nationalsozialisten war im wesentlichen bereits Ende 1948 abgeschlossen. Dieser Vorgang ist mit dem polemischen Begriff der , Renazifizierung"c, der bald die Runde machte, allerdings falsch charakterisiert: Die Wiedereingestellten entfalteten keine politische Aktivität zugunsten neofaschistischer Gruppierungen, sondern paßten sich als weitgehend apolitische Mitläufer der neuen politischen Ordnung an; insgesamt gesehen blieb die politische Kontrolle über den Verwaltungsapparat in den Händen überzeugter Demokraten. Insofern wird man nicht sagen können, daß der so bedeutsame Versuch der politischen Säuberung zur Installierung einer demokratisch gesinnten Verwaltungselite gescheitert ist. Die Integration des Millionenheeres ehemaliger Mitglieder der NSDAP und anderer NS-Organisationen war zudem im Interesse des sozialen Friedens unumgänglich. Bitter war freilich für die Opfer der NS-Diktatur die Erfahrung, daß auch die strafrechtliche Verfolgung von NS-Verbrechen durch die deutsche Justiz mit dem Ende der unmittelbaren Besatzungszeit nahezu zum Erliegen kam ${ }^{71}$.

Gab das Befreiungsgesetz, das den politischen Willen der deutschen Ministerpräsidenten und der sie tragenden parteipolitischen Koalitionen unter den Bedingungen der Besatzungsherrschaft widerspiegelte, die Richtung vor, so blieb doch das Ausmaß der Rehabilitierung von einer Vielzahl von Faktoren abhängig. An erster Stelle sind hier die sich wandelnden gesellschaftlichen und parteipolitischen Kräftekonstellationen zu nennen, die auf die Durchführung des Gesetzes, auf das Verhältnis von unumgänglicher Rehabilitierung und notwendiger Säuberung, einen wesentlich stärkeren Einfluß besaßen, als ihn der kontrollierende Uberwachungsapparat der Militärregierung jemals besitzen konnte. In dem Ringen um die öffentliche Meinung kam den Kirchen als moralische Instanz eine außerordentlich große Bedeutung zu. Schließlich fand die Entnazifizierung in einem öffentlichen Verfahren tagtäglich in den Spruchkammern statt, die, da die politische Säuberung nicht als reines Verwaltungsverfahren durchgeführt wurde, auf die Unterstützung und Mitarbeit der Bevölkerung angewiesen waren.

${ }^{70}$ Ebenda. Vgl. Billerbeck, Abgeordnete, S. 195.

71 Waren bis Ende 1949 von deutschen Gerichten insgesamt 4419 Personen wegen NS-Verbrechen rechtskräftig verurteilt worden, so fiel die Anzahl 1950 auf 809 Verurteilungen, 1951 auf 259. In den folgenden Jahren kam die Strafverfolgung fast zum Stillstand. Vgl. Broszat, Siegerjustiz, S. 540f.; Steinbach, NS-Gewaltverbrechen; Jörg Friedrich, Die kalte Amnestie. NS-Täter in der Bundesrepublik, Frankfurt a. Main 1984; Adalbert Rückerl, Die Strafverfolgung von NS-Verbrechen 1945-1978. Eine Dokumentation, Heidelberg 1979. 


\section{Die Offensive der evangelischen Kirche 1946}

Zehn Tage nach der Verkündung des Befreiungsgesetzes trafen sich am 15. März in Stuttgart die Vertreter der Landeskirchen der US-Zone zu einer ersten Besprechung. Den Vorsitz führte Asmussen als Leiter der Kirchenkanzlei der EKD, die zusätzlich mit Pfarrer Mochalski und Oberkirchenrätin Elisabeth Schwarzhaupt vertreten war. Während die drei hessischen Teilkirchen mit ihren Führungsspitzen, Landesbischof Kortheuer (Nassau), Präsident Müller und Pfarrer Guyot (Hessen-Darmstadt) und Pfarrer Fricke (Frankfurt), hochrangig repräsentiert waren, ließen sich die anderen Landeskirchen auf Sachbearbeiterebene vertreten ${ }^{72}$.

Fricke berichtete, daß der Alliierte Kontrollrat nach Auskunft der Religious Affairs Branch der hessischen Militärregierung weitere Sonderregelungen für Pfarrer abgelehnt habe, da die bayerische und die pfälzische Landeskirche keine überzeugenden Bemühungen zur Selbstreinigung unternommen hätten. Anschließend gaben die Vertreter der Landeskirchen über den jeweiligen Stand der Selbstreinigung Auskunft. Nach der Mitschrift Kortheuers befand sich die Landeskirche Kurhessen-Waldeck ,,noch im Stadium der ersten Schritte". In Baden habe die Kirchenleitung 12 bis 15 Pfarrer entlassen. In Hessen-Darmstadt seien 14 Pfarrer suspendiert, drei in den Wartestand und acht auf eine andere Stelle versetzt worden; darüber hinaus habe die Kirchenleitung sieben Dekane ihres Amtes enthoben. Für Württemberg gab Kortheuer die Zahl von 62 entlassenen Pfarrern an, tatsächlich hatte der Oberkirchenrat jedoch bis Mitte 1946 nur elf Pfarrer in den Ruhestand versetzt. Für Bayern, Frankfurt und Nassau vermerkte Kortheuer keine Angaben $^{73}$.

Zur grundsätzlichen Stellung der evangelischen Kirche trug Asmussen einige Thesen vor: Trotz heftiger Bedenken gegen das Befreiungsgesetz sei es nicht verantwortbar, ,,daß die Kirche um des Evangeliums willen einen Kampf gegen die politische Macht (Deutscher Staat und Besatzungsmacht) aufzunehmen habe, um dieses Gesetzes willen. Mit anderen Worten, wir müssen das Gesetz grundsätzlich als verbindlich auch für Pfarrer und Kirchenbeamte anerkennen. [...] Das Kriterium für das Eingreifen des Staates ist nicht die Evangeliumsverkündigung, sondern die nach seiner Meinung fehlerhafte und schuldhafte politische Stellungnahme einzelner Pfarrer." Offen sei derzeit jedoch, wie weit der Eingriff in die Kirche reiche und ob er noch als tragbar erscheine. Weiterhin warf Asmussen die Frage auf, die nach der heftigen Ablehnung des Stuttgarter Schuldbekenntnisses durch die Gemeinden, alle Kirchenführer bewegte: , Ob und in welcher Weise soll unsere Solidarität mit unserem Volke zum Ausdruck gebracht werden? ‘ 74

Die Erwartungen vieler Gemeinden an die Kirchenführung formulierte ein Schreiben des Kirchenvorstandes der Münchner Stephanuskirche an den bayerischen Landeskirchenrat. Es ging von der Feststellung aus, ,,daß das Gesetz vom Geist des Hasses, der

72 LKAS, OKR 104 f-I, Aktennotiz Schwarzhaupts über Besprechung am 15. 3. 1946. Den Stuttgarter Oberkirchenrat vertraten die Oberkirchenräte Weeber und Eichele, die kurhessische Landeskirche Rechtsanwalt Blesse, die badische Landeskirche Oberlandeskirchenrat Friedrich, den bayerischen Landeskirchenrat Dekan Langenfaß.

${ }^{73}$ ZEKHN, Az 1/3438, Aktennotiz Kortheuers über Besprechung am 15.3.1946, o. D. Zur Selbstreinigung in Württemberg vgl. Kap. V/1.

74 ZEKHN, Az 1872 I-1, Referentenbesprechung über Entnazifizierung, o. D. 
Vergeltung und der Verfolgung erfüllt ist und nichts spüren läßt von Güte und Versöhnungsbereitschaft ${ }^{\text {“ }}$. Die Gemeinde erwarte einen deutlichen Protest der Kirchenleitung. „Es soll nicht wieder, wie etwa in der Judenfrage, der Vorwurf gemacht werden können, daß sie geschwiegen hat. "75 Die evangelische Gemeinde in Bad Reichenhall bezeichnete das Befreiungsgesetz schlichtweg als ,, unchristlich “: , Es mißachtet die ethischen Kräfte, die in der Offentlichkeit auch unter dem Nationalsozialismus wirksam waren, die Pflichttreue und die Opferwilligkeit, ohne diese kann auch der demokratische Staat nicht auf Dauer bestehen. [...] Aufs schärfste lehnen wir Christen es ab, daß die antifaschistischen Parteien den Fehler des Nationalsozialismus wiederholen: sich selber zur absoluten sittlichen Norm zu machen und Böse und Gut allein an dem Gegen oder Für sie selbst zu messen." Die CSU müsse darauf hingewiesen werden, daß sie bei den nächsten Wahlen an ihrer Stellung zur Entnazifizierung gemessen werde ${ }^{76}$. Die scharfe Ablehnung der Entnazifizierung verband, zumindest in Bayern, so unterschiedliche Gemeinden wie die von Kurt Frör, einem führenden Mitglied der Pfarrerbruderschaft, geleitete Stephanuskirche und die ländliche Gemeinde Bad Reichenhall, die ihrem Pfarrer, der 1925 der NSDAP beigetreten und als SA-Oberscharführer und NSDAP-Kreisamtsleiter für Schulung schwer belastet war, unbeirrt die Treue hielt. Die gereizte Stimmung in den Kirchengemeinden konnte nicht ohne Auswirkungen bleiben.

In der anschließenden Diskussion wurden darum massive Bedenken geltend gemacht: Es komme viel weniger darauf an, ,,denjenigen zu bestrafen, der dem Nationalsozialismus zur Macht verholfen hat, als den Geist des Nationalsozialismus auszurotten [...]. Weniger schuldig wären nach dieser Auffassung diejenigen, die im Anfang - besonders vor 1933 - der Partei beigetreten sind, als diejenigen, die erst später Pg geworden sind.“ Damals seien die wahren Ziele des NS-Regimes noch , vielfach undurchsichtig oder nicht erkennbar" gewesen; auch könne man den frühzeitig Eingetretenen einen ,,gewissen Idealismus" nicht absprechen 77 . Diese Argumentation entsprach der kirchlichen Interessenlage, da sich die meisten Partei-Pfarrer zwischen 1932 und 1934 der NSDAP angeschlossen hatten. Einigkeit herrschte unter den Teilnehmern, ,,daß wir von der Kirche aus für die Geistlichen nur mit gutem Gewissen eintreten können, wenn wir das gleichzeitig auch für die Betroffenen aus anderen Ständen tun" "78. Auch sollten vor dem Tätigwerden der Spruchkammern noch ,möglichst viele Fälle“ im Zuge der Selbstreinigung geklärt werden. Praktische Bedeutung erlangte diese Absichtserklärung allerdings nur in den hessischen Teilkirchen, da die bayerische und die württembergische Kirchenleitung unverändert auf Konfliktkurs mit der Militärregierung blieben ${ }^{79}$.

Ferner sollte der Rat der EKD um ein theologisches Gutachten zu der Frage gebeten werden, , ,unter welchen Voraussetzungen die Beteiligung eines Pfarrers an der nationalsozialistischen Bewegung von der Kirche als Schuld zu werten ist" ${ }^{\text {"80. }}$. Mit dieser Frage, deren theologische Beantwortung für die Kirche die selbe Bedeutung wie die politische Definition der Entnazifizierung für den weltlichen Bereich besitzen mußte, hatten sich

\footnotetext{
${ }^{75}$ LKAN, LKR 201, Pfarramt der Stephanuskirche an Landeskirchenrat vom 16.3.1946.

${ }^{76}$ LKAN, LKR 201, Ev.-Luth. Gemeinde Bad Reichenhall an Landeskirchenrat vom 8.4. 1946.

77 ZEKHN, Az 1872 I-1, Referentenbesprechung über Entnazifizierung, o. D.

${ }^{78} \mathrm{ZEKHN}, \mathrm{Az} 1 / 3438$, Aktennotiz Kortheuers über Besprechung am 15.3.1946.

${ }^{79} \mathrm{Vgl}$. Kap IV/3 und 4 sowie Kap V/1.

${ }^{80}$ LKAS, OKR $104 \mathrm{f}-\mathrm{I}$, Aktennotiz Schwarzhaupts über Besprechung am 15.3.1946.
} 
bis März 1946 nur die hessischen Teilkirchen befaßt, in denen die Bruderräte auf eine entschiedene Selbstreinigung drängten. In den Richtlinien des hessischen Untersuchungsausschusses hieß es: , Die Ubergriffe der Partei in das kirchliche Gebiet und alle Maßnahmen zur Unterdrückung des Rechts und die Knebelung des Gewissens und die großen Judenverfolgungen müssen zuletzt auch den Blindesten die Augen geöffnet haben für den unchristlichen bzw. widerchristlichen Charakter des Nationalsozialismus. Kein Pfarrer, Amtsträger oder Angestellter der Kirche durfte den Nationalsozialismus in irgendeiner Form unterstützen. [...] Hieraus folgt: Pfarrer, die sich der NSDAP angeschlossen haben, haben sich schuldig gemacht." Wer jedoch später ausgetreten und den Nationalsozialismus in irgendeiner Form bekämpft habe, habe damit , tätige Reue“ gezeigt und sei möglicherweise von seiner Schuld freigeworden ${ }^{81}$.

Nach der Referentenbesprechung vom 15. März lud Wurm die Landesbischöfe Meiser, Bender (Baden) und Wüstemann (Kurhessen-Waldeck) sowie Fricke als Vertreter der hessischen Teilkirchen zu einem Gespräch auf hoher politischer Ebene mit dem württembergischen Ministerpräsidenten Reinhold Maier (DVP) ein. Da Maier am 11. April verhindert war, standen als Gesprächspartner Justizminister Josef Beyerle (CDU) und Gottlob Kamm (SPD), der neuernannte Staatssekretär für Sonderaufgaben, zur Verfügung. Die Vertreter der Staatsregierung zeigten, wie Asmussen berichtete, ,, vollste Aufgeschlossenheit gegenüber dem Anliegen der Kirche“. Insbesondere stimmten sie einer Sonderregelung für belastete Pfarrer zu, der zufolge der öffentliche Kläger mindestens vier Wochen vor Anklageerhebung dem Befreiungsminister einen Bericht zu erstatten hatte, der anschließend dem zuständigen Landesbischof zur Stellungnahme vorgelegt wurde. Auch sollte die Presse nicht über Verfahren gegen Pfarrer berichten, um die Kirche , soviel wie möglich" zu schützen ${ }^{82}$.

Unmittelbar nach dieser Unterredung beschlossen die Kirchenführer, in einer Eingabe an den Alliierten Kontrollrat auf ,,die allgemeinen Härten und Unbilligkeiten“ des Befreiungsgesetzes hinzuweisen. Konkret nannte Asmussen das vorläufige Beschäftigungsverbot nach Art. 58 BefrG, die höhere Formalbelastung für frühzeitig eingetretene Parteimitglieder und SA-Männer, die Einstufung aller Amtsträger der NSDAP und von NS-Organisationen sowie der Offiziere im Generalsrang als NS-Aktivisten. Außerdem müsse die Kirche gegen das im Befreiungsgesetz vorgesehene Predigtverbot für belastete Pfarrer protestieren, da es einen untragbaren Eingriff ,,in ausschließlich kirchliche Zuständigkeiten“ darstelle ${ }^{\mathbf{8 3}}$. Auf dieser Basis arbeiteten Asmussen und Elisabeth Schwarzhaupt in Verbindung mit dem Stuttgarter Oberkirchenrat Rudolf Weeber ein Protestschreiben aus ${ }^{84}$, das Wurm als Ratsvorsitzender der EKD am 26. April 1946 unterzeichnete. Das sechsseitige Schreiben war an die amerikanische Militärregierung in Deutschland gerichtet, da man, so Asmussen, über die Militärregierung auf die deutschen Länderregierungen ,,Druck ausüben" wollte ${ }^{85}$. Abschriften gingen an die Länderregierungen, den Okumenischen Rat der Kirchen und den Lutherischen Weltkonvent ${ }^{86}$.

${ }^{81}$ LKAN, LKR 213, Müller an bayerischen Landeskirchenrat vom 16.3.1946. Vgl. Kap V/2.

82 ZEKHN, Az 1/3438, Asmussen an Vorl. Leitung Nassau vom 17.4.1946.

${ }^{83}$ Ebenda.

84 Vgl. LKAS, NL Wurm 274, Weeber an Wurm vom 20.4.1946; Diem, Ja oder Nein, S. 175.

${ }^{85}$ ZEKHN, Bruderrat 2, Protokoll der Bruderratssitzung vom 16./17.7.1946.

${ }^{86}$ LKAS, NL Wurm 274, Wurm an Kamm vom 23.5. 1946. Weitere Abschriften: LWF, General Correspondence Germany, Reports and Materials 1946-1954; WCC, Germany 284 (43). 
Zur Legitimation berief sich Wurm auf die Stuttgarter Schulderklärung: Die evangelische Kirche habe zur Schuld des deutschen Volkes nicht geschwiegen. , Wir können auch nicht schweigen, wenn durch das Gesetz zur Befreiung von Nationalsozialismus und Militarismus neue Schuld und neues Unrecht geschehen soll." Anschließend fuhr Wurm fort:

„,Unsere Bedenken richten sich gegen die Grundauffassung des ganzen Gesetzes. Das Gesetz steht nicht in allen Stücken im Einklang mit dem natürlichen Rechtsempfinden. Es beachtet nicht alle elementaren Rechtsgrundsätze, die die Rechtsordnungen von Kulturstaaten kennzeichnen und die ihre letzte Bindung an Gottes Gebot nicht verleugnen. Die Folge davon ist, daß die christliche Kirche nicht in der Lage ist, dem Gesetz und seiner Durchführung im Vollmaße ihre Unterstützung zu verleihen, und daß nicht allgemein die Uberzeugung besteht, dieses Gesetz diene wirklich der Gerechtigkeit."

Entgegen der naturrechtlichen Begründung des Rechts aus der Bindung an Gott argumentierte Wurm anschließend jedoch rein rechtspositivistisch:

„,Es entspricht dem allgemeinen Rechtsempfinden, daß eine Strafe erst dann verhängt werden kann, wenn ein Gesetz vorhanden ist (nulla poena sine lege). Sieht man von der selbstverständlichen Aburteilung von Straftaten ab, so will das hier in Frage stehende Gesetz darïber hinaus Handlungen und Gesinnungen bestrafen, welche lange vor dem Erlaß dieses Gesetzes liegen. Dabei waren Handlungen und Gesinnungen, die heute verurteilt werden, vom damaligen Gesetzgeber als rechtmäßig und gut eingeschätzt. Hierdurch wird das Rechtsempfinden erschüttert und von den Angeklagten eine Rechtseinsicht verlangt, die man nicht erwarten kann."

Auch sei die Entwicklung des NS-Staates zum Unrechtsstaat kaum voraussehbar gewesen; zumal das NS-Regime ,,im Inneren und auch im diplomatischen Verkehr mit dem Ausland voll anerkannt wurde und ein ernstlicher Widerstand nur von seiten der Kirche öffentlich sichtbar" geworden sei.

„Würde man nun einwenden, daß damals die Glieder des deutschen Volkes um der göttlichen Gerechtigkeit willen sich auch nicht einmal zum Scheine dem Nationalsozialismus hätten hingeben dürfen, so ist die Kirche bereit, sich auf diesen Boden zu stellen. Sie kann aber nicht anerkennen, daß eine menschliche Gerechtigkeit nunmehr zu strafen unternimmt, was allein nach göttlichem Recht als Unrecht zu gelten hat."

Das Befreiungsgesetz widerspreche dem Grundsatz, daß Bestrafung eine ,,menschliche nachweisbare Schuld“" voraussetze. ,,Es dürfte unmöglich sein, nachzuweisen, daß alle Handlungen und Gesinnungen, welche das Gesetz als strafbar ansieht, als wissentliche Verletzung einer bestehenden Norm gewertet werden können. "Vielmehr versuche das Gesetz, Gesinnungen zu bestrafen, und verstoße mit der Umkehrung der Beweislast gegen das allgemeine Gerechtigkeitsempfinden. Die evangelische Kirche sehe sich deshalb nicht in der Lage, ,,dem deutschen Volk zu verkündigen, daß dieses Gesetz und seine Durchführung in allen seinen Teilen im Dienste der göttlichen Gerechtigkeit und Wahrheit steher:87.

Wesentlich differenzierter hatte Weeber in einem ersten Gutachten für den Stuttgarter Oberkirchenrat das Befreiungsgesetz interpretiert: Es stelle im Rechtssinn kein Strafgesetz, sondern ein politisches Gesetz dar, das in einer Linie mit anderen Rechtsnormen zum Schutz von Staatsformen stehe und politische Unzuverlässigkeit mit bestimmten Sanktionen belege. Der Christ habe daher zu prüfen, ob das Gesetz , bei der Abwägung

87 Wurm an OMGUS vom 26.4.1946, in: KJ 1945-1948, S. 191-197, Zitate S. $191 \mathrm{f}$. 
von Verantwortlichkeit und Sühne einem dem Rechtsempfinden entsprechenden Ausgleich gefunden" habe. In dieser Hinsicht sei das Befreiungsgesetz schwer zu bewerten, da der Gesetzgeber Verantwortlichkeit und Sühne abgestuft habe, so daß , alles auf die Handhabung des Gesetzes ankommen wird“88. Diese Analyse hatte jedoch auf das Protestschreiben Wurms, das politischen und moralischen Grundsatzfragen mit rechtsstaatlichem Legalismus begegnete, keinen Einfluß.

Im zweiten Teil der Eingabe kamen die , allgemeinen Härten“ des Gesetzes zur Sprache. An erster Stelle stand das vorläufige Beschäftigungsverbot, das in keinem angemessenen Verhältnis zur Schuld der Mitläufer stehe, tatsächlich aber nur mutmaßliche Hauptschuldige und NS-Aktivisten betraf. Ein weiterer Punkt betraf die Differenzierung der Schuldvermutung nach dem Eintrittsdatum. Hier wandte Wurm ein, viele seien frühzeitig , , aus idealistischen Motiven in die Partei eingetreten, etwa weil sich eine Uberwindung der Klassengegensätze, eine Hebung der sozialen Verhältnisse des Arbeiterstandes, eine wirkliche Bekämpfung der Arbeitslosigkeit, eine Überwindung von Freidenkertum und Atheismus von einem Erstarken der nationalsozialistischen Bewegung versprochen hatten“. Drittens wandte er sich gegen die Einstufung aller Amtsträger von NS-Organisationen als NS-A ktivisten. Viele von ihnen hätten ihr Amt , , völlig unpolitisch" ausgeübt und nur in der Notzeit des Volkes soziale Hilfe leisten wollen. Nicht minder setzte sich die Eingabe für hohe Offiziere, auch der Waffen-SS, ein, die allein ihre soldatische Pflicht erfüllt hätten. Die Zugehörigkeit zum Generalstab könne keine Vermutung für schuldhaftes Verhalten begründen, das die Einweisung in ein Arbeitslager, den Verlust der Pensionen und der bürgerlichen Ehrenrechte rechtfertige. Die Einwände sind nicht völlig von der Hand zu weisen. Wurm ließ jedoch den springenden Punkt des Befreiungsgesetzes außer acht, daß nämlich die Formalbelastungskategorien nur eine Schuldvermutung darstellten, die die Entscheidung der Spruchkammer nicht präjudizierte und vom Betroffenen widerlegt werden konnte.

Der dritte Teil der Eingabe befaßte sich mit den Auswirkungen des Befreiungsgesetzes auf die Kirche selbst. Wie nicht anders zu erwarten war, beanspruchte Wurm für die Kirche eine Sonderstellung, die de facto auf die Freistellung der Pfarrer von der Entnazifizierung hinauslief. Bereits im ersten Satz erklärte er, es werde zu ,,Spannungen zwischen der Obrigkeit und der Kirche" kommen, falls die Spruchkammern schwer belasteten Pfarrern das Predigen verbieten sollten: ,, Wir können nur dringlich warnen, daß die Obrigkeit es als Recht in Anspruch nimmt, zu bestimmen, wer ein geistliches Amt ausüben oder nicht ausüben darf. Wir haben im Kampf mit dem Nationalsozialismus mit Erfolg den Standpunkt vertreten, daß nur die Kirche das Predigtrecht entziehen darf." Andererseits betonte Wurm als Ratsvorsitzender die Bereitschaft der evangelischen Kirche zur Selbstreinigung von nationalsozialistischen Einflüssen und Pfarrern, die ihre Parteibindung über ihre kirchlichen Verpflichtungen gestellt hätten: , Denn wir sind nicht weniger als die Besatzungsmächte der Überzeugung, daß der Nationalsozialismus ein Verbrechen war und daß seine Grundsätze und ihre Anwendung immer von neuem zu Verbrechen führen müssen, von wem auch immer sie vertreten werden wollen. " 89 Es scheint Wurm nicht bewußt gewesen zu sein, daß dieser Satz in Widerspruch zu den Ausführungen des ersten Teils der Eingabe stand.

${ }^{88}$ LKAS, OKR 104f-IV, Bemerkungen zum BefrG vom 9.3.1946.

${ }^{89}$ Ebenda, S. $195 f$. 
Im folgenden hieß es, die meisten Landeskirchen hätten den Selbstreinigungsprozeß „,bereits selbständig und gründlich“ durchgeführt. Der ,,allergrößte Teil“ der Pfarrerschaft habe sich in einem ständigen, offen oder verdeckt geführten Kampf befunden, da jeder Pfarrer durch das Ordinationsgelübde ,zum Widerstand gegen Ideengut und Methoden der Partei und der NS-Staatsführung" verpflichtet gewesen sei. Deshalb müsse denjenigen Pfarrern und Kirchenbeamten, denen die Kirchenleitung ein positives Zeugnis ausstelle, zugestanden werden, daß die Schuldvermutung widerlegt sei. Der ,typische Fall" sei, daß gerade junge Pfarrer ,,im Kampf gegen Freidenkertum und Atheismus" Vertretern der NS-Bewegung begegnet seien, ,,die selbst das Ziel dieser Bewegung in einer Rückführung des deutschen Volkes zum Christentum und zu den sittlichen Grundlagen unseres Volkstums“" gesehen hätten. „Hier liegt zwar ein Irrtum über den politischen Charakter des Nationalsozialismus, nicht aber eine sittliche Schuld vor. "Das gleiche gelte auch für alle anderen Mitarbeiter der Kirche und ihrer Werke ${ }^{90}$. Die Anwendung des Befreiungsgesetzes auf die evangelische Kirche sei deshalb nur unter folgenden Voraussetzungen ,,denkbar"': Die schwersten Härten müßten gemildert und die Durchführung des Gesetzes bei kirchlichen Amtsträgern bis zum 1. Oktober 1946 hinausgeschoben werden, damit die Kirchenleitungen die Selbstreinigung zu Ende führen könnten. Danach würden die Kirchenleitungen den zuständigen Landesregierungen auf Anforderung mitteilen, ob und welche Maßnahmen sie gegen belastete Pfarrer ergriffen hätten. Sollte die staatliche Seite diese Maßnahmen als nicht ausreichend beurteilen, so müßte mit den Kirchenleitungen erneut über Sühnemaßnahmen verhandelt werden. Die Entscheidung über die Ausübung des Pfarr- oder Predigtamtes könne jedoch nur bei der Kirche liegen. Das vorgeschlagene Verhandlungsmodell entsprach dem kirchlichen Selbstverständnis, wonach Kirche und Staat gleichberechtigte Größen seien, und orientierte sich an den bisherigen amerikanischen Bestimmungen. Dieses Modell war jedoch bereits Ende 1945 am entschiedenen Widerstand der bayerischen und der württembergischen Landeskirche gescheitert, da beide keine ernsthaften Bemühungen zur Selbstreinigung gezeigt hatten.

Die überaus scharfe Kritik am Befreiungsgesetz hatte Wurm in seiner Eigenschaft als Ratsvorsitzender der EKD unterzeichnet, ohne sie jedoch vorher den übrigen Ratsmitgliedern zur Kenntnis zu bringen. ,,In der Frage der Denazifizierung haben Wurm und Asmussen“, wie Niemöller auf einer späteren Bruderratssitzung berichtete, ,,gemeinsam einen Brief an die Militärregierung gesandt, ohne daß der Rest davon etwas wußte." "91 Möglicherweise fühlte sich Wurm durch die Besprechung mit den Landesbischöfen der US-Zone vom 11. April zu einem solchen Schritt bevollmächtigt. Dennoch lag von den äußeren Umständen kein triftiger Grund vor, ein so bedeutendes Schreiben ohne förmliche Zustimmung des Rats am 26. April abzuschicken, da seit geraumer Zeit für den 1. und 2. Mai eine Ratssitzung und Kirchenführerkonferenz in Treysa angesetzt war, auf deren Tagesordnung ebenfalls die Stellung der evangelischen Kirche zur Entnazifizierung

90 In einem späteren Schreiben vom 23.5.1946 an den württembergischen Befreiungsminister Kamm betonte Wurm, daß das Befreiungsgesetz auch auf die kirchliche Verwaltung keine Anwendung finden dürfe, da die Kirchenbehörden im unmittelbaren Dienst am Auftrag der Kirche ständen. Vgl. LKAS, NL Wurm 274.

91 ZEKHN, Bruderrat 6, Protokoll der Bruderratssitzung vom 17.10. 1946. Vgl. ZEKHN, Bruderrat 2, Niemöller an Asmussen vom 22.6.1946. 
stand. Der Alleingang konnte somit wohl nur das Ziel haben, die Kirchenführerkonferenz mit einem fait accompli auf eine kompromißlose Ablehnung festzulegen. Neben dem Konflikt um neun belastete Mitglieder des Stuttgarter Oberkirchenrats, die Wurm vehement gegenüber der Militärregierung verteidigte, dürften auch persönliche Motive eine wichtige Rolle gespielt haben. Ebenfalls mit Datum vom 26. April hatte sich Wurm bei Murphy für seinen Sohn Dr. Hans Wurm eingesetzt, den die Militärregierung in Wiesbaden Anfang 1946 wegen Fragebogenfälschung verhaftet und zu einem Jahr Gefängnis verurteilt hatte. Er war 1922 der NSDAP beigetreten, hatte aber im Fragebogen als Datum 1938 angegeben. Zuvor hatte sich Wurm bereits an den hessischen Ministerpräsidenten Geiler gewandt und Vertreter des Okumenischen Rats der Kirchen um Intervention gebeten, was Stewart Herman und Bischof Bell aus verständlichen Gründen abgelehnt hatten. Der Vermittlung Murphys war es wohl zu verdanken, daß Hans Wurm Ende 1946 vorzeitig entlassen wurde ${ }^{92}$.

An den Beratungen in Treysa nahmen neben den Ratsmitgliedern auch die Vertreter sämtlicher Landeskirchen, insgesamt etwa 50 Personen, teil. Präses Koch eröffnete die Debatte mit der Bemerkung, daß die Entnazifizierung steigendes Befremden im deutschen Volk hervorrufe und die Gemeinden ein ,,deutliches Wort" der Kirchenführung erwarteten. Daraufhin erklärte Niemöller, daß er jede ,, Gesinnungsschnüffelei“" ablehne, und verlas das vielen Teilnehmern noch unbekannte Schreiben an den Okumenischen Rat der Kirchen, das er am 23. März im Auftrag des Rats verfaßt hatte:

„Der erste Eindruck dieses Gesetzes ist erschütternd deswegen, weil sich auch nicht ein einziges Mitglied des Rates der Erkenntnis verschließen konnte, daß dieses Gesetz das eben begonnene Wirken der Kirche im Sinne einer Verständigung und Befriedung im deutschen Volk und einer geistigen Erneuerung so gut wie unmöglich macht. [...] Es öffnet den niedrigen Instinkten des Neides und Hasses alle Tore. Die Auffassung geht dahin, daß nunmehr eine Verfolgung einer bestimmten Gesinnungshaltung in einem Umfang legalisiert und betrieben wird, wie sie selbst unter dem Naziregime niemals gewesen ist. [...] Wir bitten deshalb den ökumenischen Rat und die ihm angeschlossenen Kirchen, sich bei den Regierungen der Besatzungsmächte und auf jede sonst geeignet erscheindende Weise dafür einzusetzen, daß dieses Gesetz entsprechend revidiert und so gehandhabt wird, daß die begonnene Neubesinnung nicht gehindert, sondern gefördert wird."93

Anschließend unterrichtete Wurm die Kirchenführer von seinem Schreiben an die amerikanische Militärregierung. Danach berichteten die Vertreter der Landeskirchen über die Situation in den verschiedenen Besatzungszonen. Präses Beste erklärte, daß die sowjetische Militärverwaltung die Entfernung von belasteten Pfarrern und Kirchenbeamten der Kirche selbst überlasse. Aus Hamburg berichtete Landesbischof Schöffel, die Kirche habe staatliche Ausschüsse mehr zu fürchten als die britische Militärregierung. Oberlandeskirchenrat Fleisch aus Hannover unterstrich, die Engländer seien bisher ,,sehr maßvoll“ gewesen, was Präses Beckmann für die rheinländische Kirche bestätigte; in der französischen Zone sei für die Entnazifizierung der Pfarrer ein von der Kirche berufener Ausschuß zuständig. Größere Konflikte wurden allein aus der US-Zone von der bayerischen und der württembergischen Kirche gemeldet.

92 Vgl. Wetzlarer Neue Zeitung vom 5.2. 1946; LWF, LWF Correspondence Germany 1945-1954, Marie Wurm an Michelfelder vom 3.4.1946; WCC, General Correspondence 10, Bell an Freudenberg vom 28.6. 1946; Herman an Bell vom 19.7. 1946; LKAS, NL Wurm 272, Wurm an Murphy vom 19.1.1947.

93 EZA, EKD 1/45, Rat der EKD an ORK vom 23.3.1946. 
Dennoch war die Stimmung recht gereizt, wie sich nicht nur am Votum Landesbischofs Stählin aus Oldenburg ablesen läßt: , Wir müssen ein Wort gegen die Entnazifizierung sagen, denn wir müssen gegen Unrecht auftreten. Sie ist die verkappte Form eines innerdeutschen Bürgerkrieges. Wenn wir hier nichts sagen, können wir nicht Buße predigen. "Koch sprach sich in Übereinstimmung mit Meiser und anderen für ein deutliches, öffentliches Wort der Kirche aus, da ,,die Menschen wie das Wild gehetzt werden“. Der kurhessische Landesbischof Wüstemann erklärte gar, sollte das Befreiungsgesetz auf die Pfarrer angewandt werden, so trete der , status confessionis “ ein ${ }^{94}$. Daß die Entnazifizierung ein gravierendes Unrecht darstelle und die Kirche keinesfalls ihre Pfarrer nach politischen Richtlinien überprüfen oder staatliche Eingriffe dulden dürfe, war die feste Überzeugung aller Diskussionsredner. Lediglich Fricke betonte: , Man muß auch die Seite des Volkes sehen, die unter dem Nationalsozialismus gelitten hat. Die NS-Gesinnung war nicht eine Gesinnung unter anderen, sondern bedeutete schon eine Tat. Wir dürfen nicht zu sehr gegen das Gesetz sprechen." "95

Am 2. Mai verabschiedete der Rat der EKD eine Stellungnahme zur Entnazifizierung, die sich an den Alliierten Kontrollrat, an die Militärregierungen der vier Besatzungszonen und an die deutschen Länderregierungen richtete. Den Entwurf hatten auf Vorschlag Asmussens Präses Karl Koch, Ratsmitglied Heinrich Held, Oberkirchenrat Hermann Ehlers aus Oldenburg, der badische Landesbischof Julius Bender und Oberkirchenrat Wilhelm Bogner aus München ausgearbeitet. Auch der Rat berief sich auf das Stuttgarter Schuldbekenntnis, um seine ,,ernsten Bedenken“ zu legitimieren, versicherte aber gleichzeitig, daß die Kirche die Notwendigkeit der , Reinigung des deutschen Volkes von den verderblichen Einflüssen des Nationalsozialismus" anerkenne:

„,Die Kirche ist der Ansicht, daß jeder, der ein Verbrechen im Zusammenhang mit der nationalsozialistischen Herrschaft begangen hat, bestraft werden muß. Die Bildung von Massenorganisationen, die erst die nationalsozialistische Herrschaft und ihre Verbrechen ermöglichte, läßt besondere Fragen aufstehen. Viele Deutsche tragen aus ihrer Zugehörigkeit zu NS-Organisationen für die geschehenen Untaten eine persönliche Mitverantwortung, wenngleich die Kirche nicht daran vorbeigehen kann, daß viele aus lauteren Beweggründen den nationalsozialistischen Organisationen in Unkenntnis ihres wahren Wesens beigetreten sind. Zu beklagen ist, daß viele trotz späterer besserer Einsicht aus Schwachheit gegenüber dem Terror ihre Mitgliedschaft nicht gelöst haben. Die Bestrafung der Mitglieder von NS-Organisationen bis hin zur Entfernung aus ihrem Amt sollte aber in jedem Fall nur erfolgen, wenn nachgewiesen wird, daß sie durch die Zugehörigkeit oder ihr Handeln den Verbrechen des Nationalsozialismus persönlich Vorschub geleistet haben und daher Mittäter oder Begünstigter sind. Das ist ein Grundsatz der Gerechtigkeit."

Das derzeitige Verfahren sei jedoch ,, weithin nicht geeignet, zu wirklich gerechten Ergebnissen zu führen“. Vor allem dürfe man nicht Personen ,, nur um ihrer äußeren Zugehörigkeit oder einer vermuteten Gesinnung willen zunächst bestrafen “-das zielte auf die Entlassungen durch die Militärregierung und das vorläufige Beschäftigungsverbot nach

94 EZA, EKD 1/45, Protokoll der Ratssitzung vom 1./2.5. 1946: , Wir müssen darauf hinweisen, daß das Gesetz Unrecht enthält. Wir dürfen die Kirche nicht aus der Solidarität derjenigen, die dieses Unrecht erleiden, lösen. Unrecht tun, können wir aber nicht. Hier tritt der status confessionis ein. Vor Einzelschritten, die unsere Grundsätze verlassen, wird gewarnt. Wir müßten auch Grundsätze über die Methoden, die wir anwenden wollen, aufstellen. Es geht um die Kirche im weiteren Sinne (Innere Mission)."

95 Ebenda. 
Art. 58 BefrG - ,,und es ihnen erst danach ermöglichen, sich zu rechtfertigen“. Neben diesen ,,grundsätzlichen Bedenken“ hielt es der Rat allerdings für angebracht, weiterhin zu erklären:

„,Die Entfernung vieler Menschen aus Ämtern, die sie an sich untadelig wahrgenommen haben, und ihre Ausstoßung in wirtschaftliche Verelendung geht über die Maßnahmen hinaus, die in den vergangenen Jahren in der gleichen Frage in Deutschland getroffen wurden. Sie zerstört das langsam wachsende Rechtsempfinden und schafft die Grundlagen für einen Nihilismus, der weit über Deutschlands Grenzen hinaus wirken wird. Auch bei solchen Menschen, die, oft unter kirchlichem Einfluß, zu der Erkenntnis gekommen sind, daß ihre Beteiligung am Nationalsozialismus ein Irrweg war und eine angemessene Sühne erfordert, wird die Frucht dieser Erkenntnis jetzt wieder gefährdet."

Abschließend erklärte der Rat, die Kirche wolle keineswegs den nationalsozialistischen Geist verteidigen; sie wisse aber, ,,daß das Schwinden des Vertrauens in die menschliche Rechtsordnung zu einem Hindernis werden kann, die Verkündigung des göttlichen Gebotes und der göttlichen Gnade zu hören“. Die mehrfach geäußerte Úberzeugung, daß die Entnazifizierung die Annahme der kirchlichen Verkündigung erschwere oder gar verhindere, war sicherlich ein gewichtiges Motiv, wenngleich die Frage nach Ursache und Wirkung wohl nicht so eindeutig zu beantworten ist. Die Erklärung schłoß mit der Formulierung: Nur wenn die notwendigen Maßnahmen mit ,,einleuchtender Gerechtigkeit und in der Verantwortung vor Gott" getroffen würden, ,, wird der Weg frei gemacht, daß das deutsche Volk ein neues Verhältnis zu den Völkern der Erde finden kann" ${ }^{\text {‘c96. }}$

Der Schweizer Evangelische Pressedienst kommentierte denn auch sofort: ,Man würde es wohl verstehen, wenn die deutsche Kirche für ihr Volk bittet, daß Gnade vor Recht gehen möchte und daß es nicht für seine ganze Schuld gerichtet werde. Töne aber, die uns deutlich zeigen, daß man die Verantwortung für die zukünftige Haltung Deutschlands schon wieder" - wie nach dem Ersten Weltkrieg - , ,den anderen zuschieben möchte, sollte man aus der Evangelischen Kirche in Deutschland nicht mehr hören müssen. “97 Insgesamt gesehen, war die Ratserklärung in ihren Formulierungen wesentlich gemäßigter und konzilianter als das Protestschreiben Wurms. In der Sache lehnte sie aber das Befreiungsgesetz ebenfalls entschieden ab. Auch der Rat verfocht die Ansicht, daß die Entlassung von NSDAP-Mitgliedern aus dem öffentlichen Dienst nur bei nachgewiesener persönlicher Schuld an NS-Verbrechen, also bei Schuld in den traditionellen Kategorien des Strafrechts, gerechtfertigt sei. Mit der Reduzierung der Entnazifizierung auf die strafrechtliche Verfolgung von NS-Verbrechen war der Entnazifizierung im Sinne der politischen Säuberung der Stachel gezogen.

Die wohl schärfste Kritik aus innerkirchlichen Kreisen kam, wie so oft, von Barth. Er schrieb Mitte Juni an Niemöller: Die Kirche habe während der NS-Zeit , zu tiefsinnig geschwiegen", ihre Anerkennung der Notwendigkeit der politischen Säuberung sei bisher ,,zu widerwillig und matt “, ihre Selbstreinigung , ,zu wenig ernsthaft und durchgreifend“ " und das Schuldbekenntnis durch vielfältige Abschwächungen ,,zu getrübt", als daß sie die ,,innere Autorität und Glaubwürdigkeit" besitze, um heute so auftreten zu können. Nachdrücklich betonte Barth, daß die Entnazifizierung ,,eine Angelegenheit der politischen Moral" sei. Im Unterschied zu den Nürnberger Kriegsverbrecherprozessen gehe es

${ }^{96}$ Beschluß A, in: KJ 1945-1948, S.198f.

${ }_{97}$ Schweizer Evangelischer Pressedienst, Nr. 24 vom 25.6.1946. 
dabei nicht um die Bestrafung von Verbrechen, sondern um den Ausschluß bestimmter Personenkreise von künftiger politischer Einflußnahme. Daß jemand der NSDAP aus Idealismus beigetreten sei und sie später aus Schwachheit nicht verlassen habe, beweise durchaus nicht seine Eignung für Führungspositionen: ,, Eben der Typ derer, die ihre Ämter , an sich untadelig wahrgenommen' (und im übrigen pariert!) haben, war doch die stärkste Stütze des NS-Regimes."

$\mathrm{Zu}$ der Aussage, die Entnazifizierung gehe weit über die Maßnahmen des NS-Regimes hinaus, bemerkte Barth scharf: ,Das geht weit über die Wahrheit hinaus!! Hat man die Millionen von Juden und Sozialisten nun schon wieder vergessen, denen wahrlich Schlimmeres widerfahren ist? ${ }^{\text {( } 98}$ Ebenso empört reagierte Adolf Freudenberg, der wegen der , ,nicht-arischen“ Abstammung seiner Ehefrau aus dem diplomatischen Dienst ausgeschieden war und eine Anstellung beim Okumenischen Rat gefunden hatte. Asmussen versicherte daraufhin, der Vergleich habe sich nicht auf die Verfolgung jüdischer Beamten bezogen, und Niemöller entgegnete Barth: ,, Kein vernünftiger Mensch bei uns wird an Juden und Sozialisten denken, weil diese eben nicht unter die unpolitischen Beamten fallen. "99 Hätte der Rat, so fuhr Barth fort, in seiner Erklärung das Anliegen der , kleinen, unselbständigen, törichten Mitläufer (der gläubigen Hörer gewisser kirchlicher - auch bekenntniskirchlicher (!) - pronazistischer Kundgebungen und Kanzelerklärungen von anno dazumal (!!) mit Hinweis auf deren geringere Verantwortlichkeit verfochten, so wäre sie ein ordentliches christliches Werk gewesen, mit dem man mit gutem Gewissen auch vor die Alliierten treten konnte. Die Gerechtigkeit, in der die Erklärung diese wichtige Unterscheidung unterläßt, ist höchst ungerecht. Sie blickt eben offenbar - und nicht ohne peinliche Selbstrechtfertigungsversuche der Kirche - vor allem auf die durch die Denazifikation berührte mittlere und bessere Gesellschaftsschicht: gerade dahin, wo das für den Aufstieg und die Entfaltung des Nationalsozialismus entscheidend verantwortliche Tun und Lassen stattfand!" Die Erklärung zeige eine ,,noch immer gründlich unbußfertige und verstockte Kirche“, die ,,unmißverständlich" damit drohe, ,,daß das neue Verhältnis der Deutschen zu den anderen Völkern nun doch wieder von einer von diesen zu erfüllenden Bedingung abhängig gemacht wird“"100.

Hatte Barth in seinem Schreiben die Opposition Niemöllers gegen die Ratserklärung als selbstverständlich vorausgesetzt, so wurde er eines Besseren belehrt. Niemöller antwortete, er habe den Beschluß, wenn auch ,,schweren Herzens“, nicht zu verhindern gesucht. Auch er halte das Befreiungsgesetz für ein ,,parteipolitisches Machwerk“", das verabschiedet worden sei, ,,weil man die Intelligenzschicht in Deutschland beseitigen will und weitgehend ja bereits beseitigt hat, erst durch den Nationalsozialismus, dann durch die Denunziation und jetzt durch die ,Denazifizierung' . [.. .] Das Verderben wird nicht aufzuhalten sein [...], weil nach dem Winter 1946/47 die übrig gebliebenen Reste unseres Volkes ohnehin nicht mehr in der Lage sein werden, auch nur noch mit einer schwachen Stimme den Protest zu erheben, den Menschen hören können. Ich bin aber überzeugt, daß dieser Protest im Himmel wohl gehört werden wird, selbst wenn er bis an Dein Herz

98 ZEKHN, Korr. Niemöller 2002, Barth an Niemöller vom 7.6.1946.

99 ZEKHN, Korr. Niemöller 2002, Niemöller an Barth vom 15.6. 1946; EZA, EKD 1/280 a, Freudenberg an Asmussen vom 28.5.1946; Asmussen an Freudenberg vom 19.6. 1946.

100 ZEKHN, Korr. Niemöller 2002, Barth an Niemöller vom 7.6.1946. 
nicht mehr herandringt. " 101 Das impulsive Antwortschreiben Niemöllers, das wohl auch davon beeinflußt war, daß sein Bruder Wilhelm Altparteigenosse war ${ }^{102}$, gibt einen Einblick in die Befürchtungen, die den Rat der EKD bei seiner Beschlußfassung bewegt haben. Nichts lag den Ministerpräsidenten der US-Zone wie der amerikanischen Besatzungsmacht jedoch ferner als die feste Uberzeugung Niemöllers, ,,daß dies Gesetz zur Ausrottung der ,bürgerlichen' Schichten unseres Volkes führen soll, deren Schuld natürlich unbestritten ist“. Das Befreiungsgesetz sei lediglich der ,,Deckmantel für die möglichst gefahrlose Beseitigung politischer, möglicher Gegner. Es wird auch als solches verstanden."103 Doch welche Gegner sollte die Entnazifizierung ausschalten, wenn nicht Nationalsozialisten?

In welchem Ausmaß schlichte Unkenntnis, deutschnationale Denkweisen und Untergangsvisionen Denken und Handeln der evangelischen Kirchenführer bestimmten, verdeutlicht auch eine Stellungnahme des Stuttgarter Oberkirchenrats auf eine politische Umfrage der Militärregierung im Juni 1946: Wer der NS-Propaganda Glauben geschenkt habe, der finde sie nun ,,in der Vernichtung des Deutschtums im Osten, die der Judenverfolgung durch die Nationalsozialisten an die Seite gestellt werden kann", bestätigt. Die „Ausweisung der Deutschen und die Überbevölkerung Restdeutschlands, die Wegnahme der landwirtschaftlichen Überschußgebiete, die Demontage der Industrie, die Beschränkung der Kapazität der deutschen Wirtschaft, die Pläne zur Wegnahme von Saar- und Ruhrgebiet, die Verhinderung einer politischen und wirtschaftlichen Einheit in Restdeutschland [müssen] zum Tod führen“. Positive Ergebnisse der Besatzungsherrschaft vermochte der Oberkirchenrat nicht zu erkennen, weswegen seine Stellungnahme zu einer sechsseitigen Bilanz alliierten ,Unrechts“ geriet ${ }^{104}$. Noch im März 1948 äußerte der Stuttgarter Oberkirchenrat bei gleicher Gelegenheit, die Arbeit der Militärregierung könne erst in dem Moment positiv bewertet werden, ,, wo erkennbar ist, daß alle ihre Vertreter sich von den Ideen des Morgenthauplans gelöst haben. [. . .] Auf gar keinen Fall aber sollte es möglich sein, daß Persönlichkeiten hier ihr Unwesen treiben dürfen, deren Motiv Rache ist." Die Demontagepolitik, die in der US-Zone nie eine große Rolle gespielt hatte, galt selbst 1948 als Beleg für noch immer vorhandene ,,Ideen des Morgenthauplans, der von weiten Kreisen der deutschen Bevölkerung für ebenso verbrecherisch gehalten wird wie die Ausrottung der Juden im Dritten Reich"105.

War den deutschen Politikern der grundsätzliche Wandel der amerikanischen Deutschlandpolitik, spätestens seit der Stuttgarter Rede des amerikanischen Außenministers Byrnes vom 6. September 1946 kein Geheimnis mehr, so blieben nicht wenige evangelische Kirchenführer dem Morgenthau-Syndrom in einer Weise verhaftet, daß weder realpolitische Veränderungen zur Kenntnis genommen noch die richtigen moralischen Maßstäbe gefunden wurden. Ähnlich verhielt es sich mit der Verwerfung des Befreiungsgesetzes, die bereits zu einem Zeitpunkt erfolgte, als noch kein einziges Spruchkammerurteil vorlag. Auch hier scheint den Kirchenführern, trotz ihrer vielfältigen Kontakte zu

${ }^{101}$ ZEKHN, Korr. Niemöller 2002, Niemöller an Barth vom 15.6.1945, abgeschickt am 23.6.1946.

${ }^{102}$ Vgl. Schmidt, Niemöller, S. 40ff.; Baumgärtel, Kirchenkampf-Legenden, S. $4 \mathrm{ff}$.

${ }^{103}$ ZEKHN, Korr. Niemöller 2002, Niemöller an Barth vom 23.6.1946. Vgl. Barth an Niemöller vom 6.7.1946.

${ }^{104}$ LKAS, NL Wurm 272, Oberkirchenrat an OMGWB-ICD vom 25.6.1946.

${ }^{105}$ LKAS, OKR 104e-III, Oberkirchenrat an OMGWB-ICD vom 16.3.1948. 
den Länderregierungen, die Intention des Gesetzes, die Rehabilitierung der Masse der NSDAP-Mitglieder, verborgen geblieben zu sein, obwohl sie für die deutschen Politiker das Kernstück bildete.

Eine deutliche Gegenposition zu den offiziellen Stellungnahmen der evangelischen Kirche bezog Barth, als er im Juli 1946, während seiner Bonner Gastprofessur, auf Anforderung der Religious Affairs Branch die Politik der Militärregierung beurteilen sollte. Barth hielt die Entnazifizierung für notwendig, doch sei ihre Durchführung ,, korrekturbedürftig“: , ,Ich stoße-abgesehen von den gezwungenen und gedankenlosen Mitläufern - immer wieder auf törichte Deutsche, die 1933 oder später der Meinung waren, irgendeine gute Sache damit vor dem Untergang zu retten oder die Partei damit von innenher verbessern zu können, daß sie ihr beitraten. Jene Gezwungenen und Gedankenlosen und diese Törichten dürfen heute - so gewiß sie nicht unverantwortlich sind - nicht blindlings ausgeschaltet werden. Und die Denazifikation muß diejenigen mitbetreffen, die sich durch ihre Gesinnung und Haltung am Heraufkommen des NS intellektuell teilweise schwerer schuldig gemacht haben als manche der späteren Aktivisten." Barth trat für eine individuelle Fallprüfung ein und für die Freistellung aller Jugendlichen ab Jahrgang 1913, auch wenn sie in der HJ oder SA höhere Posten bekleidet hätten. Sie seien in der , ,allgemeinen Verhetzung der Jahre 1918-33“ aufgewachsen und könnten deshalb nicht für ihre politischen Fehler verantwortlich gemacht werden; vielmehr gelte es diese Generation für die Demokratie zu gewinnen. Deshalb setzte er sich für stärker abgestufte Sanktionen und Bewährungsfristen für Minderbelastete ein ${ }^{106}$. Gerade weil Barth die Entnazifizierung als politische Säuberung prinzipiell unterstützte, konnte er zugunsten der Mitläufer mit ihrer geringeren Verantwortung und Schuld argumentieren.

Die fundierteste Kritik legte die Kirchlich-theologische Sozietät Württembergs im September 1946 in der Schrift ,,Kirche und Entnazifizierung“ vor. Sie hatte während des Kirchenkampfes kompromißlos bruderrätliche Positionen verfochten und stand auch nach 1945 mit ihrer Kritik, der auch Gegner theologisches Profil und Gewicht nicht absprechen konnten, in scharfer Opposition zur kirchlichen Restaurationspolitik und zur württembergischen Kirchenleitung. Die Sozietät war die einzige Gruppe innerhalb der evangelischen Kirche, die die Entnazifizierung nachdrücklich unterstützte, was nicht unerheblich zu ihrer Isolierung beitrug, da sich selbst der Bruderrat der EKD zu keiner öffentlichen Unterstützung durchringen konnte.

Die differenzierte Argumentation soll hier nur in ihren politischen Grundzügen, nicht in ihrer theologischen Begründung nachgezeichnet werden. Ausgangspunkt für die Beurteilung war die Einsicht: ,,Der Nationalsozialismus war und ist ein Verbrechen, er hat sich mit dem Militarismus verbündet und er ist mit Hilfe vermeintlich konservativer Kreise zur politischen Herrschaft und damit, seinem Wesen entsprechend, zur Alleinherrschaft gekommen. "107 Die politische Säuberung sei deshalb zur Erneuerung von Staat und Gesellschaft unumgänglich und müsse auch von der Kirche, wenn es ihr mit dem Schuldbekenntnis ernst sei, unterstützt werden. Da das Befreiungsgesetz durch die ,,gerechte Abwägung der individuellen Verantwortlichkeit und der tatsächlichen Ge-

106 NA, RG 260, 5/340-2/3, Einige Bemerkungen zur alliierten Besatzungspolitik in Deutschland vom 21.7.1946.

${ }^{107}$ Kirche und Entnazifizierung, S. 11. Zur Sozietät liegt bisher keine gründliche Untersuchung vor. Einen ersten Aufriß gibt Niemöller, Kirche, S. 211-227. 
samthaltung“ (Art. 2 BefrG) jedem Einzelfall gerecht werden wolle, stelle es einen ,"groBen Fortschritt" gegenüber der schematischen Entlassungspraxis der Militärregierung dar. Der Rat der EKD aber unterstelle dem Gesetz von vornherein die Erzeugung neuen Unrechts und wage es, die auch dem besten Gesetz innewohnende Möglichkeit des Mißbrauchs ,,mit der himmelschreienden, unsagbaren Blutschuld des Nationalsozialismus einfach als alte und neue Schuld in Vergleich zu setzen" ${ }^{108}$. Man könne doch nicht vergessen haben, daß die evangelische Kirche zur Rechtsauflösung und Willkürherrschaft während des Dritten Reiches geschwiegen habe.

Nicht minder scharf ging die Sozietät mit der positivistischen Rechtsauffassung ins $\mathrm{Ge}$ richt, die vor allem in dem Protestschreiben Wurms zum Ausdruck gekommen war: „,Wie beeilt man sich auf einmal, den Nationalsozialismus zwar nach göttlichem Recht mit hohem Pathos zu verdammen und will das schon immer getan haben, aber nach menschlichem Recht ihn unter den Denkmalschutz einer Geschmacksverirrung zu stellen! Vielleicht weil es trotz aller Hinweise auf die erfolgreiche kirchliche Abwehr doch nicht ganz vergessen ist, wie man ihn zum Bundesgenossen gegen Freidenkertum und Atheismus (damals sagte man noch getrost dafür: Kommunismus) machen wollte und dabei menschliche Strafgewalt nur begrüßenswert fand im Kampf gegen ,Verbrechen nach göttlichem Recht'." 109 Unhaltbar sei auch die Auffassung, daß nicht die Gesinnung, sondern nur strafrechtliche Verbrechen bestraft werden dürften: „,Sollen die Professoren, Lehrer, Redakteure, Amtsträger, die geistigen Herolde des verbrecherischen Systems, alle ihre Stellungen behalten oder neue, einflußreiche Posten einnehmen dürfen, bloß weil sie nicht selber Mörder oder Diebe waren?" "110 Die Umkehrung der Beweislast verletzte keineswegs das Rechtsempfinden, da die Mitglieder von NS-Organisationen zu Recht unter dem Verdacht stünden, ,,Handlanger der inneren und dann auch der äußeren Korrumpierung Deutschlands" gewesen zu sein: „,Die Berufung auf die Form sonstiger Strafprozesse kann nur den Sinn haben, ein Rechtsempfinden ins Feld zu führen, das für diesen besonderen Rechtsfall überhaupt kein rechtes Empfinden hat und deshalb auch vorwiegend nur von denen geteilt wird, die die sträfliche Schuld des deutschen Volkes nicht wahrhaben wollen. "Dieses Rechtsempfinden werde aber nicht von denjenigen geteilt, ,, die beschämt und empört sind über das, was bei uns und eben auch durch uns ungestraft geschehen durfte" "111. Die Kirche könne ihre innere Glaubwürdigkeit nur durch das Bekenntnis ihrer Schuld und die Bereitschaft, ihre belasteten Pfarrer mit allen von der Entnazifizierung betroffenen Personen gleichzustellen, zurückerlangen, nicht aber durch die Rechtfertigung des NS-Mitläufertums und die Verwerfung der politischen Säuberung. Die Stellungnahme der Sozietät war unverkennbar von der Kritik Barths inspiriert. Der Stuttgarter Oberkirchenrat, dem sie seit August vorlag, distanzierte sich noch vor dem Erscheinen der Schrift in einem Rundschreiben an alle Pfarrer ${ }^{112}$.

In Treysa hatte die Kirchenführerkonferenz, zusammen mit dem Rat der EKD, auch zwei Entschließungen zur Selbstreinigung verabschiedet, in denen das bereits von Wurm geforderte Sonderrecht für die Kirche nachdrücklich unterstützt wurde:

\footnotetext{
108 Ebenda, S. 20.

109 Ebenda, S. 28.

110 Ebenda, S. 30.

111 Ebenda, S. $32 \mathrm{f}$.

112 LKAS, OKR 104f-I, Rundschreiben des Oberkirchenrats vom 20.8.1946.
} 
„In der durch den Nationalsozialismus geschaffenen Lage haben die Evangelischen Kirchen in der Vergangenheit wie gegenwärtig Entscheidungen und Anordnungen getroffen, die der Reinigung des Pfarrerstandes von bekenntniswidrigen, z. B. deutsch-christlichen und nationalsozialistischen Einflüssen dienen. Derngemäß sind die Evangelischen Kirchen bemüht, die Reinigung des Pfarrerstandes durchzuführen. Sie erwarten von den Besatzungsmächten und den deutschen Regierungsstellen die Anerkennung, daß aus Gründen der Lehre und des Rechtes den Kirchen allein die Entscheidung darüber zusteht, wer die Funktionen des geistlichen Amtes ausüben kann und wem sie zu entziehen sind." $" 113$

Zur Problematik, daß die Kirche damit eine eigene Gerichtsbarkeit in weltlichen Angelegenheiten beanspruchte, hatte Diem bereits Ende 1945 Stellung genommen: ,Die Begründung ist darum falsch, weil es sich bei der Ausdehnung der Reinigungsaktion auf die Kirche nicht um einen Eingriff in das kirchliche Amt handelt, sondern um ein Vorgehen gegen den Amtsträger als Staatsbürger, der zudem im öffentlichen Leben eine exponierte Stellung besitzt." Der Anteil der evangelischen Pfarrer und der durch sie beeinflußten Gemeinden an den Wahlerfolgen der NSDAP sei nur zu gut bekannt, und die Kirche habe sich dessen auch im Dritten Reich gerühmt. Deshalb sei es nicht einzusehen, daß bloß die Verführten, nicht aber die Verführer gestraft würden. Vielmehr müsse die Kirche zusätzlich ein Kirchenzuchtverfahren einleiten, da allein die Kenntnis des Evangeliums Pfarrern den Eintritt in die NSDAP hätte verwehren müssen ${ }^{114}$.

Die in Treysa beschlossenen Richtlinien zur Selbstreinigung gaben weder inhaltliche Kriterien an noch banden sie die Kirchenleitungen. Sie bestimmten, daß , ,Pfarrer um der Gesamtverantwortung ihres Amtes willen" keine Funktionen in den Spruchkammern ausüben dürften. Sollten sie jedoch als Betroffene vor die Spruchkammern gerufen werden, so müßten sie sich verantworten, , auch wenn ihnen dabei Unrecht geschehen sollte". Die von staatlicher Seite verhängten Maßnahmen müßten getragen werden, ,,soweit sie nicht das Amt des Pfarrers antasten" ${ }^{115}$. Dies war der entscheidende Punkt, denn nach kirchlicher Auffassung berührten sowohl das vorläufige Beschäftigungsverbot für mutmaßliche NS-Aktivisten wie die Bewährungsfrist für Verurteilte in den Gruppen I bis III, die nur die Beschäftigung in ,,gewöhnlicher Arbeit“ zuließ, und besonders die Verurteilung zu Arbeitslager oder Sonderarbeiten bei Hauptschuldigen und NS-Aktivisten das geistliche Amt des Pfarrers. Als hinnehmbare Sanktionen blieben somit nur die für Mitläufer vorgesehenen Geldbußen. Es unterstrich die von Barth konstatierte Widerwilligkeit, daß die Verpflichtung zur Selbstreinigung erst in Punkt 6 in einem einzigen Satz ohne nähere Bestimmungen ausgesprochen wurde. Tatsächlich erlangten die Richtlinien nur in ihren negativen Bestandteilen, in dem Verbot der Mitarbeit in den Spruchkammern und der Erteilung belastender Aussagen, Bedeutung.

Wenn Niemöller schweren Herzens, wie er an Barth schrieb, die Treysaer Beschlüsse nicht zu verhindern gesucht hatte, so galt dies für die eben zitierten Richtlinien. Denn am 20. März 1946 hatte der Bruderrat in einem ,, Wort zur Reinigung der Kirche vom Nationalsozialismus" erklärt, der Nationalsozialismus sei nicht nur politische Lehre und staatliches Prinzip gewesen, sondern sei mit seinem Totalitätsanspruch zur Religion ,, und als Religion zum Antichristentum" geworden. Er habe die Kirche vernichten, den christli-

113 Beschluß B, in: KJ 1945-1948, S. $199 \mathrm{f}$.

114 WCC, Inter-Church-Aid, Germany (East and West), Diem an Freudenberg, o. D.

115 Beschluß C, in: KJ 1945-1948, S. 200 f., und Verordnungs- und Nachrichtenblatt der EKD, Nr. 14 vom Mai 1946. 
chen Glauben ausrotten und das Volk zur Auflehnung gegen Gottes Gebote verführt. Aus dieser Beurteilung mußten sich schärfere Maßstäbe für das Verhalten der Pfarrer ergeben: ,Wer als Geistlicher und kirchlich Verantwortlicher dem Nationalsozialismus verbunden war und sich nicht deutlich von ihm geschieden hat, muß sich fragen lassen, $o b$ er nicht gegen das erste Gebot gesündigt hat und ob er sich nicht der Verführung der Gemeinde Gottes schuldig gemacht hat. Der Kampf um die Freiheit der Kirche gegenüber dem totalen Staat und gegen das Eindringen des nationalsozialistischen Geistes in die Lehre und Verkündigung der Kirche war die Pflicht aller derer, die ein Amt in der Kirche hatten."

Konkret richtete sich der letzte Satz gegen die Deutschen Christen und Teile der kirchlichen Mitte, die sogenannten Neutralen, die nach Ansicht der Bruderräte in der Bewährungsprobe des christlichen Bekenntnisses während des Kirchenkampfes versagt hatten. Zugleich stellte der Bruderrat die Forderung auf, daß die Kirchenleitungen ,die Reinigung der Kirche von nationalsozialistischem Geist und Wesen mit Ernst durchzuführen und um die Sühne der schuldig gewordenen Geistlichen und anderer kirchlichen Beauftragten besorgt zu sein" haben. Der schuldig gewordene Pfarrer habe seinerseits ein Recht darauf, daß die Kirchenleitung seine Schuld ernst nehme und ihm dazu verhelfe, "wo es möglich ist, die Glaubwürdigkeit seines Dienstes zurückzugewinnen"116.

In dem Entwurf der Erklärung hatte Asmussen ferner als mögliche Maßnahmen genannt: Entfernung aus dem Amt, Pensionierung, mit oder ohne Gehaltsteile, Versetzung in den Wartestand mit längeren oder kürzeren Fristen und Versetzung in ein anderes Pfarramt. Wenn keine Bereitschaft zur Buße bestehe, solle der betreffende Pfarrer grundsätzlich entlassen werden ${ }^{117}$. Dieser Maßnahmenkatalog wurde vom Bruderrat nicht übernommen. Er ließ jedoch keinen $Z$ weifel daran, daß vor der Vergebung das Bekenntnis der Schuld und die Bereitschaft zur Sühne stehen müsse. Hier lag der wesentliche Unterschied zu den offiziellen Stellungnahmen, die in der Betätigung von Pfarrern für die NSDAP oder für die Deutschen Christen keine schuldhafte Verletzung des christlichen Bekenntnisses zu sehen vermochten.

Während der Ratssitzung und der Kirchenführerkonferenz am 1. und 2. Mai unternahmen jedoch weder Niemöller als stellvertretender Ratsvorsitzender noch Asmussen als Leiter der Kirchenkanzlei den Versuch, den Beschluß des Bruderrates inhaltlich durchzusetzen. Ein solcher Vorstoß hätte nicht nur zu einer klaren Niederlage der Bruderräte geführt, sondern auch die politisch motivierte, aber moralisch begründete Ablehnung des Befreiungsgesetzes konterkariert: Wenn der Nationalsozialismus die Verkörperung des Antichristentums war, konnte die Betätigung in NS-Organisationen nicht mehr so umstandlos als eine läßliche Verirrung aus idealistischen Beweggründen gerechtfertigt und entschuldigt werden. Drängten Niemöller und Asmussen vor der Verabschiedung des Befreiungsgesetzes auf eine resolute Ausscheidung der Deutschen Christen, so hielten sie sich nunmehr deutlich zurück. Beide standen vor dem Dilemma, die Entnazifizie-

116 Wort des Bruderrats der EKD zur Reinigung der Kirche vom Nationalsozialismus vom 20.3.1946, in: KJ 1945-1948, S. 187f. Der Beschluß trägt die Unterschrift Asmussens (WCC, Germany 284(43)). Vgl. Beschluß der a.o. Landessynode Oldenburgs zur Selbstreinigung der Kirche vom 25.3.1946, in: KJ 1945-1948, S. $188 \mathrm{ff}$.

${ }^{117}$ EZA, EKD 1/203, Die Reinigung der Kirche vom Nationalsozialismus. Anlage zum Rundschreiben der Kirchenkanzlei vom 4.3.1946. Die Anlage entsprang der Eigeninitiative Asmussens und stellte keinen Ratsbeschluß dar, wenngleich er diesen Anschein zu erwecken suchte. 
rung nicht als Unrecht ablehnen und andererseits scharfe Maßnahmen gegen die Deutschen Christen fordern zu können, weil sie Kirche und Evangeliumsverkündung in den Dienst des Antichristentums gestellt hätten.

Asmussen hatte noch Mitte März 1946 in einem Bericht für den Bruderrat festgestellt, daß keine klare Einsicht darüber bestehe, ,, was wir im Lichte des Wortes Gottes zu sagen haben über das ganze Problem der Entnazifizierung"; Anfang Mai hatte sich die evangelische Kirche endgültig festgelegt. ,,Aufs Ganze gesehen“, so war Asmussen fortgefahren, , läßt sich sagen, daß die Kirchen weder das Vertrauen der Besatzungsbehörden gewonnen haben, noch auch gegenüber dem deutschen Volk glaubwürdig geblieben sind. Es ist zu prüfen, ob diese ihre Stellung aus dem Gehorsam oder aus dem Ungehorsam fließt." " 118 Die Festlegung zugunsten der ehemaligen Nationalsozialisten war die Entscheidung für die Glaubwürdigkeit gegenüber dem eigenen Kirchenvolk. Die schnell gefaßte Ablehnung des Befreiungsgesetzes war nicht das Ergebnis einer intensiven theologischen Diskussion über Schuld und Sühne, sondern Ausfluß politisch motivierter Erwägungen und deutschnationaler Denkweisen.

\section{Reaktionen und Kontroversen}

Wie nicht anders zu erwarten, lehnte die amerikanische Militärregierung jegliche Änderung des Befreiungsgesetzes ab. Am 23. Mai 1946 beantwortete Clay das Schreiben Wurms und verwarf die Berufung auf den Rechtsgrundsatz ,"nulla poena sine lege“ als „hinfällig“. Zur Bekräftigung zitierte er anschließend den Satz aus dem Schreiben Wurms, wonach die Kirche nicht weniger als die Besatzungsmächte der Úberzeugung sei, ,,daß der Nationalsozialismus ein Verbrechen war und daß seine Grundsätze und ihre Anwendung immer von neuem zu Verbrechen führen müssen". Damit hatte Clays Rechtsberater, Charles Fahy, wie Oberkirchenrat Hartenstein kommentierte, ,, mit einer dem Detektiv Ehre machenden Schärfe den einzig wirklich schwachen Satz herausgepickt, in dem wir in ungeschützter Weise den Nationalsozialismus als solchen und seine Prinzipien als Verbrechen erklärten [... ]. Dies muß also richtig gestellt werden, sonst ist die Beweisführung ausgesprochen schwach." 119

Gegen den Vorwurf unverhältnismäßiger Strenge machte Clay geltend, daß die Schuld jedes Einzelnen von den Spruchkammern individuell geprüft werde, damit trotz formeller Mitgliedschaft auch die Entlastung bzw. Zubilligung mildernder Umstände möglich sei. Die Anwendung des Gesetzes werde die Absicht, die Mitläufer ,,in das freie Leben Deutschlands einzuschalten und sie von jedem Makel von Bedeutung zu befreien", beweisen. Nur schwere Fälle würden streng geahndet. Ausdrücklich betonte Clay, es sei kein Eingriff in den Wirkungskreis der Kirche bei der Erteilung geistlicher Amter beabsichtigt. Allerdings nehme er nicht an, daß die Kirche die Immunität ihrer Pfarrer gegenüber den bürgerlichen Gesetzen fordern wolle. Wenn ein Pfarrer wegen eines Verbrechens zu einer Gefängnisstrafe verurteilt werde und damit an der Amtsausübung gehin-

118 ZEKHN, Bruderrat 1, Bericht Asmussens vom 13.3.1946 für die Bruderratssitzung am 19./20.3.1946.

119 LKAS, NL Hartenstein 50/1, Hartenstein an Weeber vom 3.6.1946. Vgl. NA, RG 260, 17/56-2/17, Fahy an Adcock vom 11.5.1946. 
dert sei, gelte dies herkömmlicherweise nicht als eine Beeinträchtigung der Rechte der Kirche. Damit war ein weiterer wunder Punkt benannt, da die Geistlichen auch nach deutscher Rechtstradition in vollem Umfang den bürgerlichen Gesetzen unterlagen, zu denen auch das umstrittene Befreiungsgesetz zählte. Abschließend äußerte Clay seine Enttäuschung über die Haltung der evangelischen Kirche. Die Militärregierung habe viel zur Wiederherstellung der Religionsfreiheit beigetragen; sie habe jedoch die Mitarbeit der kirchlichen Behörden erwartet, , als sie daran ging, alle jene, die gemeinsame Sache gemacht haben mit einer die Gesetze Gottes aufs gröbste verachtenden und die Menschenrechte brutal zertretenden Partei, aus allen Stellungen von Bedeutung und Ansehen zu entfernen" 120 .

Wesentlich länger ließ die Reaktion des Alliierten Kontrollrats auf sich warten. Auf der Sitzung des Allied Religious Affairs Committee vom 17. Juni erklärte der sowjetische Delegierte kategorisch, da der Rat der EKD die von den Nationalsozialisten begangenen Verbrechen bisher nicht ausdrücklich verurteilt habe, sei es unter seiner Würde, ein solches Dokument überhaupt zu beantworten. Daraufhin zog der britische Vertreter sein nicht überliefertes Antwortschreiben zurück. Ebenfalls einen harten Standpunkt verfocht, wie Pfarrer Georges Casalis von der Aumônerie Protestante de Berlin berichtete, die französische Delegation: ,Le délegué français est d'avis de répondre très vivement (,vertement'), par une espèce de coup de poing donneé a l'insolence allemande. " ${ }^{2121}$ Es war der sowjetischen Delegation zu verdanken, daß die deutsche Frechheit dann doch nicht mit einem Faustschlag beantwortet wurde, weil sie die ersatzlose Absetzung des Themas von der Tagesordnung durchsetzte. Welchen Eindruck die Ratserklärung bei ausländischen Kirchenvertretern hervorrief, zeigt die Reaktion von Casalis, der - obwohl er der Bekennenden Kirche mit viel Sympathie gegenüberstand - der Auffassung ausdrücklich nicht widersprach, die evangelische Kirche sei zum Zufluchtsort für ehemalige Nationalsozialisten geworden. Da auch im Directorate of Internal Affairs and Communication keine Einigung erzielt werden konnte, erhielt Wurm am 16. September lediglich die Mitteilung, daß die Durchführung der Entnazifizierung in die Zuständigkeit der jeweiligen Besatzungsmacht falle und deshalb keine Stellungnahme des Kontrollrats erforderlich sei ${ }^{122}$.

Mit dem Antwortschreiben Clays, das die deutsche Presse Ende Mai zusammen mit Auszügen aus den Stellungnahmen Wurms und des Rats der EKD veröffentlichte, wurde der Protest der evangelischen Kirche zum Politikum, was durchaus den Intentionen der Treysaer Kirchenführerkonferenz entsprach ${ }^{123}$. Die Ablehnung des Befreiungsgesetzes

${ }^{120}$ LKAS, NL Wurm 274, Clay an Wurm vom 23.5.1946. Zit. nach amtlicher deutscher Ubersetzung, die am 24. Mai von der Presseagentur DANA verbreitet wurde. Vgl. Tagesspiegel vom 25.5.1946.

121 WCC, Germany 284 (43), Rapport mensuel, No. 4 vom 22.7. 1946. Das Protokoll der ARACSitzung vom 17.6.1946, an der Casalis teilnahm, ist im OMGUS-Bestand (NA, RG 260, 2/124-2/11-13) nicht überliefert.

122 EZA, EKD 1/281b, Alliiertes Sekretariat an Wurm vom 16.9.1946.

${ }^{123}$ Vgl. Tagesspiegel vom 25.5.1946, Neue Zeitung vom 27.5.1946, Berliner Zeitung vom 29.5. 1946, Süddeutsche Zeitung vom 4.6. 1946. Die Beschlüsse durften von den Kirchenleitungen nach dem 24. Mai bekannt gegeben werden. ,Es wurde stillschweigend gefolgert, daß nach diesem Zeitpunkt ihr Inhalt der Pfarrerschaft im großen und ganzen und den Gemeinden im allgemeinen bekannt sein werde. " So der Bericht Carl Schneiders, der als Vertreter des ORK an der Tagung teilgenommen hatte. LKAS, NL Wurm 231. 
traf die Länderregierungen zu einem überaus kritischen Zeitpunkt und führte in Hessen und Württemberg-Baden zu einer merklichen Verstimmung der Befreiungsminister, die mit der Rekrutierung des Spruchkammerpersonals vor großen Schwierigkeiten standen. Wie unpopulär die Mitarbeit war, läßt sich an der gesetzlichen Dienstverpflichtung ermessen, die die bayerische Landesregierung einen Tag vor der Landtagswahl Ende November 1946 erließ, da sie die Ablehnung dieses Gesetzes durch das neukonstituierte Parlament befürchtete. In Hessen sollen 93 Prozent der vorgeschlagenen Personen die Mitarbeit an den Spruchkammern unter Berufung auf Gewissens- oder religiöse Gründe abgelehnt haben. Auch in Württemberg beklagte sich Befreiungsminister Kamm lebhaft über mangelnde Unterstützung durch CDU und DVP ${ }^{124}$, die sich auf den Protest der Kirche als moralische Legitimation berufen konnten.

Als am 11. Juni der Entnazifizierungsausschuß des Länderrats tagte, forderte der Vertreter des hessischen Befreiungsministeriums Grimpe die Verabschiedung einer von ihm ausgearbeiteten Resolution, die sich gegen das Protestschreiben Wurms wandte. Dagegen betonte Ziebell vom bayerischen Sonderministerium, daß ein ,,neuer Kirchenkampf “ vermieden werden müsse. Auch Kamm hielt eine persönliche Aussprache für erfolgreicher. Schließlich jedoch setzte sich Grimpe mit dem Argument durch, der Angriff der Kirche sei öffentlich erfolgt und müsse deshalb auch öffentlich Punkt für Punkt widerlegt werden. Die Erwiderung sollte im Rechtsausschuß des Länderrats entworfen und durch beide Ausschüsse beschlossen werden ${ }^{125}$.

Wenige Tage später informierte Kamm die Stuttgarter Oberkirchenräte Eichele und Weeber nochmals über Grundzüge und Intentionen des Befreiungsgesetzes, wobei er seine Verstimmung, daß sich Wurm an die Militärregierung und nicht an die zuständigen deutschen Ministerpräsidenten gewandt hatte, deutlich erkennen ließ: ,,Er hätte es für richtiger gehalten, daß sich die Kirche nicht in diese hochpolitische Auseinandersetzung [...] hineinziehen lasse und damit ähnliche Fehler begehe, die sie schon um 1933 und früher begangen habe." Die nachdrückliche Versicherung Kamms, er werde die politische Säuberung gerecht und sachlich durchführen, verfehlte nicht ihre Wirkung: ,,Dr. Eichele und ich", so die Aktennotiz Weebers, ,,sind von der bona voluntas, die uns gegenüber zum Ausdruck gebracht wurde, beeindruckt gewesen. "126 Auch Adolf Arndt vom hessischen Justizministerium, der als führender Jurist der SPD an der Ausarbeitung des Befreiungsgesetzes beteiligt war, mahnte die Kirche, vor einer erneuten Stellungnahme zuerst mit den verantwortlichen Stellen Kontakt aufzunehmen: Der Protest Wurms verkenne ,,von Grund auf“"Wesen und Absichten des Gesetzes und sei geeignet, ,,diesen so schweren, aber unerläßlichen Schritt zum inneren und auch äußeren Frieden zu gefährden“127. Dem Schreiben lag eine ausführliche Stellungnahme bei, die Arndt vermutlich für den Rechtsausschuß des Länderrats entworfen hatte.

Darin führte Arndt aus der Entstehungsgeschichte des Befreiungsgesetzes den Nachweis, daß nicht die Formalbelastungskategorien, sondern die individuelle Einzelfallprü-

124 Wittig, Praxis, S.178; Fürstenau, Entnazifizierung, S.182; Sauer, Neubeginn, S.148f. Zum Problem der Personalrekrutierung vgl. Niethammer, Entnazifizierung, S. 354 ff.; Woller, Gesellschaft, S.120ff.; Ettle, Entnazifizierung in Eichstätt, S. $41 \mathrm{ff}$.

125 BA, Z 1/1208, Protokoll des Entnazifizierungsausschusses vom 11.6.1946.

${ }^{126}$ LKAS, OKR 104f-IV, Aktennotiz Weebers über Besprechung mit Kamm am 15.6.1946.

127 EZA, EKD 1/280a, Arndt an Rat der EKD vom 24.6.1946. 
fung das entscheidende Moment für die deutsche Verhandlungsdelegation gewesen war, die ,ganz überwiegend aus kirchentreuen, bekennenden Christen beider Konfessionen “ bestanden habe ${ }^{128}$. Scharf wandte er sich gegen den zentralen Passus im Protestschreiben Wurms, das Befreiungsgesetz erschüttere das Rechtsempfinden, weil es Handlungen und Gesinnungen verurteile, die seinerzeit vom NS-Gesetzgeber als rechtmäßig und gut eingeschätzt worden seien. Mit dieser Aussage sei der „Boden des christlichen Bekenntnisses“ verlassen: ,Es verstößt nicht nur gegen die Gesetze der Logik, sondern auch gegen die Moral, wollte man bei Verwirklichung der Gerechtigkeit die Einschätzung eines , Gesetzgebers", der ein Verbrecher war, zum Ausgangspunkt nehmen. “ Nicht minder heftig protestierte Arndt gegen die „Unterstellung“, die Entwicklung des NS-Regimes zum Unrechtssystem habe in den ersten Jahren nicht erkannt werden können: Jedermann habe von der Einsperrung der Kommunisten nach der Reichstagswahl vom 5. März 1933, der Entlassung jüdischer Richter und Beamten durch den ,,Arierparagraphen “ vom April 1933, der Zerschlagung der Gewerkschaften und demokratischen Parteien, der Morde des sogenannten Röhm-Putsches 1934, den Nürnberger Rassegesetzen 1935 und den Judenpogromen 1938 gewußt. , Die Kirche sucht nach Rechtfertigungen, wo nur von Entschuldigungen die Rede sein kann.“ Die Ausschaltung von NS-Aktivisten sei keine „Strafe, sondern nur politische Folge einer politischen Verantwortung“. Eine Bestrafung der Nationalsozialisten sei nicht deswegen unmöglich, weil diese sie nach Recht und Gesetz nicht verdient hätten, sondern ,,weil sie erneut ein unabsehbares Blutbad zur Folge hätte".

Auch die Kritik des vorläufigen Beschäftigungsverbots zeuge von wenig Sachkenntnis, $\mathrm{da}$ die davon Betroffenen bereits von den Amerikanern entlassen worden seien. Die Entlassenen erhielten aber vor den Spruchkammern erstmals die Möglichkeit zur Rechtfertigung und Rehabilitierung. Neu betroffen seien allein die Selbständigen und Unternehmer, womit gerade die Ungerechtigkeit beseitigt werde, , daß der kleine Mann, oft nur aus formellen Gründen, sein Brot verloren hatte, der Große aber unangefochten blieb“. Hinsichtlich des umstrittenen Predigtverbots bemerkte Arndt, der den religiösen Sozialisten angehörte, die Kirche habe über ein Jahr Zeit zur Selbstreinigung besessen, und berief sich auf den Brief Luthers an Spalatin vom 11. November 1521: ,, Weiter ist es doch ein geringerer Fehl, einen gottlosen Prediger auszuzischen, als seine Lehre gläubig aufzunehmen; trotzdem halten unsere Gegner das z weite für löblich und das erste für eine Todsünde." "129

Der Rechtsausschuß vertagte die vorgesehene Resolution mehrfach, da man erst den Ausgang der Gespräche Kamms und Arndts mit den Kirchenführern abwarten wollte.

${ }^{128}$ Namentlich nannte Arndt: Justizminister Dr. Beyerle und Staatssekretär Dr. Gögler aus Württemberg, Ministerialrat Dr. Neuburger aus Baden, die Staatssekretäre Dr. Pfeiffer und Dr. Ehard sowie Ministerialrat Dr. Roemer aus Bayern und sich selbst. Arndt gehörte 1947 dem Vorstand der "Arbeitsgemeinschaft für Christentum und Sozialismus" in Frankfurt an. Weitere Vorstandsmitglieder waren unter anderem der Darmstädter Oberbürgermeister Ludwig Metzger, Professor Emil Fuchs, Hermann Schafft und Walter Dirks. Vgl. Die Zeichen der Zeit, 1947, Nr.2, S. 62 .

${ }^{129} \mathrm{BA}, \mathrm{Z} 1 / 1279$, Arndt, Quo vadis?, o. D. Dort auch die wenig überzeugende Entgegnung E. Schwarzhaupts, Vermerk zu dem Gutachten von Ministerialrat Dr. Adolf Arndt, o. D. Vgl. dazu EZA, EKD 1/282 b, Arndt an die Kirchenkanzlei vom 17.9.1946. Die Kritik Arndts erschien im August, leicht gekürzt, in den Frankfurter Heften: Die Evangelische Kirche in Deutschland und das Befreiungsgesetz, 1 (1946), Nr.5, S. 35-46. 
Aus dem gleichen Grund wurde auch auf evangelischer Seite die Stellungnahme zum Schreiben Clays verschoben, für die seit Anfang Juni ein erster Entwurf vorlag. Er war mehrfach mit Karl Arndt, dem leitenden Religious Affairs Officer der württembergischen Militärregierung, abgesprochen worden ${ }^{130}$. Arndt gehörte der fundamentalistischen lutherischen Missiouri-Synode an und teilte die Sichtweise Wurms. Der von Hartenstein und Weeber verfaßte Entwurf bekräftigte im wesentlichen die bekannten Vorwürfe. Bemerkenswert ist, daß - ungeachtet der Argumentation Clays - daran festgehalten wurde, daß es unzulässig sei, Handlungen und Gesinnungen zu bestrafen, ,,die zur Zeit ihrer Verwirklichung unter kein Strafgesetz fielen und deshalb auch keine strafbaren Verbrechen und Vergehen waren. Die meisten Tatbestände [...] waren als nationale und soziale Verpflichtung gefordert und allgemein anerkannt.“"131

Aber auch ein zweiter Entwurf, der deutlich den Einfluß der Kritik Kamms und Adolf Arndts erkennen ließ und den die Kirchenkanzlei am 16. Juli vertraulich von Arnim, dem Leiter der Rechtsabteilung des Länderrats und früheren Konsistorialpräsidenten des Evangelischen Oberkirchenrats der Mark Brandenburg, zuschickte, dürfte etliches Befremden ausgelöst haben: Wenn das Gesetz nur die Ausschaltung nationalsozialistischer Einflüsse für die Zukunft zum Ziel hätte, wäre die Frage, ob das Verhalten der Betroffenen während des NS-Regimes rechtmäßig war oder nicht, tatsächlich überflüssig. ,,Als Maßnahme zur politischen Umstellung der Staatsführung ist es z. B. berechtigt, wenn Beamte, bei denen bezweifelt werden muß, ob sie gewillt oder fähig sind, ihr Amt in Zukunft im demokratischen Sinne zu führen, aus ihrem Dienst entfernt werden ohne Rücksicht darauf, ob ihr Verhalten zur Zeit der Tat illegal war. "Das Befreiungsgesetz aber, so der entscheidende Einwand, sei nicht auf die zukünftige politische Loyalität abgestellt, sondern auf die Verfolgung vergangener Tatbestände. Es verbinde zudem diese Tatbestände mit Sühnemaßnahmen, die nichts mit der Ausschaltung unerwünschten politischen Einflusses zu tun hätten, so beispielsweise bei der Einziehung von Vermögen und Sachwerten für den Wiedergutmachungsfonds. Deshalb sei das Befreiungsgesetz „,weit mehr Strafgesetz als ein Mittel zur politischen Umstellung der Staatsführung und zur Erziehung des Volkes für die Zukunft". In demokratischen Staaten, so fuhr der Entwurf anschließend fort, herrsche aber die Auffassung, ,,daß ein strafbares Verbrechen nur ein von der staatlichen Rechtsordnung mit Strafe bedrohtes Verbrechen ist. Erst totale Staaten haben mit der Verfolgung ihrer anderen Staatsauffassung versucht, diesen Grundsatz wieder aufzulösen mit der Einführung von rückwirkenden Strafgesetzen und von Rechtsanalogien im Strafrecht. "132 Damit wurde das Befreiungsgesetz in vorsichtiger, aber eindeutiger Formulierung mit Maßnahmen totalitärer Staaten - konkret: des Nationalsozialismus - gleichgesetzt. Wenn bereits geringe Geldbußen unter Berufung auf den

130 Vgl. LKAS, NL Hartenstein 50/1, 52/1, Hartenstein an Weeber vom 31.5. und vom 3.6. 1946; LKAS, NL Wurm 274, Weeber an Wurm vom 14.6.1946. Arndts Position war innerhalb von OMGWB recht umstritten, da ihm mehrfach antisemitische Außerungen und Sympathien für den Nationalsozialismus nachgesagt wurden. Vgl. NA, RG 260, 5/339-3/28, Memorandum R. Bank's vom 6.1.1948.

${ }^{131}$ LKAS, NL Hartenstein 52/1. Den Entwurf schickte Hartenstein am 6.6.1946 K. Arndt zu. Zur Autorschaft siehe EZA, EKD 1/280 a, Hartenstein an Asmussen vom 7.6.1946.

132 LKAS, NL Wurm 274, Entwurf vom 18.9.1946; leicht veränderte Fassung vom 19.7.1946: EZA, EKD 1/280b. Vgl. BA, Z 1/1279, Begleitschreiben Kirchenkanzlei an von Armin vom 16.7.1946. Der als Anlage beiliegende Entwurf ist nicht überliefert. 
Grundsatz ,nulla poena sine lege“ als Unrecht galten, so ließ sich diese Argumentation erst recht gegen ein staatliches Berufsverbot für NSDAP-Mitglieder geltend machen. Auch ein rein an politischen Gesichtspunkten orientiertes Verwaltungsverfahren hätte sich dem Vorwurf ausgesetzt, ein rückwirkendes Strafverfahren zu sein, das nicht kriminelle Tatbestände, sondern antidemokratische Gesinnung und Verhalten bestrafe. Dennoch stellte dieser Entwurf gegenüber Argumentationsweise und Diktion früherer Stellungnahmen einen gewissen Fortschritt dar, da er erstmals den großen Ermessensspielraum der Spruchkammern erkannte, die eindringlich zur Absage an den ,, Geist der Rache" aufgefordert wurden. Unverändert blieb die entschiedene Ablehnung der politischen Säuberung der Pfarrerschaft.

Das in Aussicht genommene Antwortschreiben an Clay, das vom Rat der EKD Anfang August verabschiedet werden sollte, stieß auf den heftigen Widerstand Niemöllers, der sich mittlerweile die Kritik Barths zu Herzen genommen hatte. Er vertrat nun die Auffassung: ,Daß jetzt Strafen festgesetzt werden, die nach NS-,Recht' unzulässig gewesen wären, ist nur recht und billig. “ Die Berufung auf den strapazierten Grundsatz ,,nulla poena sine lege" sei nicht haltbar, da der NS-Staat die Umkehrung von Verbrechen in Recht vollzogen habe; auch die Sühnemaßnahmen hätten ihre Berechtigung. Wer 1000 RM als Beitrag für die NSDAP gezahlt habe, solle ruhig die gleiche Summe oder das Doppelte für die Wiedergutmachung der angerichteten Schäden zahlen. Solche Erziehungsmaßnahmen müßten sich allerdings in den Grenzen der Billigkeit halten. Hierin sah Niemöller das eigentliche Problem, da der ,,Geist der Rache und Vergeltung“ noch überwiege. In Verkennung der tatsächlichen Verhältnisse urteilte er: ,,Das ganze Gesetz wäre halb so schlimm und gefährlich, wenn es von der Besatzungsmacht selber gehandhabt würde." Die Ausführungen zum Predigtverbot für schwer belastete Pfarrer stellten den schwächsten Punkt dar, ,wie ja tatsächlich hier unsere Position überhaupt am schwächsten ist“". Der Entwurf berufe sich auf ein Recht der Kirche, ,,das keinesfalls aus Schrift und Bekenntnis in dieser Form abgeleitet und auch nicht mit Berufung auf unseren Kampf gegen den NS-Staat begründet werden kann". Die Kirche habe niemals den Kanzelparagraphen in Preußen grundsätzlich bekämpft; auch die Bekennende Kirche habe ihren Bekenntniskampf nicht in dieser Richtung geführt. Tatsächlich hatte die Bekennende Kirche, was Niemöller nicht anführte, Bonhoeffer die Aufnahme in das Fürbittengebet verweigert, weil er aus politischen Gründen, nicht aber wegen seiner Predigttätigkeit als Pfarrer, verhaftet worden sei ${ }^{133}$. Man könne deshalb die Militärregierung nur bitten keine Predigtverbote auszusprechen, , ,ohne daß tatsächlich Verfehlungen des Predigers in seiner Verkündigung vorgelegen haben und nachgewiesen sind"134.

Neben Niemöller scheint auch Meiser, wenn auch aus entgegengesetzten Gründen, den Entwurf abgelehnt zu haben. Dafür spricht die Veröffentlichung des Protestschreibens Wurms vom 26. April, die ausgerechnet Anfang August im Amtsblatt der bayerischen Landeskirche erfolgte. Heinemann billigte dagegen den Entwurf ${ }^{135}$. Da die internen Gegensätze nicht überwunden werden konnten, verzichtete der Rat schließlich auf

${ }^{133}$ Vgl. Bethge, Bonhoeffer, S. 893.

134 EZA, EKD 1/280 b, Niemöller an Asmussen vom 24.7.1946. Abschrift an Wurm: LKAS, NL Wurm 274.

135 Amtsblatt für die Evangelisch-Lutherische Kirche in Bayern rechts des Rheins, Nr.15 vom 2.8.1946, S.77f.; EZA, EKD 1/281 a, Heinemann an Kirchenkanzlei vom 14.9.1946. 
ein offizielles Antwortschreiben, wozu auch die Verhandlungen mit dem Länderrat und den Befreiungsministerien beigetragen haben dürften. Die Versicherung Asmussens, die evangelische Kirche werde sich künftig weiterer Stellungnahmen zur Entnazifizierung enthalten, bewog den Rechtsausschuß des Länderrats Anfang September zum Verzicht auf die geplante Richtigstellung ${ }^{136}$. Der Verzicht nach monatelanger Vertagung bestätigte im nachhinein die Einschätzung Hartensteins: , Niemand wünscht einen Kirchenkampf, das ist unsere große Stärke gegenüber den Deutschen. “137

Im Oktober beschloß der Rat der EKD, einen neuen Vorstoß zugunsten der belasteten Pfarrer zu unternehmen: Der Staat habe zwar das Recht, mit der Verhängung von Sühnemaßnahmen in die bürgerlichen und staatsbürgerlichen Rechte belasteter Pfarrer einzugreifen, der Eingriff in das Predigtamt stehe aber nur der Kirche zu. ,,Es kann ihm u. a. untersagt werden, öffentliche Vorträge zu halten, schriftstellerisch sich zu betätigen und in anderen Gemeinden zu predigen. Was ihm bleibt, ist sein Gemeindepfarramt. " Die Kirche werde anhand der Spruchkammerurteile allerdings prïfen, ob sich der betreffende Pfarrer kirchlich so verhalten habe, daß ihm das Pfarramt ,für immer oder auf Zeit zu entziehen" sei ${ }^{138}$. Eine Unterredung von Dibelius mit Walter Dorn, dem Entnazifizierungsberater Clays, ergab allerdings, daß Clay entgegen dem Rat Dorns jede Sonderregelung entschieden ablehnte: Die Kirche müsse einsehen, ,,daß Pastoren, die doch einen erheblichen Einfluß auf die Mentalität der Bevölkerung hätten, nicht einfach aus dem Entnazifizierungsvollzug ausgenommen werden könnten"139. Den Widerstand führte Dibelius auf die bevorstehenden Präsidentenwahlen in den USA zurück, da sich Truman nicht dem Vorwurf einer laschen Entnazifizierungspolitik aussetzen wolle. Zu einer Verständigung, die auch von Julius Bodensieck, dem Vertreter des Federal Council of the Churches of Christ in Amerika, unterstützt wurde, werde es daher erst nach den Wahlen kommen. Im Moment jedoch müsse mit der Verhaftung unbotmäßiger Pastoren gerechnet werden.

„,Ich habe Herrn Dr. Dorn“, so schrieb Dibelius wenig später an Wurm, ,, in voller Offenheit gesagt, daß ich eine solche Wendung der Dinge keinesfalls bedauern würde. Die Amerikaner seien nun einmal feindliche Besatzungsbehörde und es sei für eine Kirche keineswegs das Ideal, mit einer Besatzungsbehörde auf Kosten der eigenen Volksgenossen in ungestörter Freundschaft zu leben." Das Problem sei nur, ob sich unter den Pfarrern, die sich bisher keineswegs ,, als heroische Naturen“ erwiesen hätten, eine ausreichende Anzahl finden lasse, die bereit sei, um der Freiheit der Kirche willen ins Gefängnis zu gehen. Unter den Berliner Pfarrern gebe es, ,, kaum einen einzigen, dem ich das zutraue“. Ebenso unverblümt konstatierte Dibelius: ,,Kirchlich gesehen liegt die Schwierigkeit darin, daß wir, in dem wir auf der Predigtfreiheit für solche Geistliche bestehen, die sich in ihrer Amtsführung nicht tapfer für die Substanz der Kirche eingesetzt haben, hier sozusagen mehr für einen formalen als für einen materiellen Anspruch kämpfen, der

136 Vgl. BA, Z 1/1309, Protokoll des Rechtsausschusses vom 4.9.1946; HStAS, EA 4/2, Bü. 600, Aktennotiz Beyerles vom 5.9.1946.

${ }^{137}$ LKAS, NL Hartenstein 50/1, Hartenstein an Weeber vom 3.6.1946.

138 Beschluß des Rats der EKD vom 10. 10. 1946, in: LKAN, LKR 213, Rundschreiben des bayerischen Landeskirchenrats vom 15.11. 1946. Vgl. NA, RG 260, 5/341-1/6-10, Wurm an OMGUS vom 11.10.1946.

139 EZA, EKD 1/281 b, Aktennotiz Dibelius' über Besprechung mit Dorn am 21.10.1946. 
sich aus dem Wesen des geistlichen Amtes ergibt. Aber ich meine, daß wir diesen Anspruch zu verteidigen schuldig sind." 140

Die Androhung eines neuen Kirchenkampfes zeigte schneller Wirkung, als Dibelius erwartet hatte, da Clay die amerikanischen Kirchen nicht gegen die Politik der Militärregierung aufbringen wollte ${ }^{141}$. Ende Oktober teilte Karl Arndt Wurm mit, daß Clay die Aufhebung des Predigtverbots nur mangels Zuständigkeit abgelehnt habe, da eine entsprechende Änderung des Befreiungsgesetzes ausschließlich in die Kompetenz des deutschen Gesetzgebers falle. Daraus folgerte der Entnazifizierungsreferent der bayerischen Landeskirche, es sei mit einem Eingreifen der Militärregierung nicht zu rechnen, ,,wenn die Kirche aus den ergangenen Predigtverboten der Spruchkammern zunächst keine Konsequenzen zieht" ${ }^{\text {142 }}$. Der Anfang November unternommene Vorstoß, das Predigtverbot durch eine Abänderung des Befreiungsgesetzes oder durch entsprechende Ausführungsbestimmungen aus der Welt zu schaffen, scheiterte allerdings am Widerstand des hessischen Befreiungsministeriums ${ }^{143}$.

In Bayern und Württemberg wiesen die Kirchenleitungen fast alle vom Predigtverbot betroffenen Pfarrer an, ihre Tätigkeit uneingeschränkt fortzusetzen, wobei sie auf die stillschweigende Duldung der Mißachtung von Spruchkammerurteilen seitens der Befreiungsministerien rechnen konnten. In Württemberg besaß Wurm zusätzlich die Rükkendeckung der Religious Affairs Branch, während in Bayern der Widerstand der Landesmilitärregierung noch einige Zeit erfolglos anhielt. Die schärfste Waffe, die den Kirchenleitungen bei der Mißachtung des Befreiungsgesetzes zur Verfügung stand, war die Androhung der öffentlichen Mobilisierung des evangelischen Wählerpotentials. Von diesem Druckmittel, das auf die wahltaktischen Uberlegungen der CSU in Bayern sowie der CDU und LDP in Württemberg seinen Einfluß nicht verfehlen konnte, machte besonders Meiser erfolgreich Gebrauch. In Hessen traf der Selbstreinigungswille der Bruderräte auf eine sozialdemokratisch dominierte Landesregierung, die auf der strikten Einhaltung der Spruchkammerentscheide bestand. In Bremen schließlich beugte sich die Kirchenleitung dem Zwang der Verhältnisse und leistete den Anordnungen der Militärregierung nur hinhaltenden Widerstand ${ }^{144}$.

Im Rückblick wird deutlich, daß die evangelischen Kirchenführer die Intentionen des deutschen Gesetzgebers, der sich im Rehabilitierungscharakter des Befreiungsgesetzes niederschlug, nicht erkannten, sich aber andererseits auch nicht bemühten, das Urteil sachkundiger Experten einzuholen oder diesem Urteil keinen Glauben schenkten. Die prinzipielle Verwerfung beruhte zum Teil auf der Erfahrung der schematischen amerikanischen Entlassungspraxis, als deren Fortsetzung das Befreiungsgesetz gesehen wurde;

\footnotetext{
${ }^{140}$ EZA, EKD 1/281 b, Dibelius an Wurm vom 24.10.1946.

141 Vgl. NA, RG 84, 757/24, Murphy an Dorn vorn 4.11, 1946. Zur Kritik des Apostolischen Visitators, Kardinal Muench, siehe Barry, Nuncio, S. 76. Uber Bodensieck urteilte Dibelius in seinem Schreiben an Wurm, er stehe ,,völlig auf unserer Seite“. Die harte Haltung hinsichtlich des Predigtverbots werde bei den amerikanischen Kirchen ,,weiterhin Verständnis“ finden.

142 LKAN, LKR 227, Rusam an Meiser vom 31.10.1946.

143 Vgl. NA, RG 260, 5/341-1/6-10, Kirchenkanzlei an die Befreiungsministerien der US-Zone vom 4. 11. 1946; Kirchenkanzlei an OMGUS vom 4. 11. 1946; HStAW, 504/176, Hessisches Befreiungsministerium an Kirchenkanzlei vom 2.12.1946: , Wir sehen uns nicht in der Lage, dem Gesetz eine Auslegung zu geben, die gegen den klaren Wortlaut verstößt."

144 Vgl. Kap. IV/5, V/2 und V/3.
} 
zum anderen ging es eindeutig um den Schutz belasteter Pfarrer. Nicht zuletzt spiegelte sich darin auch das Bemühen wider, die durch das Stuttgarter Schuldbekenntnis entstandene Vertrauenskrise zu überwinden. Dieses Motiv kommt in einem Schreiben Asmussens an die Landesbischöfe vom November 1946 deutlich zum Ausdruck: , ,Es besteht die Gefahr, daß der Vorwurf, die Kirche hätte zum Unrecht des Nationalsozialismus zwar das Wort ergriffen, wenn aber das Unrecht von einer anderen Seite käme, schweige sie, sich tief im deutschen Volk einwurzelt. " ${ }^{145}$ Daran schloß sich der bereits erwähnte Vorschlag Asmussens zur Generalabsolution des deutschen Volkes an.

Einen Aufschluß über die ersten Spruchkammerurteile gibt die Gesamtstatistik für die US-Zone von Ende September 1946, die allerdings nur Aussagen über die Tendenz, nicht aber über die Gerechtigkeit im Einzelfall erlaubt. Sie zeigt, daß die Spruchkammern von ihrem freien richterlichen Ermessen ausgiebig Gebrauch machten und nur in seltenen Fällen dem Antrag des öffentlichen Klägers folgten:

Klageerbebung und Spruchkammerentscheidung in der US-Zone bis zum 30. September $1946^{146}$

\begin{tabular}{lcrrrrr}
\hline Gruppe & Einstufung durch Kläger & \multicolumn{5}{c}{ Spruchkammerentscheidung } \\
\hline & & I & II & III & IV & V (u.a.) \\
I & 46 & 19 & 21 & 6 & & \\
II & 1198 & 1 & 187 & 378 & 611 & 21 \\
III & 636 & & 7 & 287 & 321 & 21 \\
IV & 7145 & & & 14 & 7063 & 68 \\
V (u.a.) & 603 & & & 1 & 4 & 598 \\
\hline Summe & 9628 & 20 & 215 & 686 & 7999 & 708 \\
\hline
\end{tabular}

Nach dieser Statistik hatten die Spruchkammern gerade in 2,4 Prozent der verhandelten Fälle die Einstufung als Hauptschuldiger oder NS-Akrivist für richtig gehalten, während es nach der Formalbelastung 12,9 Prozent waren. Diese Zahlen konnten den Kirchenführern im Frühsommer 1946 noch nicht bekannt sein; andererseits besaßen sie aber auch keine Unterlagen, um ihren Vorwurf des Rache- und Vergeltungsdenkens stichhaltig begründen zu können.

Aber auch als Ende 1946 die Rehabilitierungsbemühungen der Spruchkammern nicht mehr zu übersehen waren, was Clay im November zu der Drohung veranlaßte, die Militärregierung werde die Entnazifizierung wieder in eigener Regie durchführen ${ }^{147}$, ließ die Kritik nicht nach. Nachdem Wurm in einer Predigt die Spruchkammern wieder einmal scharf angegriffen hatte, unternahm der Vorsitzende der Spruchkammer Heidelberg den vergeblichen Versuch, Wurm anhand der württembergischen Entnazifizierungsstatistik davon zu überzeugen, daß von übermäßiger Härte keine Rede sein könne: Wenn den ehemaligen Nationalsozialisten ,,von so hoher Seite aus bestätigt wird, daß sie ja auch wirklich gar nichts Schlimmes getan haben [...] dann ist vollends niemand mehr bereit,

145 EZA, EKD 1/205, Rundschreiben Asmussens vom 29.11. 1946, in: Greschat, Schuld, S. $286 \mathrm{ff}$. 146 In: Niethammer, Entnazifizierung, S. 406.

${ }^{147}$ Zur Drohrede Clays im Länderrat am 5.11.1946 vgl. Niethammer, Entnazifizierung, S. 411 f. 
darüber nachzudenken, wo die politische und moralische Schuld jedes Einzelnen gelegen hat" ${ }^{148}$. Trotz der Kenntnis der offiziellen Statistik machte Wurm zwei Wochen später in einer Predigt auf dem Kirchenbezirkstag in Cannstatt erneut die Entnazifizierung für den „,besorgniserregenden seelischen Zustand vieler unserer Volksgenossen " verantwortlich: „,Die einen wollen sich für erlittene Verluste und Schäden dadurch rächen, daß sie politisch Andersgesinnten möglichst viel Schaden antun, die anderen warten in verbissenem Trotz auf den Tag, wo sie Recht bekommen. "149 Ende November wiederholte Wurm auf der Landessynode seine Vorwürfe: Die Entnazifizierung führe zu einer ,,Stärkung der Extremisten zur Linken und zur Rechten, zur Stärkung der Elemente, die die heutige Lage benützen, um sich selber Vorteile zu verschaffen auf Kosten von anderen oder sie kommt denjenigen zugute, die sich freuen darüber, daß diejenigen, zu denen sie im Gegensatz standen, nun mit ihnen diesselbe Sühne und Strafe mitzumachen haben". Die Entnazifizierung sei zu einem ,,unblutigen Bürgerkrieg“ geworden ${ }^{150}$.

Ähnlich argumentierte Meiser, als er in seiner Ansprache zur Eröffnung des Bayerischen Landtags im Dezember 1946 hinsichtlich der Entnazifizierung ausführte: ,Man sollte denken, unser Volk würde sich angesichts der ungeheuren Katastrophe mehr auf sich selbst besinnen und als Verbrechen am Volk ächten, was die Einheit des Volkes zerreißt, seinen Gesundungsprozeß stört und seine Not verewigt." Stattdessen herrsche „,Kampf bis aufs Messer, rücksichtslose Vernichtung des Gegners, Denunziantentum und Verrat. Bis in die fernste Vergangenheit werden Lebensläufe durchforscht, Unbedachtheiten ausgegraben, Verdachtsvermutungen aufgestellt, nur damit man möglichst viele dem Gericht überliefere und die Rache ihren Lauf nehme. Mit der Auferstehung des Rechts und der Sühne für vergangene Verbrechen hat das weithin nichts mehr zu tun. Wenn wir so fortfahren, dann stehen wir - daran ist gar kein Zweifel - vor dem Selbstmord." 151

Die ungebrochene Ablehnung des Befreiungsgesetzes verdeutlicht auch die offiziöse Erwiderung, die Elisabeth Schwarzhaupt im Auftrag der Kirchenkanzlei auf die bereits erwähnte Kritik Adolf Arndts für die Frankfurter Hefte verfaßte. Sie kritisierte, daß die Sühnemaßnahmen, insbesondere die Aberkennung des Wahlrechts und die Einweisung von Hauptschuldigen und NS-Aktivisten in ein Arbeitslager, eine ,, moralische Verurteilung des Verhaltens in der Vergangenheit“ bedeuteten und mithin ,,entehrende Strafen“ seien. Andererseits sah sie die Gerechtigkeit dadurch verletzt, daß die Mitglieder der Spruchkammern als Gegner des Nationalsozialismus bekannt sein mußten oder doch wenigstens sein sollten. Dies führe in ,,vielen Fällen“ dazu, daß sie nicht als ,, leidenschaftslose Richter, sondern als persönliche Verletzte und Verfolgte" urteilen würden. Dieser Vorwurf veranlaßte die Schriftleitung der Frankfurter Hefte zu dem Kommentar, daß die Richter wohl leidenschaftslos, nicht aber dem Verbrechen gegenüber unparteiisch zu sein hätten. Der letzte Kritikpunkt betraf den Artikel 13 BefrG, der die Anerkennung geleisteten Widerstands als Entlastungsgrund vom Nachweis erlittener Nachteile abhän-

148 LKAS, NL Wurm 242, Huber an Wurm vom 4.11.1946. Nach der von Huber zitierten Statistik gab es im September 1946 in Württemberg-Baden 13685 Mitläufer, 551 Minderbelastete, 116 NS-Aktivisten und 8 Hauptschuldige.

149 WCC, Germany 284(43), Predigt auf dem Kirchenbezirkstag in Cannstatt am 17.11. 1946.

150 LKAS, OKR 104f-III, Bericht Wurms auf dem Landeskirchentag am 28.11. 1946.

${ }^{151}$ Das Volk braucht christliche Politiker, in: Meiser, Kirche, S. $204 \mathrm{ff}$. 
gig machte, was „ein seltsam primitives Verfahren“ darstelle. Die Entlastungsgründe müßten stattdessen allein nach ihrem moralischen Gewicht bemessen werden; damit redete Elisabeth Schwarzhaupt der Einführung einer generellen Entlastungsvermutung das Wort ${ }^{152}$.

Die scharfe Verurteilung der Entnazifizierung konnte auf den Beifall weitester Bevölkerungskreise rechnen. Waren nach amerikanischen Meinungsumfragen im November 1945 noch 50 Prozent der Bevölkerung mit der Entnazifizierung zufrieden, so sank der Anteil bis Dezember 1946 auf 34 Prozent. Im September 1946 stimmten 3 Prozent der Befragten der Spruchkammerarbeit voll zu, nicht einmal 20 Prozent mit großen Vorbehalten. Rund 60 Prozent enthielten sich jeder Stellungnahme, was die amerikanischen Auswerter - wohl zutreffend - als Ablehnung interpretierten ${ }^{153}$. Als Ergänzung sind die Ergebnisse anderer Umfragen zu nennen, wonach der Anteil der deutschen Bevölkerung, der den Nationalsozialismus prinzipiell für eine ,,schlechte Idee“ hielt, von knapp unter 50 Prozent bis Ende 1946 auf rund ein Drittel abfiel, während die Einschätzung des Nationalsozialismus als einer, , an sich guten, aber schlecht durchgeführten Idee " mit gewissen Schwankungen von rund der Hälfte aller Befragten geteilt wurde ${ }^{154}$. Die Proteste der evangelischen Kirche spiegelten die breite Ablehnung des Befreiungsgesetzes wider und verstärkten sie zugleich mit der moralischen Autorität der Kirche.

\section{Das Jahr 1947}

Die Stellung zur Entnazifizierung bewegte die Kirchenführer 1947 nicht minder als 1945/46. Im Januar erklärte Asmussen auf einer weiteren Kirchenführerkonferenz in Treysa: ,, Wir können nicht verschweigen, daß bei der Entnazifizierung sowohl von den amerikanischen Behörden wie von deutschen Stellen schweres Unrecht geschieht. [...] Hat unser Volk noch das Vertrauen, daß seine Belange im tiefsten Sinn bei uns aufgehoben sind? Hier ist eine wesentliche Vertrauenskrise." Lilje verlangte ebenfalls einen scharfen Protest der Kirche, und Meiser führte die ausführlich diskutierte Vertrauenskrise auf das Stuttgarter Schuldbekenntnis zurück: ,,Die Krise der Verkündigung ist mitbedingt durch den Mißbrauch, der mit der Stuttgarter Erklärung getrieben worden ist. Dieses Mißtrauen wird nicht überwunden, wenn die Stuttgarter Erklärung immer wiederholt wird. " Gegen eine erneute Kritik der Entnazifizierungspolitik wandten sich vor allem Beckmann und Fricke, der auch im Namen Niemöllers, der sich auf einer mehrmonatigen Vortragsreise durch die USA befand, darum bat, nichts zu unternehmen, was das Verhältnis zu den Besatzungsmächten beeinträchtigen könne ${ }^{\mathbf{1 5 5}}$.

152 Die Evangelische Kirche und das Befreiungsgesetz, in: Frankfurter Hefte 1 (1946), S. 872-875. Der Abdruck war ursprünglich von der Redaktion wegen ,,Rabulistik“ und ,,deutsch-nationaler Gesinnung" abgelehnt worden. Vgl. EZA, EKD 1/281 a, Kogon an Kirchenkanzlei vom 21.9.1946.

${ }^{153}$ Zit. nach Niethammer, Entnazifizierung, S. 396, Anm.227.

154 OMGUS-Survey, Trends in Attitudes toward National Socialism vom 10.10.1947, in: Merritt/ Merritt, Public Opinion, S.171f. Vgl. S.32f.

155 LKAN, NL Stählin 120, Mitschrift Stählins über Kirchenführerkonferenz in Treysa vom 22./23.1.1947. 
Diskutierten die Kirchenführer in einer stark emotional geladenen Debatte die Frage, wie die allseits konstatierte Vertrauenskrise überwunden werden könne, so standen die Befreiungsminister zu Jahresbeginn 1947 vor einem ähnlichen Problem. Im Januar hielt Kamm in einer vertraulichen Denkschrift fest, die Entnazifizierung stoße zunehmend auf öffentliche Kritik und werde auch von den Parteien nur noch halbherzig mitgetragen: „Das Befreiungsgesetz dient in seinen Auswirkungen heute nicht mehr dem ursprünglichen Ziele, der Demokratisierung des deutschen Volkes, sondern hindert sie.“ Ebenso diagnostizierte das hessische Befreiungsministerium: „Es besteht bei allen deutschen Denazifizierungs-Fachleuten Übereinstimmung darüber, daß das Befreiungsgesetz zu breit angelegt ist und daß es zu viele Personen trifft. "156 Im einzelnen forderten die Befreiungsminister die Aufhebung des vorläufigen Beschäftigungsverbots für mutmaßliche Minderbelastete, die Gleichstellung der 1933 eingetretenen NSDAP-Mitglieder mit denen von 1937, die Auflösung der Internierungslager und die Einschränkung der Anfechtung von Spruchkammerurteilen durch die Militärregierung.

Den Hintergrund für das entschiedene, aber bis Ende 1947 erfolglose Drängen auf einschneidende Anderungen bildete der drohende Kollaps der Spruchkammern, die im bürokratischen Leerlauf erstickten. So hatten die württembergischen Spruchkammern bis Dezember 1946 zwar knapp über eine Million Meldebogen bearbeitet, davon waren jedoch 918595 Nicht-Betroffene. Die tatsächlich erledigten Entnazifizierungsfälle verteilten sich auf 52092 Personen, die unter die Jugendamnestie fielen, und auf 43656 Personen, die nach der Formalbelastung als Minderbelastete und Mitläufer galten. Von den mutmaßlichen Hauptschuldigen und NS-Aktivisten waren jedoch erst 16813 Personen vor die Spruchkammern gerufen worden; das entsprach einem Anteil von 7,6 Prozent der in Gruppe I und II Klassifizierten. Im März 1947 waren in Württemberg-Baden 72,7 Prozent der Nicht-Betroffenen unterrichtet, die Jugendamnestie zu 57,6 und die gerade anlaufende Weihnachtsamnestie zu 3,3 Prozent durchgeführt. Weiterhin hatten die Spruchkammern 52,4 Prozent der Fälle mit geringer Formalbelastung (Anhang B BefrG) verhandelt, aber nur 16,3 Prozent der mutmaßlichen Hauptschuldigen und NS-Aktivisten - in absoluten Zahlen 35946 von $223940^{157}$. Die Konzentration der Spruchkammern auf die Unterrichtung der Nicht-Betroffenen und die Verhandlung der Mitläuferfälle, die vorrangig rehabilitiert werden sollten, führte unvermeidlich dazu, daß die Masse der echten Entnazifizierungsfälle unerledigt blieb.

Nach Berechnungen des württembergischen Befreiungsministeriums hatten die Spruchkammern lediglich zwei Prozent der Schwerbelasteten, entsprechend ihrer Formalbelastung, in die Gruppen I und II eingestuft, so daß von einer harten Urteilspraxis keine Rede sein konnte. Im Frühjahr 1947 verzeichneten die Statistiken für die gesamte US-Zone und für Württemberg-Baden folgendes Bild der Einstufungen:

156 LKAS, OKR 104f-III, Denkschrift Kamms über die gegenwärtigen Probleme der Entnazifizierung vom 11.1.1947; Hessische Vorschläge zur Uberwindung der Denazifizierungskrise vom Februar 1947, in: Kropat, Hessen, S. $251 \mathrm{ff}$.

${ }^{157}$ BayHStA, MSo 93, Ưbersicht über erledigte Fälle in Württemberg-Baden vom 3.9.1947. Die Prozentangaben beziehen sich auf die Gesamtzahl der bis Ende August 1947 in den jeweiligen Rubriken registrierten Fälle. 
Entnazifizierungsstatistik für die US-Zone (Ende Februar 1947) und für Württemberg-Baden (Ende März 1947)

\begin{tabular}{lrrrr}
\hline Gruppe & \multicolumn{2}{c}{ gesamte US-Zone } & \multicolumn{2}{c}{ Württemberg-Baden } \\
& absolut & $\%$ & absolut & $\%$ \\
\hline I & 450 & 0,09 & 46 & 0,02 \\
II & 4880 & 0,96 & 687 & 0,4 \\
III & 18839 & 3,7 & 4633 & 2,7 \\
IV & 163962 & 32,4 & 59490 & 35,0 \\
V & 13142 & 2,6 & 1201 & 0,7 \\
Amnestierte/ & & & & \\
eingestellte & 304725 & 60,2 & 104035 & 61,1 \\
Verfahren & 505998 & 100 & 170092 & 100 \\
\hline Summe & & & &
\end{tabular}

Zur gleichen Zeit ergaben Hochrechnungen des Länderrats, daß der vorgesehene Abschlußtermin der Entnazifizierung - März 1948 - bei gleichbleibender Arbeitsleistung der Spruchkammern unmöglich einzuhalten war. Andererseits geriet die Entnazifizierung in den Länderparlamenten zunehmend in das parteipolitische Schußfeld; deshalb war ein baldiger Abschluß aus innenpolitischen Gründen unumgänglich. Er lag aber auch im Interesse der Weststaatskonzeption, auf die sich die westlichen Besatzungsmächte nach der gescheiterten Pariser Außenministerkonferenz Mitte 1946 verständigt hatten ${ }^{159}$. Die Situation faßte ein Report der Special Branch pointiert, aber zutreffend, dahingehend zusammen, daß die Kritik der Befreiungsminister nur zu verständlich sei, da sie nur ,,a small minority of democratically inclined individuals" repräsentierten und deshalb nur die Wahl zwischen politischem Selbstmord und ,, not too subtle sabotage" besäßen ${ }^{\mathbf{1 6 0}}$. Daraus folgerte Special Branch, die Militärregierung müsse die politische Säuberung wieder in eigener Regie übernehmen, woran Mitte 1947 jedoch nicht mehr ernsthaft zu denken war.

Anfang Februar unterrichtete Kamm Asmussen über die interne Kritik der Befreiungsminister und erklärte auf Rückfrage, daß die evangelische Kirche ,,seine Bemühungen noch fördern könne" ${ }^{161}$. Zwei Tage später, am 8 . Februar, sandte Wurm als Ratsvorsitzender ein Telegramm an Clay, in dem er für eine großzügige Ausweitung der Amnestien eintrat ${ }^{162}$. Der Entwurf für eine neue Eingabe, den der Marburger Theologieprofessor Heinrich Frick ausgearbeitet hatte, lag Ende Februar vor ${ }^{163}$. Die Eingabe wurde nach

${ }^{158}$ IfZ, MA 560, SpBr-Statistik zum 28.2. 1947, in: OMGUS, Monthly Report of the Military Governor for March 1947. Die Rubrik ,Amnestierte und eingestellte Verfahren“ enthält auch diejenigen Verfahren, die per Bescheid ohne Spruchkammerverfahren eingestellt wurden. Die Angaben für Württemberg-Baden wurden zusammengestellt nach Sauer, Neubeginn, S. 153, und der zitierten Statistik des Befreiungsministeriums.

$159 \mathrm{Vgl}$. Graml, Teilung Deutschlands, S. $165 \mathrm{ff}$.

${ }^{160}$ Zit. nach Niethammer, Entnazifizierung, S. 507.

161 EZA, EKD 1/282 a, Aktennotiz Schwarzhaupts vom 6.2.1947. Vgl. Asmussen an Kamm vom 7.2.1947.

162 EZA, EKD, 1/282 a, Wurm an Clay vom 8.2.1947.

${ }^{163}$ ZEKHN, 1/3438, Wüstemann an Kortheuer vom 21.2.1947. Beiliegend Entwurf Fricks vom 19.2.1947. 
längeren Beratungen am 21. April von allen Landeskirchen der US-Zone unterzeichnet. Hierin erklärten die Kirchenführer, daß sich ihre 1946 vorgetragenen Bedenken ,,Punkt für Punkt" erfüllt hätten. Die Kirche müsse leider feststellen, ,,daß eine bereits in die Hunderttausende, wenn nicht noch höher gehende Anzahl vollkommen unschuldiger Menschen durch die Entnazifizierung in schwerste Not gebracht sind und daß bei Fortsetzung des bisherigen Verfahrens ein Massenelend unausweichlich ist. Wir meinen die Frauen und Kinder, die Alten und Kranken und sonst hilfebedürftige Anverwandte derjenigen, die durch Entnazifizierung aus Amt und Brot gebracht oder durch die Folgen für Beruf und Besitz jedenfalls derart verarmt sind, daß die bisher von ihnen ernährten Angehörigen vor dem Nichts stehen. [...] Jedenfalls droht hier ein Massenproletariat geschaffen zu werden, dessen Erbitterung um so entsetzlicher werden muß, als die überwältigende Mehrheit sich nur als unschuldiges Opfer fühlen kann. "164

Bis Ende Februar 1947 waren in der gesamten US-Zone rund eine halbe Million Entnazifizierungsfälle abgeschlossen und, wie die eben angeführte Statistik ausweist, 24169 Personen als Hauptschuldige, NS-Aktivisten oder Minderbelastete verurteilt. Ihr Familienanhang dürfte 100000 Personen kaum überschritten haben; jedenfalls konnte von „,Millionen unschuldig Betroffener", wie es an anderer Stelle hieß, keine Rede sein. Auch wenn man die Internierungslager, in denen sich im Juni 1947 noch rund 48000 Personen befanden ${ }^{165}$, hinzurechnet, läßt sich das durch die Entnazifizierung geschaffene ,Massenproletariat" nicht belegen; zumal von Arbeitslosigkeit und materieller Not 1946/47 auch andere Bevölkerungskreise schwer betroffen waren.

Die Versicherung, die Kirche werde ausschließlich aus seelsorgerlicher Pflicht vorstellig, konnte kaum davon ablenken, daß es doch um eine politisch motivierte Kritik an der Entnazifizierung als solcher ging: Sie bilde ,,den Nährboden einer um sich greifenden moralischen Zerrüttung“" und verführe zu ,,Unwahrhaftigkeit und Heuchelei". Die Kirche könne nicht schweigen, ,,wenn in breiter Offentlichkeit der Glaube an Kirche und Gerechtigkeit, der Sinn für Ordnung und der Wille zum Rechtsstaat derart gefährdet werden". Wie die Prohibition in den USA, habe auch die Entnazifizierung das Gegenteil der ursprünglichen Zielsetzungen bewirkt und müsse deshalb in einem mutigen Schritt geändert werden. Im einzelnen enthielt die Eingabe vier als Vorschläge bezeichnete Forderungen, die auf die Aufhebung des bisherigen Entnazifizierungsverfahrens abzielten: 1. Die Einstellung aller Verfahren gegen mutmaßliche Mitläufer und Entlastete; ,,dazu Wegfall aller Zukunftsfolgerungen nach Art langfristiger oder dauernder Belastung, sei sie ideel oder materiell"“.

2. Die Einschränkung des betroffenen Personenkreises auf diejenigen, die , in hoher Führungsstellung“ die NS-Gewaltherrschaft wesentlich gefördert, sich krimineller Vergehen oder Denunziationen schuldig gemacht haben. Alle anderen Personen seien so rasch wie möglich wieder in den Wirtschaftsprozeß und in die öffentliche Verwaltung einzugliedern.

3. Den Verzicht auf die Umkehrung der Beweislast.

4. Den Verzicht der Militärregierung, einzelne Spruchkammerentscheidungen anzufech$\operatorname{ten}^{166}$.

164 In: KJ 1945-1948, S. 201-206, Zitat S. 202 f.

165 Niethammer, Entnazifizierung, S. 456, Anm. 433.

166 Ebenda, S.205f. 
Zur besseren Beurteilung ist nochmals ein Blick in die Entnazifizierungsstatistik nötig. Die Tendenz der deutschen Spruchkammern, die amerikanischen Entlassungsanordnungen in extensiver Auslegung der Bestimmungen großzügig aufzuheben, wird durch die Gegenüberstellung aller bis Ende März 1947 ergangenen Spruchkammerentscheidungen mit der Klassifizierung durch Special Branch während der amerikanischen Säuberungsphase offensichtlich: Waren nach den Kriterien der Militärregierung 40900 der erfaßten Betroffenen entlassungspflichtig (mandatory removal) und weitere 16339 zur Entlassung empfohlen (adverse recommendation), so verurteilten die Spruchkammern davon nur 5187 Personen als Hauptschuldige oder NS-Aktivisten zu einem Berufsverbot von mindestens fünf Jahren. Ober drei Viertel wurden aber durch die Einstufung als Mitläufer oder durch Verfahrenseinstellung infolge der Amnestien rehabilitiert ${ }^{167}$. Die Sühne für Mitläufer bestand in aller Regel aus einer einmaligen Geldzahlung von höchstens 2000 RM, dem Schwarzmarktwert von zehn Schachteln der Zigarettenmarke "Camel“; zumeist wurden jedoch wesentlich geringere Beträge festgesetzt. Bei den Amnestien wie im gewöhnlichen Spruchkammerverfahren wurde, nach dem Urteil Niethammers, ,im Normalfall soziale Schwäche (geringe Einkünfte, Körperbehinderung, Kriegsgefangenschaft, niedrige berufliche Stellung, Jugend etc.) durchweg und auch ohne gesetzliche Grundlage als mildernder Umstand berücksichtigt ${ }^{* 168}$. Selbst Träger des Goldenen Parteiabzeichens der NSDAP, d.h. Personen mit einer Mitgliedsnummer unter 100000, wurden nur selten als NS-Aktivisten eingestuft ${ }^{169}$.

Der Blick in die Statistik zeigt, daß die Kirchenleitungen in ihrer Kritik der massiven Rehabilitierungstendenz der Spruchkammern keine Rechnung trugen. Allem Anschein nach erlaubte die prinzipielle Ablehnung der Entnazifizierung nicht mehr die nüchterne Analyse der tatsächlichen Praxis. Wenn überhaupt, so ließen sich die Kirchenführer ausschließlich von interessierter Seite berichten, wozu der hohe Anteil belasteter Pfarrer erheblich beigetragen haben dürfte. Anhand der überlieferten Akten läßt sich jedenfalls kein Versuch der Kirchenführer belegen, ihre Befürchtungen durch sachkundige Information über die tatsächlichen Auswirkungen des Befreiungsgesetzes abzusichern. Wie das Protestschreiben Wurms vom April 1946 schürte auch die Eingabe vom April 1947, die im Mai den Pfarrämtern bekanntgegeben wurde ${ }^{170}$, vor allem Ressentiments und trug zu einer weiteren Verschärfung der Entnazifizierungskrise bei.

Als Sonderproblem der Entnazifizierungspolitik erwiesen sich die Internierten, deren vorweggenommene Sühne mit Abstand die schwerste war. Die gezielte Verhaftung der NS-Prominenz aller Ebenen und der Mitarbeiter des SS-SD-Gestapo-Komplexes im Zuge des ,,automatischen Arrests“ hatte unmittelbar mit der militärischen Besetzung Deutschlands eingesetzt und sollte die Bildung einer NS-Untergrundbewegung verhindern. Von den rund 117000 in der US-Zone bis Dezember 1945 verhafteten Personen befanden sich im Januar 1947 noch 51000 in Internierungslagern, obwohl sie die militärische Sicherheit der Besatzungsstreitkräfte nicht mehr bedrohten. Einen Anhaltspunkt

${ }^{167}$ Niethammer, Entnazifizierung, S. 544.

${ }^{168}$ Ebenda, S. 545.

169 Die Spruchkammer Ansbach stufte bereits in 1. Instanz von den örtlichen Inhabern des Goldenen Parteiabzeichens nur fünf als NS-Aktivisten ein. 32 galten als Minderbelastete, 23 als harmlose Mitläufer, einer als entlastet. Weitere 18 kamen ungerechtfertigt in den Genuß der Amnestien bzw. der Verfahrenseinstellung aus sonstigen Gründen. Vgl. Woller, Gesellschaft, S. 163.

${ }^{170}$ LKAS, NL Wurm 194/1,1, Rundschreiben des Oberkirchenrats vom 27.5.1947. 
über die Zusammensetzung gibt die Statistik von vier bayerischen Internierungslagern. Danach befanden sich im Januar 1947 unter 19076 Internierten 12702 Angehörige der SS, 330 des SD, 530 der Gestapo und 683 der SA sowie 4731 Politische Leiter der NSDAP ${ }^{171}$. Die Internierten gehörten zumeist nicht zur Führungsschicht des Dritten Reiches, stellten aber zu einem großen Teil die Unterführer des Terrorapparats und der NS-Bewegung dar. Ihre pauschale Freilassung konnte deshalb von der Militärregierung ebensowenig erwartet werden wie ihre schnelle Entnazifizierung durch die Spruchkammern, die bereits mit der Rehabilitierung der Mitläufer überlastet waren. Die Priorität der Mitläuferfälle führte in Extremfällen zu dreieinhalbjähriger Haft, aber auch zu äußerst milden Urteilen. Die Internierungslager, in denen teilweise katastrophale sanitäre Verhältnisse herrschten, waren ein bevorzugtes Mittel der Kritik, um den Strafcharakter wie das generelle Unrecht der Entnazifizierung zu belegen.

Zu Weihnachten 1946 führten etwa Kardinal Faulhaber, Erzbischof Gröber und Wurm als Ratsvorsitzender der EKD in einem Aufruf an die amerikanischen Christen bewegte Klage. In den Internierungslagern befänden sich ,,neben einer geringen Anzahl von wirklichen Verbrechern eine vielfache Zahl von Personen in $\mathrm{Haft}$, über die auf Grund von Verdächtigungen und Verleumdungen oder infolge von Zugehörigkeit zu einer Organisation oder wegen ihrer Beamtenstellung die automatische Haft verhängt ist. [...] Darunter befinden sich Beamte, Ärzte, Gelehrte, Offiziere von hervorragenden Eigenschaften und völlig einwandfreier Haltung, selbst viele Tausende von Frauen und Müttern, die der NSDAP angehörig im Rahmen der Partei eine sozial caritative Arbeit geleistet haben, aber nicht propagandistisch hervorgetreten sind."172 Niemand wünsche, Verbrecher ihrer gerechten Strafe entgehen zu lassen, doch könne man nicht verstehen, „,daß so viele Männer und Frauen, denen kein Verbrechen nachgewiesen werden kann“, so lange in Haft gehalten würden, ohne daß Vorbereitungen für ein geordnetes Verfahren zu erkennen seien.

Wo Differenzierungen dringend geboten gewesen wären, meinte Wurm im Februar 1947 - den Tenor zahlreicher Eingaben und Beschwerden charakterisierend -, feststellen zu müssen: ,,Solche Internierungslager sind nicht Zeichen christlicher Kultur und Humanität, für deren Verwirklichung sich die Siegermächte verpflichtet haben. Wir können nur immer wieder sagen, daß durch solche Maßnahmen, die durch ihre lange Dauer sich besonders tief einprägen, der Geist des Unrechts und der Gewalt, von dem die Welt endlich befreit werden sollte, nicht gehemmt, sondern in seiner unheimlichen Mächtigkeit geradezu bestärkt wird. " 173 Wurde die Internierung von seiten der Militärregierung und der deutschen Behörden als eine Art Untersuchungshaft gerechtfertigt, so erhob die evangelische Kirche in ihren Appellen Ausnahmen zum Regelfall und sah im Regelfall des internierten SS-Angehörigen, SD oder Gestapo-Mitarbeiters den ,,Geist des Unrechts

${ }^{171}$ Niethammer, Entnazifizierung, S. 456. Vgl. Fürstenau, Entnazifizierung, S. 44; Niethammer, Entnazifizierung, S. $255 \mathrm{ff}$., 456; Sauer, Neubeginn, S. $168 \mathrm{ff}$.

${ }^{172}$ LKAS, NL Wurm 231, An die Christen in den Vereinigten Staaten von Amerika vom 24.12.1946. Die im ursprünglichen Entwurf vorgesehene Fürsprache für die Nürnberger Kriegsverbrecher war auf Anraten Karl Arndts weggelassen worden.

${ }^{173}$ LKAN, LKR 214, Wurm an 3. US-Armee über OMGWB vom 6. 2.1947. Vgl. HStAS, EA 1/22, Bü. 4446, Oberkirchenrat an OMGWB und Befreiungsministerium vom 16.12.1947; LKAN, Dekanat München 36/6, Meiser an Sonderministerium vom 16.4 1947; EZA, EKD 1/283 a, Rat der EKD an Clay vom 11.2.1948. 
und der Gewalt" wirksam. Wurm selbst scheute sich nicht, die Internierungslager in aller Offentlichkeit mit den Konzentrationslagern gleichzusetzen ${ }^{174}$. Der Fürsprache für die Täter im engeren und weiteren Sinne stand in den ersten Nachkriegsjahren kein einziges Wort der Kirche gegenüber, das sich für die Wiedereingliederung und materielle Entschädigung des Millionenheeres der NS-Opfer einsetzte.

Die Gegenposition bezog erneut die württembergische Sozietät in einem Memorandum, das Wurm vor der offiziellen Stellungnahme der Landeskirchen bekannt war ${ }^{175}$. Die Sozietät beurteilte das Befreiungsgesetz auch weiterhin als einen ,großen Fortschritt" gegenüber der amerikanischen Entlassungspraxis und bescheinigte ihm, bei allen vorhandenen Schwierigkeiten, die ,Anforderungen eines gerechten Gesetzes" zu erfüllen. Nachdrücklich distanzierte sich die Sozietät von jenen, ,,die von vornherein das Gesetz ablehnten, seine Durchführung direkt oder indirekt sabotierten und darum auch jetzt kein Recht haben, sich über Mängel bei der Durchführung zu beklagen, an denen sie selbst Schuld sind. [ . . .] Vor allem wäre es von größter Bedeutung gewesen, wenn die Kirche im Bewußtsein der Solidarität der Schuld mit dem ganzen Volk ihre Diener denselben Maßnahmen wie alle übrigen unterworfen hätte, anstatt für diese Ausnahmerecht in Anspruch zu nehmen. Wo sie ein Beispiel der Bußfertigkeit und des rechten Tragens der Sühnemaßnahmen hätte geben müssen, haben umgekehrt ihre Methoden der Selbstrechtfertigung Schule gemacht. Sie hat damit zu ihrer alten Schuld aus der Zeit der nationalsozialistischen Herrschaft neue Schuld auf sich geladen und das Stuttgarter Schuldbekenntnis vom November 1946 [sic!] selbst nicht ernst genommen." 176

Anschließend trug die Sozietät differenzierte und sachkundige Bedenken vor, die darauf abzielten, bei der Militärregierung Verständnis für milde Mitläuferurteile zu wecken. Das deutsche Volk sei sich darin einig, ,,die weniger Belasteten möglichst milde zu behandeln und endlich gegen die wirklichen Hauptschuldigen vorzugehen. Soweit diese Tendenz aus einer gefährlichen Bagatellisierung der nationalsozialistischen Gefahr stammt, wird man sie nicht begrüßen, ihr aber auch durch jene entgegengesetzte Tendenz der einfachen Verschärfung der Maßnahmen nicht wirkungsvoll begegnen können." Sie entstamme vielmehr der wachsenden Erkenntnis, daß das Maß der Mitschuld zwischen Nicht-Betroffenen und Mitläufern oft nicht eindeutig zu unterscheiden sei, und die Einstufung von zu vielen Zufälligkeiten abhänge, als daß ,,man heute mit Recht in solch unterschiedlichem Maß zur Verantwortung gezogen werden könnte“.

Die Sozietät forderte die Einschränkung, nicht aber die völlige Aufhebung des Widerspruchsrechts der Militärregierung und schlug deshalb die Bildung eines obersten Revisionsgerichts für alle strittigen Urteile vor. Forderten die Kirchenleitungen den Wegfall aller Sühnemaßnahmen für Mitläufer, die Eingrenzung der Entnazifizierung auf führende Nationalsozialisten und Kriminelle sowie die Aufhebung der umgekehrten Be-

${ }^{174}$ LKAS, NL Hartenstein 8, Ansprache Wurms in der Markuskirche in Stuttgart vom 24. 2. 1948: „Es hat nun ein Streit um Worte begonnen. Das Gesetz sei kein Strafgesetz. Es gehe nur um Sühnemaßnahmen. Aber diejenigen, die von Sühnemaßnahmen betroffen sind, 3 Jahre KZ, vom Beruf weg, deren Familien in Not kommen, werden es immer als Strafe betrachten, die sie als ungerechtfertigt empfinden."

$175 \mathrm{Vgl}$. LKAS, OKR 115f., Wurm an Diem vom 21.4.1947.

176 NA, RG 260, 5/341-1/6-10; EZA, EKD 1/283 a, Memorandum zum gegenwärtigen Stand der Durchführung des Gesetzes Nr. 104 vom 31.3.1947. Das Stuttgarter Schuldbekenntnis war am 18./19. Oktober verabschiedet worden. 
weislast, so setzte sich die Sozietät für die Begrenzung der Beschäftigungsverbote ,,auf bestimmte und genau präzisierte wirkliche Schlüsselstellungen in Wirtschaft und Verwaltung" ein. Während es den Kirchenführern letztendlich um die Aufhebung der gesamten Entnazifizierung ging, wollte die Sozietät, die ebenfalls der Rechtssicherheit eine überragende Bedeutung zusprach und für eine großzügige Behandlung der Mitläufer plädierte, mit ihren Vorschlägen den politischen Säuberungsgehalt retten. Wie lähmend sich die Fehlkonstruktion des Befreiungsgesetzes auf die Mitarbeit selbst überzeugter NS-Gegner auswirkte, zeigte sich auch im Falle der Sozietät, die ihre weitere Unterstützung von der Annahme der Änderungsvorschläge abhängig machte. Im Unterschied zu den Kirchenführern betonte sie aber, diese Feststellung ,,ohne Bitterkeit" zu treffen, ,,da wir Deutschen als Besatzungsmacht selbst niemals in der Lage waren noch je die Absicht hatten, unsere Macht in solcher Weise in den Dienst des Rechts zu stellen. Als Christen können wir warten, ohne an dem Recht zu verzweifeln." Eine andere Frage sei jedoch, ob auch das deutsche Volk warten könne, , ohne in nicht wieder gutzumachender Weise an allen Möglichkeiten eines demokratischen Rechtsstaates zu verzweifeln" ${ }^{\text {"177 }}$.

Das Memorandum der Sozietät stellte die mit Abstand fundierteste Stellungnahme aus dem kirchlichen Raum zu den Problemen der Entnazifizierung dar und war auch, wie William Griffith, der Leiter der Special Branch der bayerischen Militärregierung, meinte, ,,some of the best thinking [...] by anti-Nazi Germans on the subject of denazification"178. Die Antwort auf die Frage, weshalb die Kirchenleitungen nicht auf diese sachgerechte Kritik zurückgriffen, enthält ein Schreiben Wurms an Diem. Darin warf er der Sozietät vor, sie verkenne nach wie vor, daß die Entnazifizierung niemals prinzipiell gerechtfertigt werden könne ${ }^{179}$.

Die erneute öffentliche Kritik der evangelischen Kirche wurde von zahlreichen Eingaben und Petitionen der Landesbischöfe Meiser und Wurm begleitet ${ }^{180}$. Aber auch die Parteien distanzierten sich 1947 zunehmend von der Entnazifizierung, da sie am Wahlverhalten der , kleinen Pg's" nicht achtlos vorübergehen konnten. Zugleich verlor das Befreiungsgesetz für die Länderregierungen an Bedeutung, da es seine staatspolitische Funktion als Rahmenabkommen mit der Militärregierung zur Stärkung der deutschen Selbständigkeit weitgehend erfüllt hatte und die Militärregierung nun ihrerseits im Zuge der Weststaatskonzeption an einer beschleunigten Ubertragung politischer Kompetenzen interessiert war. Entsprechend der durch den Ost-West-Konflikt gewandelten internationalen Rahmenbedingungen stieß die Entnazifizierungspolitik, an der Clay unverändert festhielt, auch in den USA auf wachsende Kritik, da sie weithin als Hindernis für einen schnellen Wirtschaftsaufschwung in der amerikanischen Besatzungszone galt ${ }^{181}$.

Ende Juli 1947 wandte sich Kardinal Faulhaber im Namen der Bischöfe der US-Zone und im Einvernehmen mit Kardinal Frings, dem Vorsitzenden der Fuldaer Bischofskon-

177 Ebenda.

178 EZA, EKD 1/283 a, Griffith an Asmussen vom 20.5.1947.

179 LKAS, OKR 115f. Wurm an Diem vom 21.4.1947.

180 Die wichtigsten: LKAN, LKR 218, Landeskirchenrat an Sonderministerium vom 10. 1.1947;

Pfarrarchiv St. Lukas, München, Landeskirchenrat an Sonderministerium vom 16.4.1947;

LKAN, LKR 214, Landeskirchenrat an Sonderministerium vom 3. 5.1947. HStAS, EA 11/1,

Bü.411, Oberkirchenrat an Befreiungsministerium vom 24.3.1947, Oberkirchenrat an OMGWB vom 4.7.1947.

181 Vgl. Niethammer, Entnazifizierung, S.486ff.; Griffith, Denazification Program, S. $455 \mathrm{ff}$. 
ferenz, mit einer Denkschrift an Clay. Damit gab auch der katholische Episkopat seine bislang vorherrschende Zurückhaltung auf. Noch im März 1947 hatte Faulhaber konkrete Verbesserungsvorschläge in den Mittelpunkt gerückt ${ }^{182}$; jetzt standen die politischen Auswirkungen der Entnazifizierung zur Debatte. Einleitend betonten die Würdenträger, die katholische Kirche habe nicht nur in Opposition zur NS-Gewaltherrschaft gestanden und die ,Wiedererrichtung einer echten Demokratie“ ersehnt, sondern erachte auch die Befreiung des deutschen Volkes ,, von allem, was mit dem Nationalsozialismus und Militarismus zusammenhängt", als eine vordringliche Aufgabe. Dazu seien die Abkehr von den ,,schädlichen, ja verbrecherischen Grundsätzen der Nazi-Doktrin über den totalen Staat"c, der Sinn für die Freiheit und Würde des Menschen und die Wiederherstellung der rechtsstaatlichen Ordnung unumgänglich. Jedes Entnazifizierungsverfahren sei aber nur so viel wert, wie es zur Verwirklichung dieser Ziele beitrage. Durch das Befreiungsgesetz sei jedoch eine ,,gefährliche und besorgniserregende Lage“ entstanden: ,Die Entnazifizierung wird von radikalen politischen Gruppen, vorab von den Kommunisten, immer wieder dazu mißbraucht, innenpolitische Gegner und führende Leute der Wirtschaft zu beseitigen [...]. Das Gesetz wird dazu mißbraucht, die ,legale‘ Grundlage für $Z$ wang und Terror gegen einen sehr großen Teil des Volkes abzugeben. So trägt es wesentlich dazu bei, daß die Verhältnisse im öffentlichen Leben Deutschlands sich von denen des vorherigen totalitären Regimes kaum unterscheiden. Es entsteht somit ein Zerrbild der Demokratie, welches die Absichten der Besatzungsmacht auf die politische Umerziehung des deutschen Volkes vereitelt. “183

Anschließend forderten die Bischöfe die Amnestie aller ,,nominellen Parteigenossen“ und die Aufgabe der Entnazifizierung zugunsten einer ausschließlich strafrechtlichen Verfolgung von NS-Verbrechen, während alle übrigen belasteten Personen mit einer gestaffelten Geldbuße ohne sonstige Rechtsnachteile belegt werden sollten. Da man wohl kaum mit der Annahme dieser Forderungen rechnen konnte, legte die Denkschrift als Alternative weitere Änderungsvorschläge vor, die auf die Erweiterung des Mitläuferbegriffs, die Erleichterung der Entlastung und die Lockerung des Beschäftigungsverbots abzielten.

Die Kritik der katholischen Kirche wurde von dem Apostolischen Visitator für Deutschland, dem ehemaligen Bischof von South Dakota, Aloisius Muench, uneingeschränkt unterstützt. Muench hatte bereits im Januar 1947 dem Senator William Langer aus North Dakota geschrieben: ,,Many of our American officials are disgusted with the grave miscarriage of justice in handling de-nazification cases. [...] If a Congressional Committee would come to Germany [...] we could clean up a stinking mass of injustice, and possibly save whatever is left of our efforts to restore democracy in Germany. "184 Solche Interventionen konnten auf Dauer weder auf Langer noch auf den amerikanischen

182 LKAN, LKR 213, Faulhaber an Ehard vom 4.3.1947. Dazu Niethammer, Entnazifizierung, S. 495f. Begleitender Schriftwechsel mit Ehard, siehe BayHStA, MA (Abgabe 1976), vorl. Nr. 3070 und 3096.

${ }^{183}$ NA, RG 260, 5/341-3/32; EZA, EKD 1/283 a, Faulhaber an Clay vom 27.7.1947. Die Denkschrift war namens der bayerischen Bischöfe von Kardinal Faulhaber sowie von Erzbischof Conrad von Freiburg, Bischof Baptista von Rottenburg, Bischof Johannes von Fulda und Kapitularvikar Rauch für die Diözese Limburg unterzeichnet. Vgl. Niethammer, Entnazifizierung, S.496f. Englische Übersetzung in: Barry, Nuncio, S. 309-312.

${ }^{184}$ Zit. nach Barry, Nuncio, S. 144 f. Vgl. Niethammer, Entnazifizierung, S. 493. 
Kongreß, der 1947 definitiv von der Entnazifizierungspolitik abrückte und damit die Militärregierung unter Zugzwang setzte, ihre Wirkung verfehlen. Die Antwort Clays auf die Eingabe der katholischen Bischöfe verteidigte nochmals das Befreiungsgesetz und verwies auf die über zwei Millionen amnestierter Mitläufer, gestand aber auch die Berechtigung weiterer Einschränkungen zu, um die Entnazifizierung ,, as soon as possible" abzuschließen ${ }^{185}$. Das Schreiben war wesentlich defensiver gehalten als der Entwurf Dorns, der die Mängel nicht dem Befreiungsgesetz, sondern der fehlenden Unterstützung durch die Deutschen anlastete: ,Persuading these best elements of German society to participate in denazification process has been and will remain the crucial problem of administering the Law for Liberation with justice and fairness. In view of the urgency and importance of this task it would appear that the Catholic clergy could do much in this matter to improve the present administration of the Law." 186

Daran war jedoch, wie der politische Grundtenor der Eingabe deutlich signalisierte, nicht mehr zu denken. Die Kritik der katholischen Bischöfe fiel zeitlich mit der Distanzierung jener Kreise in CDU/CSU zusammen, die in den ersten beiden Besatzungsjahren die Entnazifizierung aus primär staatspolitischen Erwägungen mitgetragen hatten. Das Abrücken des konservativen Reformflügels wie die Aufgabe der öffentlichen Zurückhaltung durch den Episkopat einerseits und der Stimmungsumschwung in den USA im Gefolge des Kalten Krieges andererseits traf die Entnazifizierung ausgerechnet zu dem Zeitpunkt, als die Masse der Mitläufer rehabilitiert, die Mehrzahl der schweren Fälle aber noch nicht verhandelt war. Der Druck auf die Militärregierung verschärfte sich, als in der sowjetischen Besatzungszone mit dem SMAD-Befehl Nr. 201 von Mitte August praktisch alle einfachen NSDAP-Mitglieder aus dem Entnazifizierungsverfahren herausgenommen wurden. Im Oktober stimmte Clay widerstrebend dem 1. Anderungsgesetz zum BefrG zu, das die Masse der kleinen Amtsträger durch einen Sühnebescheid vom Beschäftigungsverbot befreite und die Anklage mutmaßlicher NS-Aktivisten als Mitläufer zuließ ${ }^{187}$. Die Verfahrenserleichterungen trugen den Änderungswünschen der Befreiungsminister vom Frühjahr 1947 Rechnung und entsprachen weitgehend dem sachlichen Gehalt der kirchlichen Einwände, trugen aber keineswegs zur Befriedung der angespannten Situation bei, sondern schürten eher den Wunsch, das Befreiungsgesetz nun vollends aus den Angeln zu heben.

\section{Endkrise der Entnazifizierung und neuer Vorstoß der Kirchen}

Die Vorreiterrolle übernahm wiederum die evangelische Kirche, wobei neben der grundsätzlichen Ablehnung der Entnazifizierung auch konfessionelle Rivalitäten mitspieiten, wie einem Schreiben Pressels an Wurm zu entnehmen ist: ,Nachdem die evangelische Kirche durch Sie, sehr verehrter Herr Landesbischof, bisher sowohl in der Entnazifizierung wie in der Internierungsfrage durchaus die Vorhand hatte, sollten Sie sich auch jetzt nicht durch die bisher gegenüber beiden Problemen noch sehr leise tretenden

185 NA, RG 260, 5/341-3/32, Clay an Faulhaber vom 29.9.1947. Vgl. Spotts, Kirchen, S.92.

186 NA, RG 260, 5/341-3/32, Entwurf Dorns vom 25.8.1947.

${ }^{187}$ Vgl. Niethammer, Entnazifizierung, S.510ff.; Griffith, Denazification Program, S. $478 \mathrm{ff}$. 
katholischen Kirche ins Hintertreffen drängen lassen. "188 Nach dem Vorstoß des katholischen Episkopats, dem in der deutschen Offentlichkeit vielfach die Abschwächung des Befreiungsgesetzes zugeschrieben wurde, mußten solche Überlegungen an Gewicht gewinnen.

Mitte Dezember 1947 wandte sich Wurm erneut an das Befreiungsministerium und die Militärregierung von Württemberg-Baden: Zweieinhalb Jahre nach dem Zusammenbruch des Nationalsozialismus geschehe noch immer ,täglich Unrecht“. Millionen stünden noch immer unter Anklage, ,,eine große Zahl von ihnen vorwiegend deshalb, weil sie einer Täuschung oder einem auf sie ausgeübren Druck erlegen waren. Unter ihnen sind viele, von denen man weiß, daß sie nie Nationalsozialisten waren, die vielmehr erst durch die Spruchkammern verspätet und grundlos zu solchen gestempelt werden. " Das Befreiungsgesetz habe ,,übelste Instinkte“ geweckt: ,Menschen, die während der 12 Jahre mäuschenstill in einer Ecke gewesen sind, können sich jetzt als Antifaschisten aufspielen und ihren $\mathrm{Haß}$ an anständigen Mitbürgern austoben. “189 Das Plädoyer für angeblich schuldlos Verurteilte berücksichtigte weder die Massenrehabilitierung durch das folgenlose Mitläuferprädikat noch die im Oktober verabschiedeten Verfahrenserleichterungen für kleine Amtsträger, sondern schürte mit der Diffamierung des Spruchkammerpersonals Ressentiments. Die sofortige Kanzelverlesung der Eingabe kündigte, wie Wurm Ministerpräsident Maier mitteilte, ,,eine zwar nicht in der Sache, aber in der Art des Vorgehens veränderte Haltung der württembergischen Kirchenleitung “ an: ,, Ich möchte hoffen, daß nach dem Bankrott ihrer Außenpolitik die USA eher zu einer Revision ihrer Besatzungspolitik bereit sein würden. " ${ }^{190}$ Die letzte Schlacht sollte mit verstärktem öffentlichen Druck geschlagen werden.

Entsprechend begann das Jahr 1948 mit einem großen Paukenschlag. Am Sonntag, den 1. Februar, ließ die Kirchenleitung von Hessen-Nassau in allen Gemeinden eine von Niemöller verfaßte Kanzelabkündigung verlesen: Die evangelische Kirche habe sich stets für eine ,,echte Befreiung unseres Volkes vom Ungeist des Nationalsozialismus“ eingesetzt; sie habe aber auch darauf hingewiesen, daß das Befreiungsgesetz ,,sehr leicht zum Instrument der Vergeltung " werden könne:

„Diese Befürchtungen sind weit übertroffen worden; denn der Versuch, den Nationalsozialismus mit den Mitteln dieses Gesetzes auszurotten, ist auf der ganzen Linie gescheitert. Dagegen hat diese Art der Denazifizierung zu Zuständen geführt, die auf Schritt und Tritt an die hinter uns liegenden Schreckensjahre erinnern. Hunderttausende von Menschen stehen unter beständigem Druck und erliegen der Versuchung, zu aller erdenklichen Unwahrhaftigkeit und Lüge zu greifen, um sich reinzuwaschen. Zehntausende haben Arbeit und Brot verloren oder warten in den Internierungslagern auf ihren Spruch oder nach längst gefälltem Spruch auf die Freilassung. Das alte System der Sippenstrafe ist wiedergekehrt; und wenn ein Fall glücklich geklärt und entschieden ist, so werden die Sprüche in ihrer Mehrzahl wieder umgestoßen, so daß ein Ende dieser Zustände nicht abzusehen ist. [...] Heute ist die völlige Katastrophe offenbar. Unser Volk ist nicht auf den Weg der Versöhnung geführt worden, sondern auf den Weg der Vergeltung, und die gesäte Saat neuen Hasses ist üppig aufgegangen. " 191

${ }^{188}$ LKAS, OKR 104f-IV, Pressel an Wurm vom 20.6.1947.

${ }^{189}$ LKAS, NL Wurm 275, Wurm an OMGWB und Befreiungsministerium vom 16.12.1947.

190 HStAS, EA 1/22, Bü. 4446, Wurm an Maier vom 16.12.1947.

191 Wort an die Gemeinde, in: KJ 1945-1948, S.206f. 
Dieser scharfen Anklage steht die Entnazifizierungsstatistik von Ende Februar 1948 entgegen, die in der gesamten US-Zone 3,18 Millionen Betroffene verzeichnete, von denen 2,1 Millionen amnestiert worden waren. In 700192 durchgeführten Spruchkammerverfahren waren gerade 1046 Personen als Hauptschuldige (Gruppe I) und 15389 als NS-Aktivisten (Gruppe II) eingestuft worden. Weitere 77965 galten als Minderbelastete (Gruppe III), wobei das in dieser Gruppe verhängte Beschäftigungsverbot durch das 1. Anderungsgesetz bereits aufgehoben war. 325083 zählten als Mitläufer (Gruppe IV), 14251 als Entlastete (Gruppe V). Im Zuge des Verfahrens wurden weitere 251287 Personen amnestiert und 15171 Verfahren aus anderen Gründen eingestellt. 450551 Fälle, darunter 187215 Spruchkammerfälle, mußten noch bearbeitet werden ${ }^{192}$.

Die politische Sprengkraft der Kanzelabkündigung lag allerdings nicht in der Verkennung des Rehabilitierungscharakters des Befreiungsgesetzes, die sie mit allen offiziellen Äußerungen der evangelischen Kirche teilte, sondern in dem sich anschließenden Aufruf: ,,Unter diesen Umständen müssen wir allen Christen die ernste Frage vorlegen, ob sie es noch verantworten können, sich freiwillig an der Durchführung eines Verfahrens zu beteiligen, das $\mathrm{Haß}$ sät, statt der Gerechtigkeit und Versöhnung zu dienen. Es ist eine ernste Frage an das Gewissen, die wir damit stellen; und nach unserem Maß der Erkenntnis müssen wir bitten: wirkt an dieser Sache, die so viel Unrecht im Gefolge hat, nicht länger aus freien Stücken als öffentlicher Kläger oder als freiwilliger Belastungszeuge mit! Oder ihr kommt in die Gefahr, das Amt der Versöhnung zu verraten, das euch aufgetragen ist." "193

Der unverhüllte Boykott-Aufruf der hessischen Kirchenleitung, der auch an die Vorsitzenden und Beisitzer der Spruchkammern erging, während den Pfarrern jede freiwillige Mitwirkung förmlich untersagt wurde, löste ein mittleres politisches Erdbeben aus. Doch zuvor soll die Entstehungsgeschichte genauer dargestellt werden.

Ein erster Entwurf von Otto Fricke war am 22. Dezember 1947 von Niemöller abgelehnt worden. Auf der nächsten Sitzung der Kirchenleitung legte Niemöller einen eigenen Entwurf vor und setzte ihn mit Unterstützung der anwesenden Mitglieder gegen Fricke durch, der im Befreiungsgesetz die Möglichkeit zu einer gerechten politischen Säuberung gegeben sah und die Aufgabe der Kirche nur darin erblickte, ,,die Barrikaden wegzuräumen, die die Urteile der Spruchkammern nicht zur Durchführung kommen lassen“. Damit zielte Fricke auf die Eingriffe der Militärregierung ab. Am 12. Januar 1948 unterbreitete Synodalpräsident Wilhelmi den Vorschlag, vor der Verlesung der Kanzelabkündigung die politischen Parteien und die katholische Kirche zu unterrichten und „,mit diesen über sachliche Einzelfragen noch ein Gespräch zu führen“. Stattdessen entschied sich die Kirchenleitung mehrheitlich dafür, die Erklärung erst ,,ganz kurz vor der Veröffentlichung in Abschriften zu übersenden" ${ }^{194}$ ". Eine Woche später wurde der 1. Februar zur Verlesung der Kanzelabkündigung festgesetzt. Spätestens zu diesem Zeitpunkt war jedoch die Kirchenleitung von der Religious Affairs Branch, wie ein Protokoll vom

192 BA, Z 1/1105, Angaben nach: von Arnim, Ministerialrat im Rechtsamt des Länderrats an Sträter vom 8.5.1948.

${ }^{193}$ Wort an die Gemeinde, in: KJ 1945-1948, S.206f.

${ }^{194} \mathrm{Vgl}$. ZEKHN, 106/4, Sitzungsprotokoll vom 22.12.1947. Der Entwurf Frickes ist nicht überliefert. Sitzungsprotokoll vom 5.1.1948. Dort auch 1. Entwurf Niemöller. Sitzungsprotokoll vom 12.1.1948. 
14. Januar ausweist, davon unterrichtet worden, daß, ,nach dem Willen des Generals Clay die ganze Entnazifizierung im Sommer 1948 abgeschlossen werden soll“"195. Auf der letzten Sitzung, am 28. Januar, unterrichtete Fricke die Mitglieder der Kirchenleitung von ihm vertraulich bekanntgewordenen weiteren Erleichterungen, die man als ,,einschneidende Maßnahmen “ bezeichnen müsse, und beantragte die Verschiebung der Kanzelabkündigung. Fricke hatte am 21. Januar im Alleingang den stellvertretenden Chef der Special Branch der hessischen Militärregierung von dem geplanten Vorstoß unterrichtet und dabei offensichtlich von der neuen OMGUS-Anordnung erfahren, wonach künftig alle Belasteten ,,regardless of offices, rangs or positions“ schon durch die Anklage als Mitläufer herabgestuft werden sollten. Yakoubian erklärte weiterhin, daß die Militärregierung nicht gegen die Kanzelabkündigung einschreiten werde, obwohl sie zu zahlreichen Mißverständnissen Anstoß gebe ${ }^{196}$.

Auch Wilhelmi meldete nun in einer schriftlichen Stellungnahme schwere Bedenken an: Die Änderungen des Befreiungsgesetzes seien so einschneidend, daß sich in der Praxis eine neue Gesetzesanwendung ergeben werde. Er erinnerte die Kirchenleitung daran, daß die umstrittenen Formalbelastungskategorien auf den Druck der Militärregierung in den Anhang des Befreiungsgesetzes aufgenommen worden waren. Mit ihrer Aufhebung komme nun der ,,gute Kern des eigentlichen Befreiungsgesetzes" zum Durchbruch. „,Wenn jetzt von kirchlicher Seite zum Ausdruck gebracht wird, ein Christ dürfe sich nicht freiwillig an der Durchführung dieses Gesetzes beteiligen, so stößt man diese Leute, die Jahre lang unter schwersten Gewissenskonflikten sich bemüht haben, das Beste aus den Bestimmungen herauszuholen, in einem Augenblick vor dem Kopf, wo sie die berechtigte Hoffnung haben, nunmehr nach rechtlichen und christlichen Gesichtspunkten Entscheidungen fällen und damit der Versöhnung im Volke dienen zu können." Auch könne man nicht schlechthin den Grundgedanken der Entnazifizierung verurteilen, politische Verstöße gegen , ,die Gesetze der Menschlichkeit bzw. die Naturgesetze“ zu ahnden. Wenn die Kirche jetzt die Christen zum Rückzug auffordere, ,,so muß dies auf die Mehrheit des Volkes den Eindruck machen, als wolle man jede Strafe, auch der Schuldigen, sabotieren“. Deshalb dürfe die Erklärung , unter keinen Umständen jetzt, und wohl auch später nicht in dieser Form" verlesen werden. Vielmehr müsse man die Handhabung der neuen Richtlinien abwarten ${ }^{197}$. Diese Bedenken, die die Frage nach der öffentlichen Verantwortung der Kirche stellten, vermochten allerdings die Mehrheit der Kirchenleitung nicht zu überzeugen ${ }^{198}$. An der Entstehungsgeschichte zeigt sich erneut die fehlende Bereitschaft der Kirchenführer, sich vor der Verabschiedung öffentlicher Erklärungen sachkundig zu informieren; auch schwerwiegende Einwände aus eigenen Reihen blieben ohne Resonanz.

In der Militärregierung löste die Frage, weshalb Niemöller ausgerechnet im Frühjahr 1948 zum Boykott aufrief, einiges Rätselraten aus. Am plausibelsten erschien Erwin Wendt, Mitarbeiter im politischen Beraterstab Clays, die Erklärung: „, Denazification is

195 ZEKHN, Az 1841-40, Niederschrift über Besprechung bei der Militärregierung am 14.1. 1948. Ausfertigung für die Kirchenleitung.

196 Vgl. ZEKHN, 106/4, Sitzungsprotokoll vom 28.1.1948; NA, RG 84, 805/23, POLAD-Memorandum vom 5.2.1948. Zur OMGUS-Anordnung vgl. Niethammer, Entnazifizierung, S. 512 .

197 ZEKHN, 104/4, Stellungnahme Wilhelmis, o. D.

${ }^{198} \mathrm{Vgl}$. ZEKHN, 106/4, Sitzungsprotokoll vom 28.1.1948. 
on its last legs in the US-Zone. Niemöller may have thought that he or his church group would get credit for dealing the death-blow of an unpopular ordeal which population has passed. Niemöller himself is at least a pseudo-Nazi. At any rate, he is a strongly nationalistic German. Insofar as denazification also attacks ultra-nationalism, Niemöller's views conflict with the programm." 199 Diese Einschätzung wurde von James Riddleberger, dem Direktor des Office of German and Austrian Affairs im State Department, geteilt; er widersprach aber der Beurteilung Niemöllers als eines ,Pseudo-Nazi““200. Zweifellos stand die neue Kirchenleitung der im Herbst 1947 nach harten innerkirchlichen Konflikten gegründeten Evangelischen Kirche in Hessen und Nassau unter einem starken Profilierungszwang und dürfte deshalb mit Bedacht die Entnazifizierungsfrage zum Gegenstand ihrer ersten öffentlichen Erklärung gemacht haben. Mit diesem Thema konnte sie sich des Beifalls aus allen kirchlichen Lagern sicher sein, und mit keinem anderen konnte Niemöller als umstrittener Kirchenpräsident die Sympathien auch derjenigen gewinnen, die sein Eintreten für das Schuldbekenntnis 1945/46 als nationalen Verrat empfunden hatten. In dieser Hinsicht stellte die Kanzelabkündigung vor allem ein innerkirchliches Versöhnungsangebot dar. Die Wandlung Niemöllers vom Prediger des Schuldbekenntnisses zum scharfen Kritiker des Befreiungsgesetzes wurde auch von Wurm mit Genugtuung registriert ${ }^{201}$.

Zwei Tage nach der Kanzelverlesung trat der hessische Befreiungsminister Binder den Vorwürfen auf einer Pressekonferenz entgegen. Er versuchte anhand der hessischen Entnazifizierungsstatistik die ,,groben Ubertreibungen" zu widerlegen und gab dabei an, daß weniger als fünf Prozent der Spruchkammerurteile durch die Militärregierung aufgehoben worden seien. Nicht minder unzutreffend sei der Vorwurf der Sippenhaft, da niemand wegen der Taten seiner Verwandten verurteilt werde. Die Behauptung, die Entnazifizierung erinnere an die Schreckensjahre des NS-Regimes, bezeichnete Binder als „, unverantwortlich, wenn nicht gar als demagogisch“. Er hoffe jedoch, daß die Kirchenleitung ihren Boykott-Aufruf überprüfen werde und sich dabei ,, weniger von den Ressentiments der ihr angehörenden früheren Nationalsozialisten als von der Verpflichtung gegenüber denjenigen ihrer Mitglieder leiten lassen wird, die als Zeugen ihres Glaubens Opfer des nationalsozialistischen Schreckens geworden sind und die den Heutigen das Vermächtnis hinterlassen haben, daß die von der Kirche geforderte Versöhnung erst möglich ist, wenn zuvor der Gerechtigkeit Genüge getan und eine politische Schuld gesühnt ist" "202. Das hessische Kabinett stellte sich am 4. Februar hinter Binder und erklärte, man hätte mindestens erwarten können, daß sich die Kirchenleitung vorher informiert und auch ein Wort für die Opfer der NS-Diktatur gefunden hätte ${ }^{203}$. Mitte Februar trat die Kirchenleitung mit der Erklärung an die Offentlichkeit, sie habe lediglich ein ,,geistlich-seelsorgerliches Wort" an die evangelischen Christen richten und nicht zum Ungehorsam gegen staatliche Gesetze aufrufen wollen. Im übrigen aber liege genügend Mate-

199 NA, RG 805/23, POLAD-Memorandum vom 5.2.1948.

200 NA, RG 84, 805/23, Riddleberger an State Department vom 6.2.1948.

$201 \mathrm{Vgl}$. LKAS, NL Hartenstein 8, Ansprache Wurms in der Markuskirche in Stuttgart vom

24.2. 1948; Wurm, Erinnerungen, S. 189. Scharfe Kritik kam hingegen von Diem. Vgl. Stuttgarter Zeitung vom 21.2.1948.

${ }^{202}$ HStAW, 501/1269, Erklärung vom 3.2.1948. Zur hessischen Entnazifizierungsstatistik vgl. Kropat, Hessen, S. 243.

203 BA, Z 1/1105, Erklärung vom 4.2.1948. 
rial vor, ,, das unsere Angaben als keineswegs übertrieben, sondern als äußerst zurückhaltend erkennen läßt" ${ }^{\text {“204. }}$.

Am 6. Februar holten die evangelischen Kirchenführer der US-Zone in einer gemeinsamen Erklärung zu einem neuen Vorstoß aus. Auch sie betonten einleitend, die evangelische Kirche habe von Anfang an das ,,echte, grundsätzliche Anliegen der politischen Säuberung bejaht" , um dann mit einer Aufzählung der ,,schwersten Fehler" des Befreiungsgesetzes fortzufahren: ,Zu schweren Bedenken gab ferner Anlaß, daß auf Grund des Gesetzes auch solche Handlungen und Gesinnungen unter Strafe gestellt werden konnten, die zu keiner Zeit strafwürdig waren. [...] Die automatischen Wirkungen der kollektiven Schuldvermutung erzeugten weithin das Bewußtsein, daß schweres Unrecht geschieht. Dazu kommt, daß nicht selten versucht wurde, die Spruchkammern zum Austrag politischer Gegnerschaft und persönlicher Feindschaft zu mißbrauchen. Auch das Denunziantentum fand Gelegenheit, sich zu betätigen. "205

Zur Behebung der ,,entstandenen schweren Schädigungen im Volksleben“ wiederholten die Bischöfe ihre Forderungen vom April 1947, ohne den inzwischen erfolgten Änderungen des Befreiungsgesetzes Rechnung zu tragen. Die abgründige Unkenntnis der Materie zeigte sich etwa in der Forderung, alle Sühnemaßnahmen für die Gruppen IV und V aufzuheben, obwohl die Entlasteten in Gruppe V seit jeher von allen Sühnemaßnahmen befreit waren. Ahnlich verhielt es sich mit dem Beschäftigungsverbot, das seit dem 1. Anderungsgesetz vom Oktober 1947 nurmehr für Hauptschuldige und NS-Aktivisten galt. Die rasche Wiedereingliederung der Mitläufer in den Wirtschaftsprozeß und in die öffentliche Verwaltung war ebenfalls eine Forderung, die in der Praxis längst durchgeführt war. Auch die Hauptforderung, die Entnazifizierung auf diejenigen Personen einzuschränken, ,,die in hoher Führungsstellung die nationalsozialistische Gewaltherrschaft wesentlich gefördert haben, und auf diejenigen, die sich kriminell vergangen oder durch erwiesene Denunziationen schuldig gemacht haben", konnte im Frühjahr 1948 kein Argument mehr sein. Denn paradoxerweise erfolgte der erneute Angriff auf die Entnazifizierung zu dem Zeitpunkt, als die Masse der schweren Fälle zur Entscheidung stand. Die Kundgebung der evangelischen Bischöfe der US-Zone schloß mit dem Aufruf: , Es möge so rasch wie möglich die Bahn freigemacht werden für eine echte Selbstbesinnung und Umkehr unseres Volkes, für seine Läuterung von dem Geist der Vergeltung, des Unrechts und der Gewalt. Man bestrafe Missetäter, aber man gebe dem ganzen Volk die Möglichkeit, geschehenes Unrecht durch Fleiß, Arbeit und Opfer wiedergutzumachen und ein friedliches, von $\mathrm{Haß}$ und Vergeltungssucht befreites Leben wieder anzufangen." 206

Zum eigentlichen Anlaß, der Kanzelabkündigung, vermieden die Bischöfe jegliche Stellungnahme; die erneute Verwerfung der Entnazifizierung als schweres Unrecht rechtfertigte jedoch inhaltlich den Boykott-Aufruf und wurde auch so in der Offentlichkeit verstanden ${ }^{207}$. Anders verhielten sich die katholischen Bischöfe von Mainz und Lim-

${ }^{204}$ HStAW 504/194, Erklärung vom 16.12.1948. Ebenso Niemöller in seinem Rechenschaftsbericht für die Synode im November 1948. Vgl. Kirchentag, S. 195.

${ }^{205}$ LKAN, LKR 201; LKAS, NL Wurm 275, Erklärung vom 6.2.1948. Gez. Wurm, Meiser, Wüstemann, Bender, Niemöller.

206 Ebenda.

${ }^{207}$ Vgl. Süddeutsche Zeitung vom 3.2.1948; Neue Zeitung vom 9.2.1948; Main-Post vom 2.3.1948; New York Times vom 8.2.1948. 
burg. Sie kritisierten ebenfalls das Befreiungsgesetz, forderten aber am 13. Februar alle Christen ,zur angestrengten Mitarbeit" auf ${ }^{208}$.

Keine kirchliche Verlautbarung trug in solchem Maße zur öffentlichen Polarisierung bei wie der Aufruf Niemöllers. Die heftigsten Proteste kamen von Mitarbeitern der Spruchkammern, die sich als Opfer einer beispiellosen Diffamierungskampagne sahen. Der Vorsitzende der Spruchkammer Alsfeld berichtete, daß in verschiedenen Orten des Landkreises die Kirchendiener den Sonntagsgottesdienst am 1. Februar besonders angekündigt und alle Gemeindeglieder zum Besuch aufgefordert hätten. Nach der Predigt sei dann die Erklärung verlesen worden: „Betont wurde dabei der Erste öffentliche Kläger $O$. herausgestellte. Dies verursachte bei den Kirchenbesuchern eine gewisse Unruhe und alle schauten vorwurfsvoll auf Herrn O. Herr O. schilderte diese Situation als äußerst peinlich. [...] Das Resultat ist nun, daß bei den Vorsitzenden und sonstigen Angehörigen der Spruchkammern eine gewisse Unsicherheit eingetreten ist. Herr O. hat seinen Gewissenskonflikt daraufhin erklärt, ebenfalls wollen verschiedene Beisitzer zurücktreten. “209

Der Vorsitzende der Spruchkammer Bergstraße, ebenfalls ein aktives evangelisches Gemeindeglied, hielt dem sozialen Druck stand und schrieb der Kirchenleitung voller Empörung: , Es ist nicht wahr, daß an unserer Spruchkammer nach dem Prinzip der Vergeltung geurteilt und $\mathrm{Haß}$ gesät wird [...]. Wir müssen mit einem überaus schmerzlichen Gefühl als Mitglieder der evangelischen Kirche diese Behauptung der Obersten Kirchenleitung der Wahrheit gemäß als das bezeichnen, was sie ist, nämlich als eine Lüge. “ Die Hauptursache aller Mängel liege darin, daß sich nicht genügend befähigte und verantwortungsbewußte Menschen zur Verfügung gestellt hätten; daran sei die evangelische Kirche mit ihrer maßlosen Kritik nicht unschuldig. Wenn die Kirchenleitung jedoch nun zur offenen Sabotage aufrufe, ,,indem sie alle freiwillig der Wahrheit gemäß gegebene Belastung ablehnt, so vergeht sie sich damit an Gottes Wort und an der Zukunft unseres Volkes in außen- und innenpolitischer Beziehung in allerschwerster Weise. Jede Versöhnung setzt das Schuldbekenntnis voraus."210 Der Vorsitzende der Spruchkammer Darmstadt-Stadt stellte der Kanzelabkündigung die Frage entgegen: , Wie kommt die Kirchenleitung dazu, die Opfer der nationalsozialistischen Gewaltherrschaft zu vergessen und sich nunmehr einseitig derer anzunehmen, die Tausende qualvollem Leben, ja dem Untergang kalt lächelnd überliefert haben, nur allzu häufig von persönlicher Rachgier beseelt, oder wo dieses Persönliche gefehlt hat, allein stark in dem Bestreben, dem Nationalsozialismus voll zu dienen und sich selbst als Eiferer zu empfehlen?" Die Wiederherstellung des Rechtsstaats verlange die Sühne für vergangene Verbrechen. Wer sie verhindern wolle, , ,zerschlägt in denen, die jahrelang Unrecht und Verfolgung dulden mußten, den Glauben an den Sieg des Rechts, ohne den eine Versöhnung nicht möglich ist. "211

Auch die öffentlichen Kläger sämtlicher Spruchkammern Unterfrankens äußerten in einer einstimmig gebilligten Resolution ihr Befremden, daß die evangelische Kirche der Entnazifizierung ausgerechnet in dem Moment in den Rücken falle, in dem die wirklich schweren Fälle zur Verhandlung anstünden. Dadurch müsse der Eindruck entstehen, daß

${ }^{208}$ Zit. nach Neue Zeitung vom 19.2.1948. Vgl. Berliner Zeitung vom 18.2.1948.

${ }^{209}$ HStAW, 501/1269, Aktennotiz des Vorsitzenden der Spruchkammer Alsfeld vom 1.2.1948.

$210 \mathrm{HStAW}, 501 / 1269$, Spruchkammer Bergstraße an Kirchenleitung vom 2.2.1948.

211 HStAW, 501/1269, Spruchkammer Darmstadt-Stadt an Kirchenleitung vom 4.2.1948. Vgl. Spruchkammer Wiesbaden an Befreiungsministerium vom 6.2.1948. 
, die ehemals führenden Kreise der NSDAP der Verantwortung entzogen werden sollen. [...] Bei einer Revision des Gesetzes im Niemöller'schen Sinne müßten wir unsere weitere Mitarbeit bei der Durchführung des Gesetzes versagen. "212 Wie die Mitarbeiter der Spruchkammern, reagierte auch die Presse ganz überwiegend negativ, was die Militärregierung mit Genugtuung registrierte ${ }^{213}$. Auch Theodor Heuss, der bereits im Dezember 1945 als württembergischer Kultusminister die amerikanische Entnazifizierungspolitik scharf kritisiert hatte, hielt die „,ethisch-religiöse Position“ der Kanzelabkündigung für , ,unhaltbar“, da sie die Arbeit der Spruchkammern , ,einer schier unerträglichen Beleuchtung" [sic!] aussetze ${ }^{214}$.

Ähnlicher Ansicht waren auch die Oberbürgermeister von Darmstadt und Frankfurt, Ludwig Metzger und Walter Kolb, die als Synodalmitglieder eine Sondersitzung der Landessynode forderten, befürwortet von Fricke als einem Mitglied der Kirchenleitung ${ }^{215}$. Der Antrag wurde jedoch im Synodalvorstand abgelehnt. Zwar verfügte die kleine innerkirchliche Oppositionsgruppe über die besseren Argumente, doch besaß die Kirchenleitung den Zuspruch der Gemeinden. Die Auswertung von über 400 Zuschriften ergab, daß 92 Prozent ihre ,,uneingeschränkte Zustimmung “ zum Ausdruck brachten, woraus man den Schluß zog, die Gemeinden hätten die Kanzelabkündigung ,,als notwendige Tat der Kirche" verstanden ${ }^{216}$. Anderer Auffassung waren die SPD- und KPD-Ortsvereine Frankfurts. Sie verlangten, unterstützt von der VVN, daß die Einweihung der Paulskirche am 18. Mai nicht, wie vorgesehen, von Niemöller vorgenommen werden dürfe. Die mit der Renovierung beschäftigten Arbeiter schlossen sich der Forderung an und drohten mit Streik, falls Niemöller nicht unverzüglich von der Rednerliste gestrichen werde. In der Entschließung hieß es, Niemöller könne nicht mehr als Repräsentant des demokratischen Deutschlands angesehen werden. Die außerordentlich gereizte Stimmung bewog Oberbürgermeister Kolb schließlich zur Ausladung ${ }^{217}$.

Eine weitere peinliche Situation ergab sich für die Kirchenleitung, als Pfarrer Willi Borngässer, CDU-Stadtrat und Vorsitzender des Roten Kreuzes in Wiesbaden, einer Vorladung der Spruchkammer Wiesbaden nicht Folge leistete. Er sollte als Hauptbelastungszeuge gegen den DC-Dekan Walter Mulot auftreten. Da er das unter Berufung auf die Kanzelabkündigung ablehnte, mußte er am 12. Februar polizeilich vorgeführt werden. Borngässer verweigerte daraufhin jede Aussage und erklärte: Wenn die Kirchenleitung kundtue, nicht mehr gewillt zu sein, an der Durchführung eines bestimmten Gesetzes mitzuwirken, so müsse entweder der Staat die Kirche zwingen, diese Verkündigung zurückzuziehen, oder aber die Kirchenleitung absetzen. Anscheinend wollte Borngässer den Konflikt verschärfen, um die neue Kirchenleitung in Schwierigkeiten zu bringen. Hierfür spricht, daß er sich zuvor in einem Offenen Brief gegen die Wahl Niemöllers zum Kirchenpräsidenten gewandt und vor der Presse die Kanzelabkündigung mit den Worten kommentiert hatte: ,,Aber daß ausgerechnet ein Mann, dessen permanentes Schuldbe-

${ }^{212}$ LKAS, NL Wurm 275, Resolution vom 27.2.1948.

$213 \mathrm{Vgl}$. Presseauswertung in den Berichten: NA, RG 84, 805/23, Riddleberger an State Department vom 6.2.1948 und 16.2.1948, American Consulat Baden-Baden an State Department vom 17.2.1948; NA, RG 260. 8/27-1/31, Semi-Monthly Religious Affairs Report 1.2.-15.2.1948. ${ }^{214}$ Rhein-Neckar-Zeitung vom 21.2.1948. Zur Kritik Heuß' an der Entnazifizierung vgl. Sauer, Neubeginn, S. 139.

${ }^{215} \mathrm{Vgl}$. Neue Zeitung vom 15.2.1948; ZEKHN, 106/4, Sitzungsprotokoll vom 16.2.1948.

216 ZEKHN, Az 1872 I-3, Entnazifizierung. Bericht an die Synode vom November 1948.

${ }^{217}$ Vgl. Neue Zeitung vom 19.2. und 18.5. 1948; Fuldaer Volkszeitung vom 24.2. 1948. 
kenntnis entscheidend zu der Entwicklung der Entnazifizierung beigetragen hat, jetzt plötzlich eine Kehrtwendung um $180 \mathrm{Grad}$ macht, das will mir nicht in den Kopf. "218 Die Spruchkammer verurteilte Borngässer wegen Zeugnisverweigerung zu einer Geldstrafe von $100 \mathrm{RM}$ und setzte das Verfahren gegen Mulot aus. Befreiungsminister Binder erklärte anschließend vor der Presse, eine derartige Mißachtung bestehender Gesetze könne keinesfalls geduldet werden ${ }^{219}$. Darauf sah sich die Kirchenleitung zu der Klarstellung genötigt, sie habe den Pfarrern lediglich freiwillige Belastungsaussagen verboten, ,weil solche freiwillige Betätigung für die Gemeinde Christi ein schweres Ärgernis bedeutet“"220. Im Zusammenhang mit dem Fall Borngässer ist auch die weitere Erklärung zu sehen, es sei der Kirchenleitung lediglich um den ,,Verzicht auf die Ausübung staatsbürgerlicher Rechte, nicht aber um das Verbot der Erfüllung staatsbürgerlicher Pflichten " gegangen $^{221}$. Für diese Präzisierung hatte man sich allerdings über zwei Wochen Zeit gelassen.

Ein ähnlicher Vorgang ereignete sich in München, als Pfarrer Karl Dörfler, der Leiter des Evangelischen Männerwerks, die Aussage verweigerte. Er wurde von Meiser gegenüber dem Sonderminister Hagenauer mit den Worten verteidigt: ,, Wenn ein Pfarrer aus seelsorgerlichen und gewissensmäßigen Gründen es ablehne, als Zeuge vor diesem politischen Gericht aufzutreten, so müsse auch der Staat dem Rechnung tragen."222 Hagenauer äußerte hierfür Verständnis, womit die Angelegenheit erledigt war, da die CSU keinen Konflikt mit der Landeskirche wünschte.

Schwieriger gestaltete sich die Beilegung des Konflikts in Hessen, da die SPD-Landtagsfraktion in einer Großen Anfrage der Kirchenleitung Mißachtung der Verfassung und Sabotage an der Durchführung eines Gesetzes vorwarf ${ }^{223}$. Als im hessischen Kabinett Anfang April die Anfrage zur Debatte stand, erreichten Binder und Kultusminister Stein die Absetzung einer scharf gehaltenen Stellungnahme der Staatskanzlei. Sie hatte es als eine bedenkliche Zeiterscheinung bezeichnet, ,,daß unter dem Schutz und der Duldung maßgebender Faktoren des öffentlichen Lebens Nationalsozialisten und Militaristen reinster Prägung als Wegbereiter und Ratgeber der neuen Demokratie glauben auftreten zu können“. Hierzu schweige die Kirchenleitung ,, auffallenderweise"; während sie andererseits dazu beitrage, ,das ohnehin nur selten erkennbare Schuldgefühl nationalsozialistischer Parteigänger zu beruhigen“ "224. Da solch kämpferische Töne Mitte 1948 nicht mehr zeitgemäß waren, erhielt die SPD-Anfrage ein stilles Begräbnis.

Gewann die evangelische Kirche mit ihrer Kritik die Sympathie der Entnazifizierten, wobei sie auf die Zustimmung der bürgerlichen Parteien rechnen konnte ${ }^{225}$, so stand auf

${ }^{218}$ Zit. nach Der Spiegel vom 7.2.1948, S. 4 f. Zu Borngässers Kritik an Niemöller vgl. NA, RG 260, 5/342-1/32, Daily Report 106 vom 14.4.1948.

219 Vgl. Stuttgarter Zeitung vom 14.2.1948; Marburger Presse vom 19.2.1948.

220 Kirchenleitung an Befreiungsministerium vom 18.2.1948. Vgl. Neue Zeitung vom 22. 2. 1948.

${ }^{221} \mathrm{HStAW}, 504 / 194$, Erklärung vom 16.2.1948. Vgl. Neue Zeitung vom 19.2.1948.

222 LKAN, LKR 227, Aktennotiz über Besprechung Meisers mit Hagenauer am 20.2. 1948. Vgl. NA, RG 260, 5/341-1/6-10, ICD-Nachrichtendienst, News of Germany, Nr. 92 vom 2.3.1948.

${ }^{223}$ HStAW, 501/16, Große Anfrage der SPD-Fraktion vom 10.2.1948.

${ }^{224} \mathrm{HStAW}, 501 / 16$, Kabinettsvorlage vom 16.3.1948.

225 Vgl. LDP-Kurier vom 9.2.1948; Berliner Zeitung vom 18.2.1948; Rheinischer Merkur vom 14. 2.1948; LKAN, LKR 201, CSU an Landeskirchenrat vom 16.3.1948; FDP an Meiser vom 2.4.1948. 
der anderen Seite die wachsende Verbitterung vieler KZ-Opfer, die sich exemplarisch in folgendem Schreiben Luft machte: ,, Wo sind denn die Herren im Dritten Reich mit ihrer Courage geblieben? [...] Leider war es doch in der Kirche so, daß am Altar, vorwiegend wiederum am evangelischen, für Führer und Reich gebetet wurde. [...] Auch nach meiner Rückkehr aus dem KZ habe ich von der Kanzel nur gehört, daß für die armen Kriegsgefangenen und die armen Flïchtlinge gesprochen wird. Keiner hat je an uns gedacht und erwähnt, daß wir wieder zurück sind aus der Tyrannei. Wir sind die Vergessenen, aber um so fester wollen wir an diese Unterlassungssünde denken. Daß die Kirche sich just zu einem Zeitpunkt rührig macht, wo gerade die Hauptschuldigen ihrer Aburteilung entgegensehen, ist mehr als eigenartig. "226

Charakteristisch für die Polarisierung, die das Engagement der Kirche zugunsten der ehemaligen Nationalsozialisten hervorrief, ist auch der Offene Brief Wilhelm Keils, des großen alten Mannes der württembergischen Sozialdemokratie. Er schrieb nach der hessischen Kanzelabkündigung an Landesbischof Wurm: Der Gegensatz zwischen der organisierten Arbeiterschaft und den Kirchen habe endgültig überwunden geschienen, ,,nachdem glaubenstreue Christen und demokratische Sozialisten gemeinsam die grauenvollen Folgen der Hitlerschen Gewaltherrschaft zu spüren bekommen hatten. Diese Hoffnung erhält durch Ihr Eingreifen zugunsten der geschworenen Feinde der Demokratie einen gefahrdrohenden Stoß. Ich unterstelle nicht, daß Sie den Feinden der Demokratie helfen wollen, in der Wirkung aber läuft Ihr Eingreifen auf den Schutz derer hinaus, die sich durch ihren aktivistischen Einsatz für eine Verbrecherpolitik an unserem Volk und an der ganzen Menschheit so entsetzlich versündigt haben. "Da die Entnazifizierung der Mitläufer bereits beendet sei, könne die kirchliche Kritik nur den Schwerbelasteten zugute kommen. ,,Daraus ergibt sich die schlimme Folge, daß bei allen überzeugten Demokraten nun wieder die Vorstellung genährt wird: Die Kirchen marschieren Arm in Arm mit den Feinden der Demokratie."227 Interessanter als die öffentliche Antwort Wurms 228 ist sein privates Schreiben an Keil, das die politische Motivation des kirchlichen Engagements offen aussprach: , Ich kann mir wohl denken, daß es in einzelnen Parteien Leute gibt, die an einer strengen Handhabung des ohnehin schlechten Gesetzes ein Interesse haben, weil infolge seiner Auswirkung auf das höhere und mittlere Beamtentum eine Menge von Stellen freigeworden sind, die mit Persönlichkeiten, deren politische Linientreue größer ist als ihre Vorbildung und Befähigung, besetzt worden sind. Es wird überall im Lande geklagt, darüber, daß die KPD hieraus großen Vorteil gezogen habe, bis in die Ministerien hinein. "229 Als höflicher Mensch sprach Wurm zwar von ,,einzelnen Parteien“, nannte aber nur die Kommunisten namentlich, die in Württemberg-Baden keinen nennenswerten Einfluß besaßen. Nicht minder argwöhnisch wurde in kirchlichen

226 LKAN, LKR 201, Schwab an Landeskirchenrat vom Februar 1948.

227 LKAS, NL Wurm 275, Keil an Wurm vom 26.2.1948. Vgl. LKAN, LKR 201, Fraktionsausschuß der bayerischen SPD an Landeskirchenrat vom 12.4.1948: „Dadurch, daß die gesamte Entnazifizierung so dargestellt wird, als sei sie ein Unrecht auch gegenüber denjenigen, die durch ihre Mitgliedschaft zur NSDAP und ihr Handeln erst die gnadenlose Terrorherrschaft ermöglicht haben, und die dadurch zu Märtyrern erklärt werden, werden für die Entwicklung einer wirklich demokratischen Gesinnung keinerlei Voraussetzungen geschaffen."

${ }^{228}$ LKAS, NL Wurm 275, Antwort auf den Offenen Brief des Herrn Landtagspräsidenten Keil vom 27.2.1948.

229 LKAS, NL Wurm 275, Wurm an Keil vom 28.2.1948. 
Kreisen freilich das Vordringen von Sozialdemokraten und freisinnigen Liberalen beobachtet, da sie für die Trennung von Kirche und Staat eintraten.

Am 6. März unternahm die hessische Landeskirche, gemeinsam mit den katholischen Bischöfen von Mainz und Limburg, einen weiteren Vorstoß. Die Federführung lag diesmal bei den katholischen Bischöfen, was sich weniger in der allgemeinen Zielrichtung als vielmehr in der Diktion, der präzisen Kenntnis der Durchführungsverordnungen und einem detaillierten Forderungskatalog bemerkbar machte. Im Unterschied zu den Protesten, die die evangelischen Kirchenführer allein verantworteten, fand sich auch ein $\mathrm{Hin}$ weis auf die Opfer des NS-Regimes: Die Kirchen , setzen sich auch mit Nachdruck dafür ein, daß begangenes Unrecht wiedergutgemacht und den Opfern desselben einigermaßen Genugtuung gegeben wird". Nach dieser Vorrede ging es dann allerdings nurmehr um die Wiedergutmachung an den Opfern der Entnazifizierung. Das Befreiungsgesetz habe sich als völlig ungeeignet erwiesen, ,,eine wirkliche innere Abwendung des Volkes vom Nationalsozialismus und Militarismus zu bewirken oder auch nur anzubahnen“. Diese Beurteilung bestand nicht zu Unrecht, verkannte aber die Zielsetzung einer politischen Säuberung, wenn es im nächsten Satz hieß: ,,Es sollte die vornehmste Aufgabe eines solchen Gesetzes sein, die Betroffenen nicht so sehr oder überhaupt nicht für ihre frühere politische Einstellung oder Gesinnung zur Verantwortung zu ziehen, sondern sie zu echtem demokratischen Denken und Handeln hinzuführen. Daher müßte bei der Beurteilung entscheidender Wert auf die innere Einstellung der Betroffenen und das dementsprechende Handeln in den letzten drei Jahren gelegt werden. “230

Auf diesen häufig vorgebrachten Einwand entgegnete Binder, das Befreiungsgesetz habe vor allem den Zweck verfolgt, mit der Entlassung der NSDAP-Mitglieder aus führenden Stellungen Platz für demokratische Kräfte zu schaffen. Die innere geistige Wandlung des deutschen Volkes könne nicht per Gesetz herbeigeführt werden, sondern sei in erster Linie die Aufgabe der Parteien, des Erziehungswesens, der Publizistik , , und nicht zuletzt auch der religiösen Gemeinschaften“"231. Dennoch steht außer Frage, daß die viel zu breite Anlage der Entnazifizierung das Ziel einer effektiven Säuberung konterkarierte. Die Bewahrung des politischen Säuberungsgehalts war jedoch nicht das Anliegen der Bischöfe. Ihnen ging es darum, ,,die politische Säuberung nach dem Befreiungsgesetz jetzt so schnell wie möglich in einem abgekürzten Verfahren zum Abschluß zu bringen".

Der Zeitpunkt war, wie bei dem Vorstoß des katholischen Episkopats im August 1947, sorgfältig gewählt. Auch daß sich die Eingabe an die Militärregierung richtete und Ministerpräsident Stock nur eine Abschrift bekam, was ihn merklich verstimmte ${ }^{232}$, hatte durchaus seinen Sinn. Denn seit Januar 1948 drängte die Militärregierung auf Anweisung Washingtons auf die rasche Beendigung der Entnazifizierung. Bis Mitte März widersetzten sich jedoch die Befreiungsminister der geforderten Herabstufung fast aller noch nicht verhandelten Schwerbelasteten zu Mitläufern, da sie davon die völlige Diskreditierung ihrer bisherigen Arbeit befürchteten. Auf erneuten Druck Washingtons mußte Clay seinen hinhaltenden Widerstand aufgeben und konnte nur mit Mühe die Uberschreitung des gesetzten Abschlußtermins vom 8. Mai 1948 bei besonders schweren Fällen durchsetzen.

230 NA, RG 260, 5/341-1/6-10; HStAW, 501/16, Eingabe an OMGH vom 5.3.1948. Gez. Niemöller, Stohr, Dirichs.

${ }^{231}$ HStAW, 501/16, Antwortschreiben Binders vom 17.3.1948.

$232 \mathrm{Vgl}$. HStAW, 502/1023, Aktennotiz vom 15.3.1948; Stohr an Stock vom 30.3.1948. 
In der sowjetischen Besatzungszone war die Entnazifizierung per SMAD-Befehl bereits Ende Februar für beendet erklärt worden. Das Ergebnis des abrupten Kurswechsels, der die Entnazifizierungspolitik nochmals als eine abhängige Variable der amerikanischen Innenpolitik und internationaler Konstellationen ausweist, war das am 25. März erlassene 2. Ánderungsgesetz zum Befreiungsgesetz ${ }^{233}$.

Es erlaubte, mit geringen Ausnahmen, die Einstufung aller Belasteten im Schnellverfahren zu Mitläufern und beschränkte das Beschäftigungsverbot auf verurteilte Hauptschuldige. Damit blieb das Befreiungsgesetz formell in Kraft, wirkte sich aber wie eine Amnestie für Schwerbelastete aus, zumal die Militärregierung die Überwachung der Spruchkammerentscheide gänzlich einstellte. Mittlere Politische Leiter der NSDAP und SA-Führer, die vor Ort die NS-Diktatur repräsentiert hatten, konnten nun zu Mitläufern erklärt und damit wiedereinstellungsfähig werden, womit sie de facto dem unbelasteten Bürger gleichgestellt waren. Mit dem 2. Änderungsgesetz waren, wie die hessische Militärregierung und das Befreiungsministerium übereinstimmend feststellten, acht der 14 Punkte der Eingabe ganz oder weitgehend erfüllt ${ }^{234}$. Die restlichen Forderungen waren von so grundsätzlicher Art, daß, wie Kenny, der Leiter der Religious Affairs Branch der hessischen Militärregierung, gegenüber Kirchenvertretern ausführte, ,,das ganze Gesetz über den Haufen geworfen werden müßte. Die meisten von Ihnen wären wohl hiermit sehr einverstanden." Worauf das Protokoll „Heiterkeit" vermerkte ${ }^{235}$. Nicht erfüllt blieb vor allem die Aufhebung der Schuldvermutung für Mitglieder der sogenannten „,verbrecherischen Organisationen“ wie SD, Gestapo und SS, die Freilassung aller Internierten, von denen es im März in der US-Zone noch rund 18000 gab $^{236}$, und die rückwirkende Revision aller bereits abgeschlossenen Spruchkammerverfahren entsprechend den neuen Richtlinien. Hier versprach Binder allerdings eine großzügige Handhabung des Gnadenrechts.

$\mathrm{Zu}$ den besonderen Anliegen der Eingabe zählte weiterhin die Wiedereinstellung aller entlassenen Beamten: ,, Insbesondere muß gefordert werden, daß Betriebsräte und Behördenleiter keine Beschäftigungsverbote verhängen, die nicht in dem Spruch der Kammer vorgesehen sind. “237 Die gleichzeitige Forderung der Abmilderung der bereits ergangenen Spruchkammerurteile im Zuge einer Totalrevision konnte jedoch nichts anderes als die Wiedereinstellung aller entlassener Beamten bedeuten. In einem Entwurf war sogar - ,,im Interesse eines guten Verhältnisses zwischen Militärregierung und der deutschen Bevölkerung“ - die Entlassung der deutschen Angestellten verlangt worden, die für die Special Branch der Militärregierung arbeiteten ${ }^{238}$. Auch Meiser setzte sich vehement für die entlassenen Beamten ein, als er sich im August 1948 bei der Bayerischen Staatsregierung darüber beschwerte, es gebe bei manchen Behörden eine allgemeine Einstellungssperre für ,, bestimmte Gruppen entlassener Beamter (z. B. Pg vor 1933) “. Damit kämen , aufs neue Kollektivmaßnahmen zur Anwendung“", die dem Grundsatz der

\footnotetext{
233 Vgl. Niethammer, Entnazifizierung, S. $512 \mathrm{ff}$.; Griffith, Denazification Program, S. $500 \mathrm{ff}$.

${ }^{234}$ HStAW, 501/16, Antwortschreiben Binders vom 17.3.1948; ZEKHN, Az 1872-I-3, Antwortschreiben OMGH vom 17.3.1948.

235 ZEKHN, 1/98, Aktennotiz über Besprechung bei der Militärregierung am 24.3.1948.

236 Vgl. Niethammer, Entnazifizierung, S. 456, Anm. 433.

237 NA, RG 260, 5/341-1/6-10; HStAW, 501/16, Eingabe von OMGH vom 5.3.1948.

238 ZEKHN, Az 1872 I-3, Entwurf der Eingabe, o. D.
} 
„gerechten Abwägung der individuellen Verantwortung“" widersprächen. Daß die verbeamteten NSDAP-Mitglieder von vor 1933 zu den Totengräbern der Weimarer Republik gehörten, hinderte Meiser nicht daran, ihre erneute Einstellung zu fordern: ,Mit ernster Sorge sehen wir einen nicht geringen Teil des alten Berufsbeamtentum der Verelendung und der Gefahr radikaler Einflüsse preisgegeben, wenn nicht bald Abhilfe geschaffen wird." 239

Dem Engagement für die ,,alten Kämpfer" lagen nicht zuletzt konfessionspolitische Erwägungen zugrunde. So erklärte der stellvertretende CSU-Vorsitzende und Führer des evangelischen Flügels, August Haußleiter, im März 1949 während einer Aussprache evangelischer Landtagsabgeordneter mit Landesbischof Meiser über die Abschlußgesetzgebung zur Entnazifizierung: ,Zu beanstanden sei besonders die Unterscheidung zwischen $\mathrm{Pg}$ vor und nach 1933. Es sei dem Nationalsozialismus gelungen, das evangelische Franken vor 1933 gegen den politischen Katholizismus zu mobilisieren. Die evangelische Bevölkerung sei vor dem Terror der Bayerischen Volkspartei unter den Terror der NSDAP geflüchtet. Daraus sei zu erklären, daß von dieser Bestimmung vor allem der evangelische Bevölkerungsanteil betroffen sei. Der Kultusminister habe sich persönlich vorbehalten, die Fälle der Pg vor 1933 selbst zu entscheiden. Wenn man aber dem Minister die Chance gebe, persönlich zu entscheiden, werde er jedesmal seine Glaubensgenossen bevorzugen. [...] Besonders gute Leute aus dem evangelischen Bereich könnten gut gebraucht werden, vor allem diejenigen, die sich aus Gegensatz gegen den politischen Katholizismus dem Nationalsozialismus angeschlossen haben. ${ }^{240}$ Wenngleich die von Haußleiter und Meiser geforderte Wiedereinstellung der NSDAP-Mitglieder vor 1933 bei einigen Abgeordneten auf Widerspruch stieß, da sie in den Altparteigenossen keine Opfer konfessionalistischer Diskriminierung zu erblicken vermochten, blieb doch unbestritten, daß sich gerade betont evangelische Bevölkerungskreise in wesentlich höherem Maße für die NSDAP engagiert hatten und deshalb auch überdurchschnittlich von der Entnazifizierung betroffen waren.

Die Meinung mancher Zeitgenossen, Niemöller habe der Entnazifizierung den Todesstoß versetzt, stellte Wurm im August 1948 in einem Leserbrief an die Neue Zürcher Zeitung richtig. Wie üblich, bestritt Wurm der politischen Säuberung jegliche moralische Rechtfertigung: Sie habe ,,durch Weckung aller Rache- und Konkurrenzinstinkte den kalten Bürgerkrieg entfesselt, unendlich viel unnötige Leiden herbeigeführt, viel wirklich Schuldige nicht getroffen und den ganzen Wiederaufbau in Staat, Wirtschaft und Gesellschaft gehindert und erschwert“". Der Bankrott der Entnazifizierung sei längst offensichtlich gewesen, deshalb habe die Kanzelabkündigung Niemöllers keinen ,,Totschlag, sondern höchstens eine unerfreuliche Grabrede“" dargestellt ${ }^{241}$.

Der Bankrott der politischen Säuberung war unbestreitbar, aber aus anderen Gründen, als Wurm es meinte. Einen niederschmetternden Beleg gibt hierfür die letzte verfügbare Statistik der Spruchkammerurteile gegen Angehörige der sogenannten ,,verbrecherischen Organisationen“" vom April 1948:

239 LKAN, LKR 201, Meiser an Bayerische Staatsregierung vom 27. 8. 1948.

240 LKAN, LKR 210, Aussprache zwischen Landeskirchenrat und evangelischen Landtagsabgeordneten und Senatsmitgliedern am 15.3.1949.

241 Wurm an Neue Zürcher Zeitung vom 21.8.1948, in: Wurm, Erinnerungen, S. $184 \mathrm{ff}$. 
Einstufung von Angebörigen der ,,verbrecherischen Organisationen“ im Sprucbkammerverfabren bis April $1948^{242}$

\begin{tabular}{lrrrrrr}
\hline Gruppe & SD & Gestapo & \multicolumn{1}{c}{ SS } & $\begin{array}{c}\text { Pol. Leiter } \\
\text { der NSDAP }\end{array}$ & absolut & $\%$ \\
\hline I & 39 & 70 & 111 & 310 & 530 & 1,15 \\
II & 170 & 144 & 2592 & 3741 & 6647 & 14,4 \\
III & 215 & 207 & 9906 & 7756 & 18087 & 39,3 \\
IV & 98 & 92 & 9406 & 3609 & 13205 & 28,7 \\
V & 12 & 27 & 313 & 111 & 463 & 1,0 \\
amnestiert & 24 & 22 & 5328 & 1757 & 7131 & 15,5 \\
\hline Summe & 558 & 562 & 27659 & 17284 & 46063 & 100 \\
\hline
\end{tabular}

Von rund 46000 erfaßten Angehörigen des NS-Terrorapparats und des Korps der Politischen Leiter der NSDAP waren gerade 15,6 Prozent als Hauptschuldige oder NS-Aktivisten eingestuft worden. Selbst jene Gruppen, die auch nach konservativem Verständnis die NS-Diktatur personell verkörpert hatten, wurden von den Spruchkammern infolge des überstürzten Abschlusses der Entnazifizierung zu einem großen Teil zu harmlosen Mitläufern erklärt oder amnestiert.

Als Eugen Kogon im Juli 1947 in den Frankfurter Heften in einem vielbeachteten Aufsatz für ,,das Recht auf politischen Irrtum “ eintrat ${ }^{243}$, beschäftigte er sich in der gleichen Ausgabe auch mit den Erklärungen der Kirchen zur Entnazifizierung und warf die Frage auf, ob es wirklich angebracht sei: ,, Jetzt im Stil der zwischen 1933 und 1945 versäumten Sprache zu reden? Oder gäbe es gerade heute auch eine andere, wirksamere Art, die der deutschen Neigung, die Schuld überall sonst nur nicht bei sich selber zu suchen, weniger Vorschub leisten würde?" Nachdrücklich insistierte Kogon, die Kirchen hätten weder im Dritten Reich noch heute ,,jemals auch nur annähernd gleich deutliche, klare und mannhafte Worte für die Opfer des Nationalsozialismus und ihre Hinterbliebenen " gefunden; das gebe den Stellungnahmen, insbesondere jenen der evangelischen Kirche, einen ,äußerst fatalen Beigeschmack". Jede Fürsprache für die Nationalsozialisten könne mit Verständnis rechnen, wenn sie von , Worten der Einsicht in die Schrecklichkeit der Taten des Nationalsozialismus und von der Erstforderung nach Wiedergutmachung “ begleitet sei, die zu den ,,primitivsten menschlichen und christlichen Pflichten“" gehöre ${ }^{244}$.

Im Mai 1948 faßte ein namentlich nicht genannter Berliner Theologenkreis um die Zeitschrift Unterwegs, einem Organ des bruderrätlichen Reformflügels, die Enttäuschung über das Verhalten der Kirche nochmals zusammen. Auch er konstatierte, daß die erhoffte innere Umkehr ausgeblieben sei, wofür jedoch nicht die Entnazifizierung verantwortlich gemacht werden könne. Vielmehr habe sich gezeigt, daß die Durchsetzung des deutschen Volkes mit der NS-Ideologie derart tiefgreifend sei, daß die politische Säuberung fast zwangsläufig habe scheitern müssen. Auch ein Gesetz, das alle berechtigten Änderungswünsche der Kirchenleitungen respektiert hätte, hätte deshalb zu einem ähnli-

242 In: Griffith, Denazification Program, S. 720.

${ }^{243}$ Frankfurter Hefte 2 (1947), S. 641-655.

244 Kirchliche Kundgebungen von politischer Bedeutung, ebenda, S.633-638. 
chen Ergebnis geführt. Dennoch wäre es die Aufgabe der Kirche gewesen, sich an der Durchführung der Entnazifizierung aktiv zu beteiligen, , um dadurch dann auch die Vollmacht zu gewinnen, in den Fällen richtigstellend einzugreifen, wo offenbares Unrecht bewirkt worden war". Sich stattdessen von Anfang an distanziert zu haben, entbinde sie jedoch nicht von der Verantwortung für die Folgen. Wenn die Kirche ihre Kritik mit dem ihr aufgetragenen Dienst der Versöhnung begründe, zeige sich darin ein ,,falsches Verständnis“ der Heiligen Schrift. Denn der Versöhnungspredigt müsse immer die Erkenntnis der Schuld vorausgehen, wer aber seine Schuld bekenne, sei auch bereit das Urteil der irdischen Gerechtigkeit zu tragen. ,,Zur Schuldüberwindung gehört aber auch immer eine menschlich sichtbare Wiedergutmachung der Folgen und eine öffentliche Abkehr der Täter von ihrer damaligen Haltung. Das alles wird jedoch unberücksichtigt gelassen." Stattdessen würden in den kirchlichen Kundgebungen die Mitarbeiter der Spruchkammern als diejenigen bezeichnet, ,, die versagt und christlich falsch gehandelt haben. Diejenigen, die im 3. Reich zu Unrecht verfolgt wurden, erscheinen nun als solche, die heute selbstverständlich und getrost auf der Seite ihrer damaligen Verfolger stehen müßten; und wenn sie das nicht tun, so trifft sie heute die Anklage der Unversöhnlichkeit. "Damit aber mache sich die Kirche ,, in gefährlicher Weise" zum Helfer derjenigen Kreise, ,,welche sich selbst und unser Land in der geistigen Verfassung von gestern erhalten wollen. Die in den kirchlichen Erklärungen vertretenen Thesen erinnern oft sogar wörtlich an das, was überall von Mißvergnügten und ,Klassifizierten“ ausgesprochen wird. Man hat sich also auf Seiten der Kirche zu wenig davor geschützt, genau so verstanden zu werden wie die unkirchlichen Kreise, welche die gleichen Worte heute aussprechen." "245

Die tiefgreifende Problematik lag nicht darin, daß sich die evangelische Kirche für eine drastische Begrenzung des betroffenen Personenkreises, für Milde und die strikte Einhaltung rechtsstaatlicher Normen einsetzte, sondern daß sie der Entnazifizierung prinzipiell die moralische und politische Berechtigung absprach. Aus diesem Grund konnte es zu keiner Verständigung kommen, obwohl die rechtzeitige Berücksichtigung mancher Kritikpunkte zweifellos der politischen Säuberung zum Vorteil gereicht hätte. Dem Urteil William Griffiths, der als Leiter der Special Branch der bayerischen Militärregierung maßgeblich an der Durchführung der Entnazifizierung beteiligt war, wird man nicht leicht widersprechen können: ,,Certainly much of their individual criticism were fully justified, as the later course of events clearly demonstrated. But the spirit in which they were offered, and the basic objectives behind them, are something else. The violence and lack of moderation with which so many church leaders attacked all efforts to purge Germany of nazi influence compares unfavorably with the basic passivity which too often characterized them during the Nazi period, and does not encourage the belief that they essentially prefer democracy to authoritarianism. "246

Wie kein zweiter gesellschaftlicher Großverband machte sich die evangelische Kirche zum , Organisator und Anführer des allgemeinen Aufbegehrens“ ${ }^{\text {“247 }}$ gegen die politische Säuberung. Nach amerikanischen Meinungsumfragen äußerten im November 194550 Prozent aller Befragten ihre Zufriedenheit mit der Durchführung der Entnazifizierung,

\footnotetext{
245 Verhärtung statt Versöhnung, in: Unterwegs 2 (1948), S. $46 \mathrm{f}$.

246 Griffith, Denazification Program, S. 395.

247 Spotts, Kirchen, S. 94.
} 
im März 1946 sogar 57. Im Dezember 1946 fiel die Zustimmung auf 34 Prozent, im September 1947 auf 32 und im Mai 1949 betrug sie nur noch 17 Prozent. 1949 vertraten 65 Prozent von 1900 Befragten die Ansicht, das Entnazifizierungsprogramm sei schlecht ausgeführt worden. Gegen das Verfahren sprachen sich 194983 Prozent der Befragten aus unteren Einkommensgruppen, 85 Prozent mit besserer Schulausbildung und 90 Prozent mit hohen sozialökonomischen Status aus. Interessanterweise lag die Ablehnungsquote bei früheren NSDAP-Mitgliedern mit 78 Prozent niedriger als bei liberal-konservativ orientierten Parteigängern (84 Prozent). Die Kritiker des Entnazifizierungsverfahrens führten sehr häufig als Begründung an, daß die Mitläufer härter bestraft worden seien als NS-Aktivisten. Die Idee der Entnazifizierung, nicht aber ihre Durchführung, billigten 66 Prozent der Befragten. Die stärkste prinzipielle Ablehnung kam von Befragten mit Universitätsabschluß (49 Prozent) und mit niedrigem sozialökonomischen Status (55 Prozent). Die prinzipiellen Gegner begründeten ihre Ablehnung zumeist damit, daß die NSDAP-Mitglieder aus idealistischen Gründen gehandelt hätten und deshalb eine Bestrafung unzulässig sei ${ }^{248}$. Etwas andere Zahlen liefert eine repräsentative Umfrage des Allensbacher Instituts für Demoskopie vom September 1948, der die Befragung von 800 Personen aus der Westzone und West-Berlin zugrunde lag. In der Tendenz stimmen die Umfragen jedoch überein ${ }^{249}$ : Die prinzipielle Verwerfung der Entnazifizierung durch die evangelische Kirche wurde 1948/49 von rund einem Drittel der Bevölkerung geteilt, während mit der Durchführung des Befreiungsgesetzes nur rund ein Sechstel zufrieden war.

Als das Allensbacher Institut im November 1953 die Umfrage mit erweiteter Fragestellung wiederholte, zeigte sich, daß sich die Fronten kaum verschoben hatten. Von den Betroffenen lehnten knapp zwei Drittel (62 Prozent) die Entnazifizierung scharf ab, von den Nicht-Betroffenen ein Drittel; von allen 1065 Befragten waren es gleichbleibend 40 Prozent. Aber auch in der Gruppe der Nicht-Betroffenen unterstützte lediglich ein Fünftel die Formulierung, die Entnazifizierung habe wenigstens weitgehend ihren Zweck erfüllt; von allen Befragten waren es 17 Prozent. Auf prinzipielle Ablehnung stieß die Entnazifizierung bei 35 Prozent der Befragten mit einem Monatseinkommen unter 250 DM, in der Einkommensgruppe von 400 DM und mehr waren es 47 Prozent. Bei CDU- und SPDAnhängern betrug der Anteil rund ein Drittel ( 33 bzw. 35 Prozent), bei Parteilosen 46, bei Anhängern der FDP, DP, BP und des BHE 57 Prozent. Ergaben sich in regionaler Hinsicht nur geringe Unterschiede, so war die Ablehnung der Entnazifizierung auf dem Lande und in ländlichen Kleinstädten unter 20000 Einwohnern am schärfsten ausgeprägt. Hier lagen die Werte mit $40 \mathrm{bzw}$. 51 Prozent deutlich höher als in Großstädten über 100000 Einwohnern (33 Prozent). Prinzipielle Kritik äußerten 42 Prozent der Selbständigen, gefolgt von Angestellten (41 Prozent), Arbeitern (40 Prozent) und Landwirten

248 OMGUS-Survey, German Views on Denazification vom 11.7.1949, in: Merritt/Merritt, Public Opinion, S. $304 \mathrm{f}$.

${ }^{249}$ Die öffentliche Resonanz der Entnazifizierung. Ergebnisse von Bevölkerungsumfragen, September 1948 und November 1953, Allensbach 1954. Danach vertraten 194839 Prozent die Ansicht, die Entnazifizierung sei notwendig, aber falsch durchgeführt worden; nur 14 Prozent stimmten der Durchführung mit gewissen Vorbehalten zu. 7 Prozent äußerten keine Meinung. 13 Prozent der Befragten gaben an, durch die Entnazifizierung einen Schaden erlitten zu haben. 31 Prozent stimmten dem Urteil zu, daß die Entnazifizierung nicht notwendig gewesen sei und mehr Schaden als Nutzen angerichtet habe; weitere 9 Prozent hielten sie für eine reine Schikane der Besatzungsmächte. 
(36 Prozent), aber nur 35 Prozent der Beamten. Die Zustimmung zum Entnazifizierungsverfahren lag bei den Beamten mit 23 Prozent am höchsten, gefolgt von der Gruppe der Angestellten (21 Prozent) ${ }^{250}$.

Die scharfe Ablehnung der Entnazifizierung dürfte weiterhin in enger Beziehung zu den Ergebnissen einer anderen Untersuchungsreihe stehen. Regelmäßige amerikanische Meinungsumfragen ergaben, daß zwischen November 1945 und Juli 1946 durchschnittlich 48 Prozent der Befragten den Nationalsozialismus für eine gute, aber schlecht ausgeführte Idee hielten, zwischen Dezember 1946 und August 1947 stieg der Anteil auf durchschnittlich 52 Prozent. Umgekehrt fiel die Anzahl derjenigen, die den Nationalsozialismus prinzipiell verwarfen, von 41 Prozent im November 1945 auf 35 im August 1947. Diese Werte blieben bis zum Ende der Besatzungszeit relativ konstant. Die Ansicht, der Nationalsozialismus sei eine gute, aber schlecht ausgeführte Idee gewesen, erhielt im August 1947 die stärkste Zustimmung von Personen mit achtjähriger Schulausbildung (60 Prozent), unter 30jährigen (68 Prozent) und Parteianhängern der LDP/DVP (68 Prozent). Diese Meinung wurde auch von 64 Prozent der befragten Protestanten geteilt, womit sie nur knapp unter den ehemaligen NSDAP-Mitgliedern (67 Prozent) lagen. Regional stimmten dieser Ansicht 62 Prozent der Befragten aus West-Berlin zu, gefolgt von Hessen (61 Prozent) und Württemberg-Baden (60 Prozent). Das Schlußlicht bildete mit deutlichem Abstand das katholisch geprägte Bayern (50 Prozent). Die gegenteilige Ansicht, daß der Nationalsozialismus prinzipiell schlecht gewesen sei, teilten 38 Prozent der befragten Bayern, ein Drittel der West-Berliner und Hessen, gefolgt von WürttembergBaden (31 Prozent) ${ }^{251}$.

Die Umfragen erlauben keine direkte Zuordnung. Sie legen aber die Vermutung nahe, daß sich die Beurteilung des Nationalsozialismus als einer an sich guten Idee, die in besonders hohem Maße von Protestanten geteilt wurde, auch in einer schärferen Ablehnung der Entnazifizierung niederschlug. Zweifellos stützte die evangelische Kirche mit ihren Angriffen auf die Entnazifizierung solche Einstellungen und förderte zugleich den konstatierten Stimmungswandel. Während die katholischen Kirchenführer in der zeitlichen Abfolge ihrer Verlautbarungen eher den Stimmungswandel nachvollzogen, setzte die prinzipielle Kritik der evangelischen Kirche bereits zu einem Zeitpunkt ein, als Ende 1945 und Anfang 1946 noch rund die Hälfte der Bevölkerung mit der Durchführung der Entnazifizierung - d. h. mit der rigiden Entlassungspraxis der Milizärregierung - einverstanden war. Mit der maßlosen Ausweitung des betroffenen Personenkreises durch das Befreiungsgesetz schlug jedoch die öffentliche Meinung vollends um - ungeachtet der Tatsache, daß sich Spruchkammerpraxis keineswegs durch übertriebene Härte auszeichnete. Erst vor dem Hintergrund der Massenentnazifizierung konnte auch die prinzipielle Kritik der evangelischen Kirche, die den Rehabilitierungscharakter des Befreiungsgesetzes bis zuletzt nicht wahrnahm, ihre negative Wirkung voll entfalten. Als Resümee bleibt deshalb festzuhalten, daß die evangelische Kirche mit ihren Verlautbarungen, die sich auf

${ }^{250}$ Ebenda. Die Studie wurde dem Verfasser freundlicherweise von Herrn Michael Renner, Frankfurt, überlassen.

251 OMGUS-Survey, Trends in Attitudes toward National Socialism vom 10.10.1947, in: Merritt/Merritt, Public Opionion, S. $171 \mathrm{f}$.; vgl. S.32f. Das Sample beruhte auf einem Bevölkerungsquerschnitt der US-Zone sowie des amerikanischen und britischen Sektors Berlins. Die Anzahl der befragten Personen ist nicht angegeben. Vgl. auch Merritt, Digesting the Past. 
einem Mittelweg zwischen passivem Widerstand und aktiver Sabotage bewegten, erheblich zur Stärkung jener gesellschaftlichen Kräfte und geistigen Dispositionen beitrug, die auf deutscher Seite den Versuch einer tiefgreifenden politischen Säuberung zum Scheitern verurteilten. 